\title{
$(4)$
}

UNIVERSIDAD PERUANA DE CIENCIAS APLICADAS - UPC

FACULTAD DE NEGOCIOS

PROGRAMA ACADÉMICO DE ADMINISTRACION Y NEGOCIOS

INTERNACIONALES

\section{PROPUESTA DE MEJORA EN EL PROCESO DE EXPORTACIÓN AÉREA EN UNA AGENCIA DE CARGA PARA EL INCREMENTO EN SUS INGRESOS}

Tesis

Para optar por el Título profesional de Licenciado en Administración

Autor:

Vega Ramirez, Cristofeer Guillermo (0000-0003-1216-5374)

Villegas Effio, Alejandro Arturo (0000-0002-9207-0342)

Asesor:

Espinoza Huayre, Carlos Hector (0000-0002-4828-1214)

Lima, 07 Septiembre 2018 
DEDICATORIA

Dedico esta tesis a mis padres y hermano por su apoyo durante todo este proceso y por confiar en mí para lograr este objetivo.

Vega Ramirez, Cristofeer

Dedico esta tesis a mis padres y amigos que me apoyaron en cada momento de este largo camino

Villegas Effio, Alejandro 


\section{AGRADECIMIENTO}

Dirigimos nuestro agradecimiento a todas las personas que de alguna manera nos brindaron sus comentarios, consejos y tiempo. Sobretodo agradecemos el apoyo y dedicación de Carlos Espinoza para culminar esta tesis. 


\section{RESUMEN}

¿Es posible incrementar los ingresos de una agencia de carga mejorando los procesos operativos de exportación aérea en ciertas variables? A través del análisis y por las mejoras realizadas en las variables independientes Embarques, Toneladas, Embarques Prepagados y Facturas de Servicios Asumidos por la Compañía incrementamos los ingresos de una reconocida agencia de carga en $31.89 \%$.

Para lograr esto, se realizó un análisis sobre el estado actual del comercio internacional en el Perú, luego se elaboró una Matriz de Análisis y Diagnóstico Externo (MADE) e Interno (MADI) sobre la compañía para determinar los principales factores que influyen en este proceso de exportación aérea. En base a la información obtenida desarrollamos la Matriz FODA Cruzada para determinar las estrategias esenciales para la mejora del proceso de exportación aérea.

Con esta información, se determinó las variables independientes Embarques, Toneladas, Embarques Prepagados y Facturas de Servicios No Facturables; las cuales fueron analizadas con la variable dependiente Ingresos por Ventas mediante el Modelo de Regresión Lineal Múltiple, el cual permite determinar la correlación entre variables y si estas aportan al incremento o reducción de los ingresos de la compañía.

Palabras claves: Agencia de Carga, Exportación, Embarques, Aéreo, Flujograma, Incremento Ingresos, Mejora Proceso, Propuesta, Prepagado, Facturas, Toneladas. 


\section{ABSTRACT}

Is it possible to increase the profits of a freight forwarder agency by improving its process of exportation area based on some variables? Through the analysis and the improvement carried out to the embarkation independent variables, tons, prepaid embarkations and the invoices for services assumed by the company, it was determined that it is possible to increase the profits of a freight forwarder agency in a $31.6 \%$.

To accomplish this, an analysis about the current situation of the international commerce in Peru, a matrix analysis and extern diagnosis (MAED), and a matrix analysis and intern diagnosis (MAID) were carried out to determine the principal factors that influence in this exportation area process. Based on the gotten information, a SWOT matrix was also developed to determine what strategies are essential for the improvement of the exportation area process.

With this information, we determine the independent variables that were analyzed with the dependent variables profits through the multiple lineal regression model, that allow to determine the correlation between variables and to know if these ones increase or decrease the profits of the company.

Keywords: Freight Forwarder, Export, Shipments, Aerial, Flow chart, Increase Profit, Improvement Process, Proposal, Prepaid, Invoice, Tons. 


\section{TABLA DE CONTENIDOS}

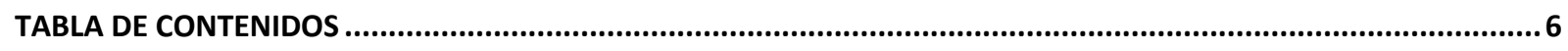

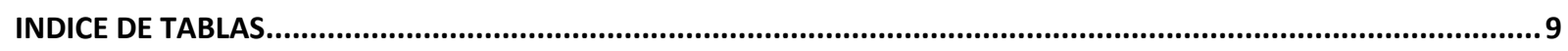

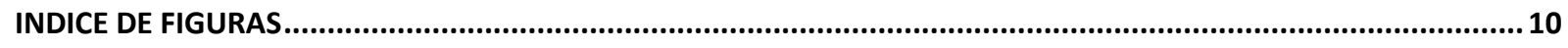

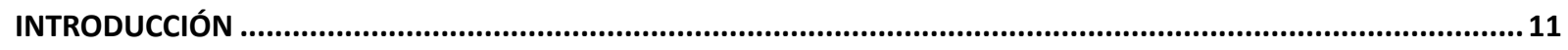

CAPÍTULO I. MARCO TEÓRICO................................................................................................................. 12

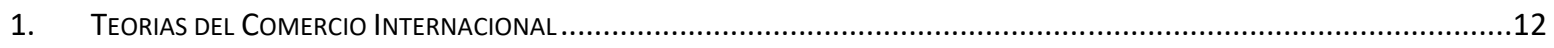

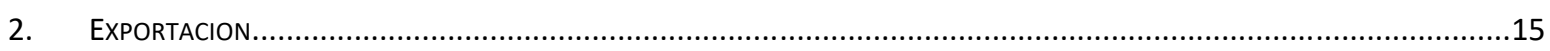

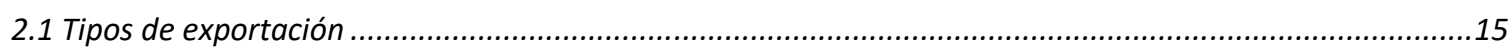

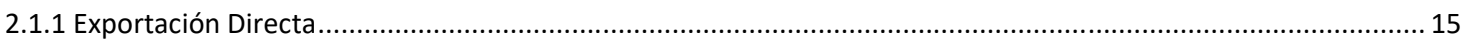

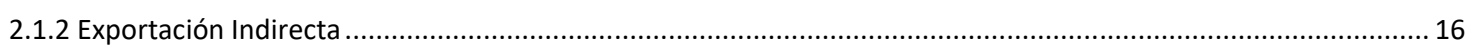

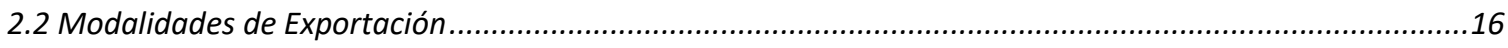

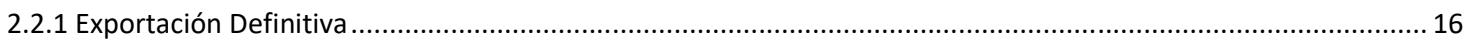

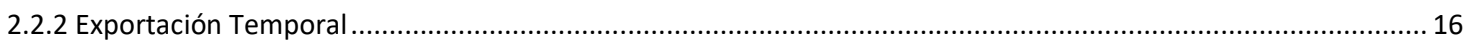

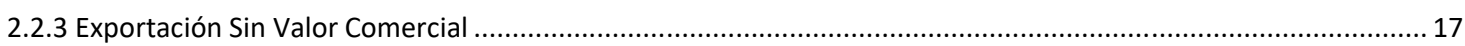

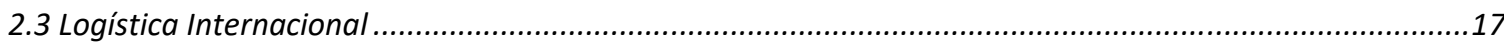

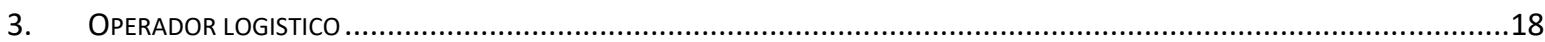

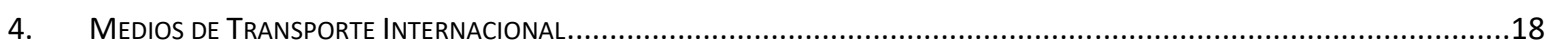

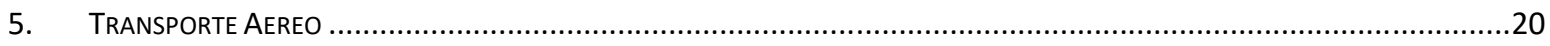

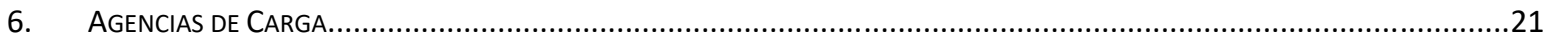

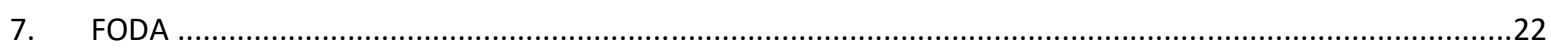

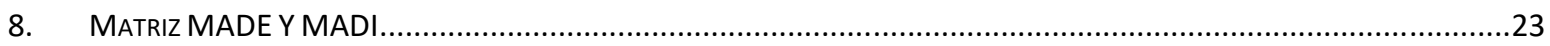

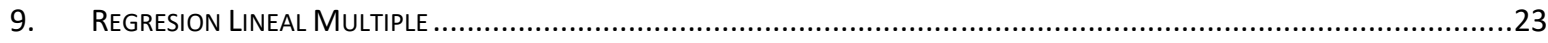

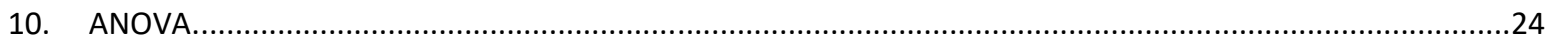

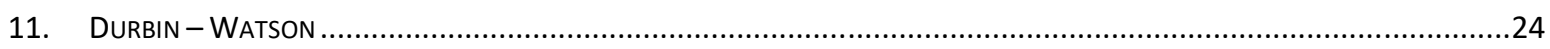

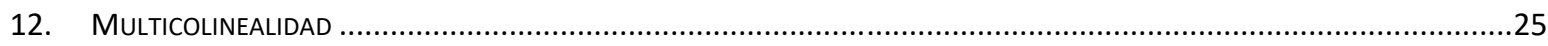

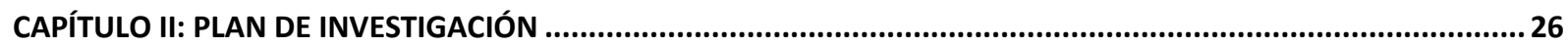

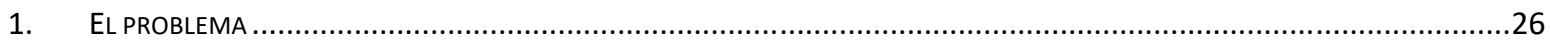

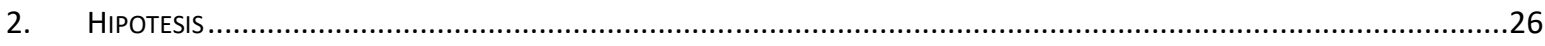

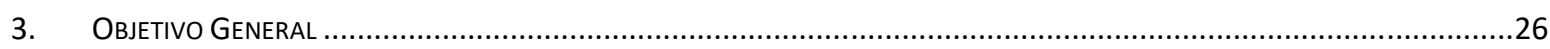




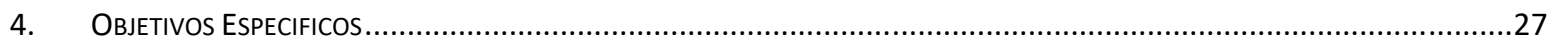

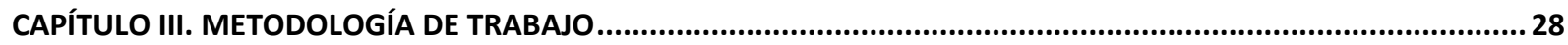

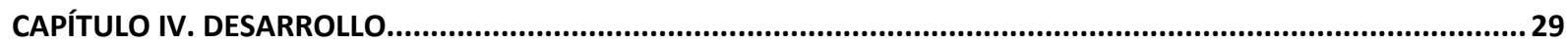

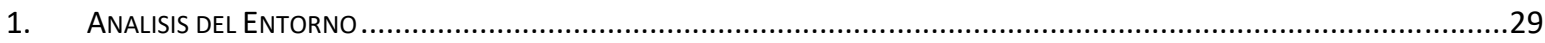

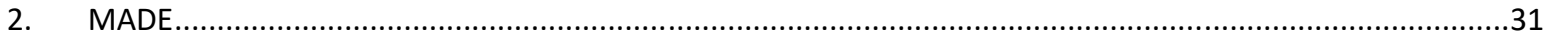

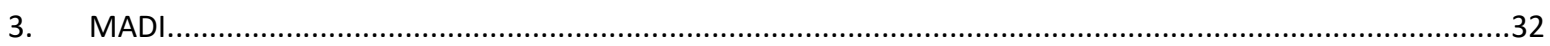

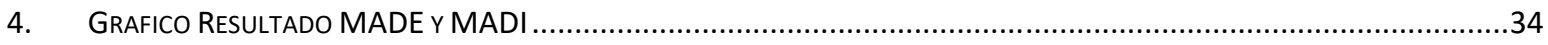

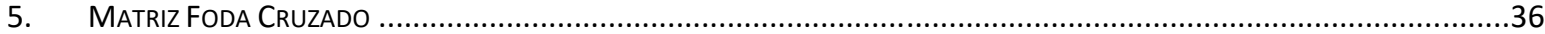

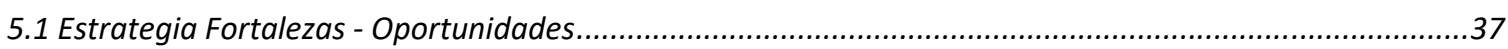

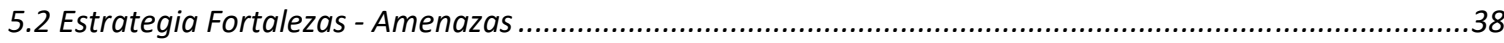

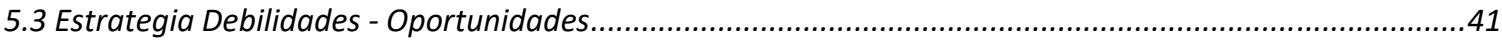

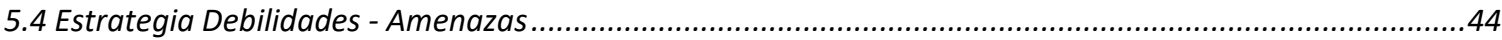

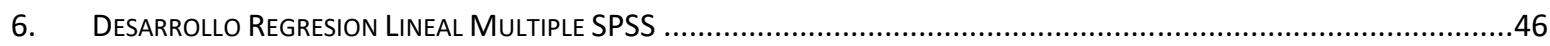

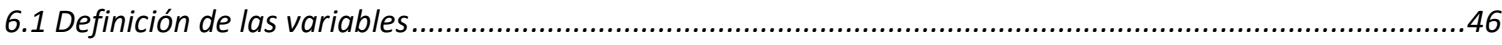

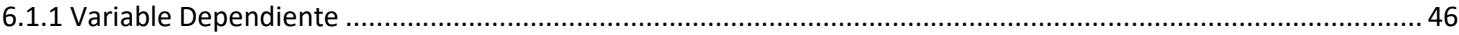

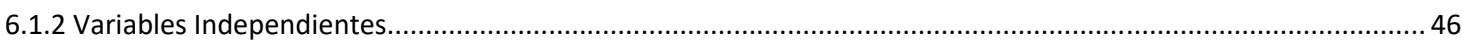

6.2 Proceso de Regresión Lineal Múltiple en el SPSS...................................................................................47

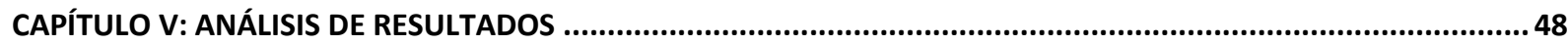

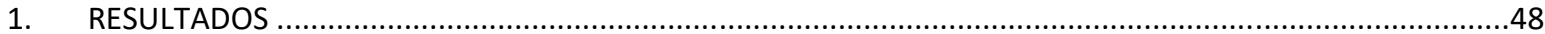

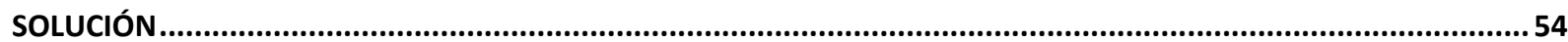

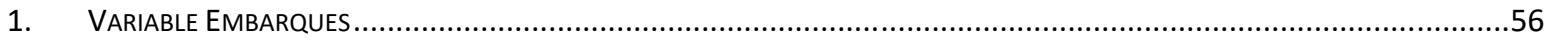

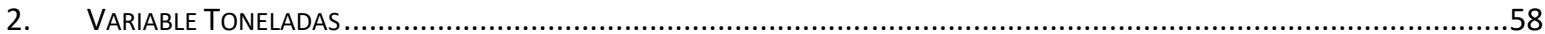

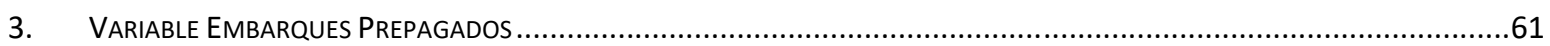

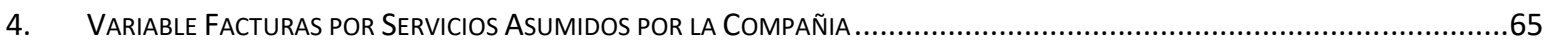

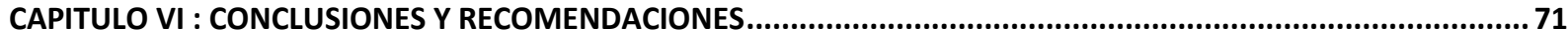

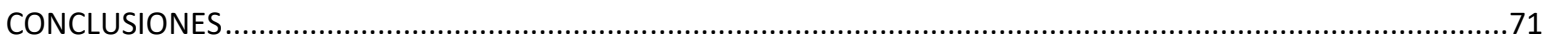

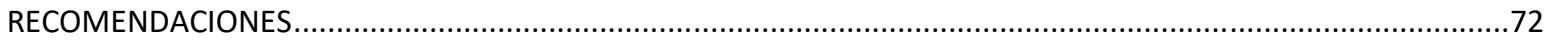

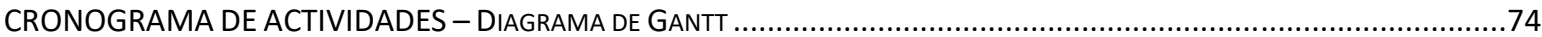

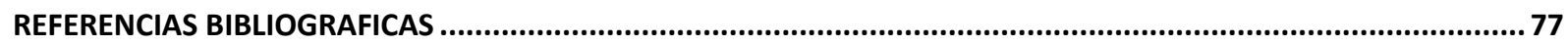

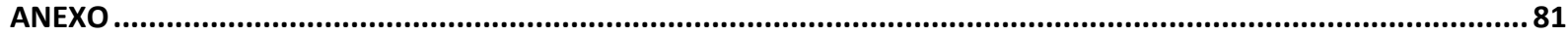

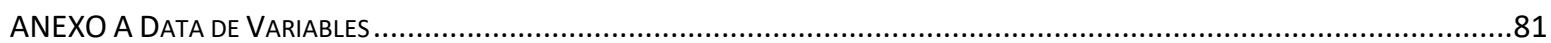


ANEXo B Proceso de Regresion lineal Multiple en el SPSS.

ANEXO C ESTADÍSTICO DE DURBIN WATSON (NIVEL DE SIGNIFICANCIA DE 5\%) 


\section{INDICE DE TABLAS}

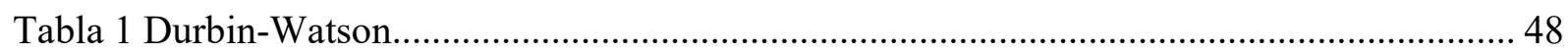

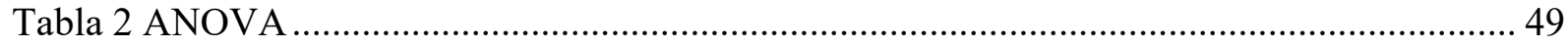

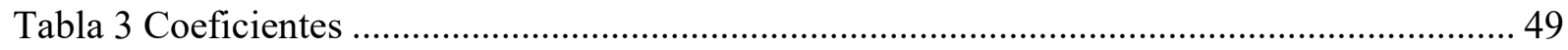

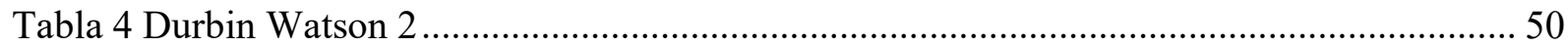

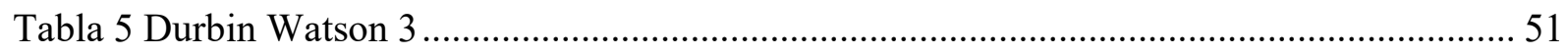

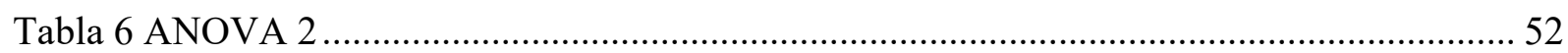

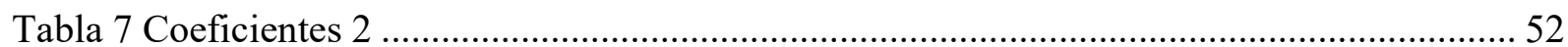




\section{INDICE DE FIGURAS}

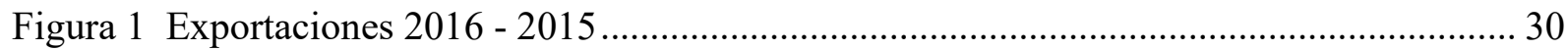

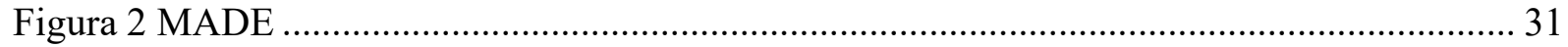

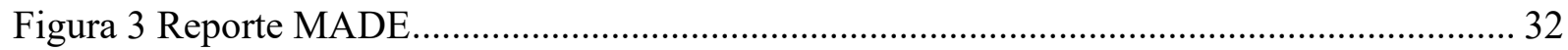

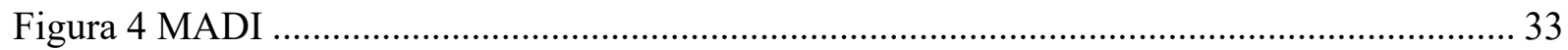

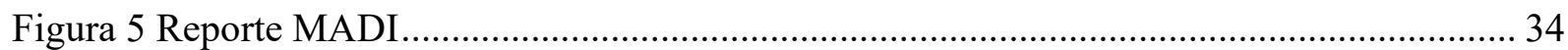

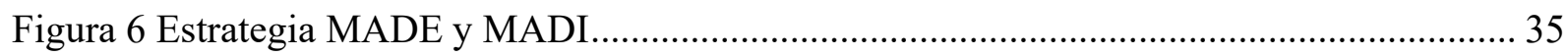

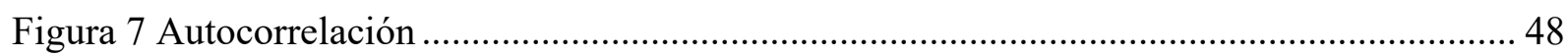

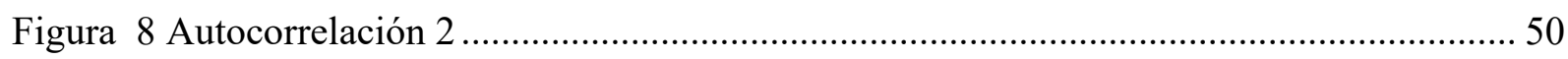

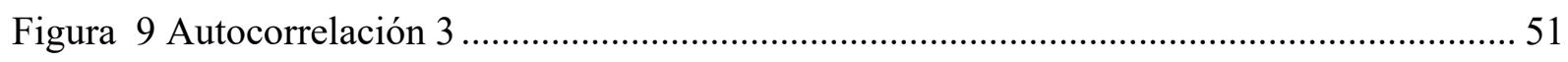

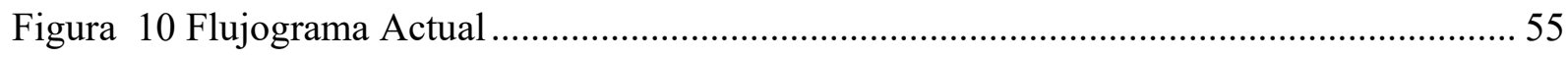

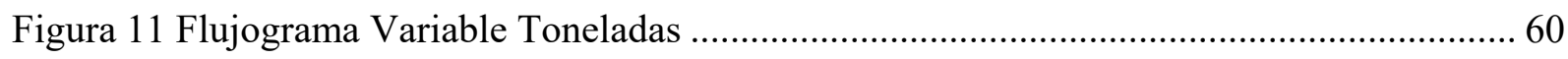

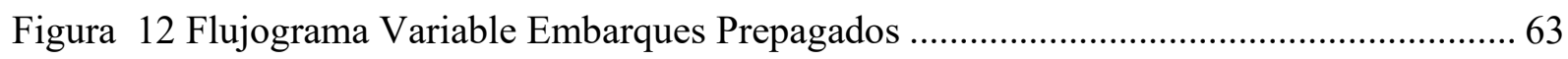

Figura 13 Flujograma Variable Facturas por Servicios Asumidos por la Compañía .................. 67

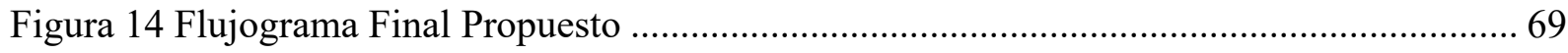

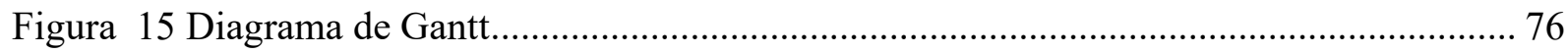




\section{INTRODUCCIÓN}

La agencia de carga evaluada en este trabajo forma parte de uno de los grupos internacionales más importantes de la industria mundial. Este grupo ofrece los servicios postales, transporte internacional express, transporte de mercancías, gestión de las cadenas de suministros y comercio electrónico en más de 200 países. La Sucursal de esta compañía lleva operando en el Perú muchos años y se encarga de atender operaciones logísticas de manera estandarizada y brindar soluciones multimodales de expedición hasta proyectos industriales individualizados.

Esta investigación nos permitió evaluar las actuales variables involucradas en el proceso de exportación aérea de esta Agencia de Carga y determinar qué variables influyen en los ingresos de la compañía y cuáles de estos no están aportando al crecimiento del ingreso en la empresa. Para ello, se realizamos un análisis de las variables involucradas en el proceso de exportación así como del entorno externo e interno de la compañía (MADE, MADI y FODA) para así, poder determinar las correctas mejoras a implementar en el proceso.

El motivo principal de abarcar el proceso logístico de exportación aérea fue el interés propio de lograr soluciones en nuestro ámbito laboral que nos permitiera ganar experiencia aplicando y usando las herramientas aprendidas en nuestra carrera universitaria, siempre enfocando la investigación en logro aplicativo del rubro, ya que es la logística y sus procesos el área que a nosotros, los integrantes de la investigación, nos apasiona. 


\section{CAPÍTULO I. MARCO TEÓRICO}

\section{Teorías del Comercio Internacional}

El actual mercado es muy distinto a lo indicado en las antiguas teorías del comercio internacional las cuales no evalúan variables que ahora son imprescindibles según lo mencionado por García, M. (2009) el cual indica que "La respuesta se encuentra en el descubrimiento y análisis de variables anteriormente no contempladas por la TCCI, las cuales son imprescindibles para entender la economía internacional contemporánea: Economías de escala, comercio intraindustrial, economías externas, competencia imperfecta, movilidad de factores, etc."(p. 20). Dichas variables hoy en día deben ser atendidas y aplicadas de distinta manera en cada punto de la industria en la que se trabaje.

Además, se menciona que el comercio entre industrias parecidas es decir intraindustrial es bastante común, según lo que menciona Steimberg, F. (2009). esto sucede debido a las economías de escala que pueda tener un país, así como el mercado imperfecto, los cuales permiten que cada industria y compañía pueda enfocarse en la diferenciación de su producto permitiendo que el consumidor o cliente final pueda contar con una gran variedad de productos y precios.

Entre las principales teorías clásicas está el Mercantilismo, la cual según Ramales, M.(2013) establecía que los metales preciosos (principalmente el oro y la plata) eran la base para la riqueza del país y otorgaba poder a una nación.

Los mercantilistas pensaban que la obtención de una mayor existencia de metales preciosos era a través de otras naciones, es decir apoyaban la exportación puesto que sumaban las riquezas de la nación, pero no veían con buenos ojos las importaciones ya que esto implicaba la salida de sus riquezas. El mantener una balanza comercial favorable era signo de riqueza y poder para una nación, por lo que apoyaban una política comercial proteccionistas donde se subsidiaba los 
productos de exportación y se implementaban barreras para la importación, era un juego donde las ganancias de una nación representaban la perdida de otras.

Posterior a esta teoría, surgió el modelo de la ventaja absoluta de Smith, A. (1776) la cual plantea que el comercio es una acción de suma positiva es decir beneficias a las naciones participantes. Esta teoría expresa según la Universidad Nacional Autonoma de Mexico (p. 1) que el libre comercio interior e internacional y la especialización en creación de mercancías donde eres eficiente ${ }^{1}$, es decir cuentas con ventaja absoluta de producción sobre las demás naciones, permite el crecimiento de la riqueza nacional, una mayor productividad de trabajo, menores precios y un mercado más amplio (Ramales,M. 2013).

La teoría de la ventaja comparativa de David Ricardo(1817) también apoya el libre comercio internacional, pero a diferencia de Adam Smith concluye que a pesar de que dos países cuenten con ventaja absoluta sobre un bien uno de estos será más eficiente que el otro, por lo que para la otra nación sería beneficioso invertir en otro bien donde sea más eficiente, es decir esta teoría se basa en la productividad de la mano de obra entre naciones y concluir que sectores son más beneficiosos producir para cada país.

El modelo de costo de Oportunidad de Gottfried Haberler reformula las teorías clásicas de Adam Smith y David Ricardo las cuales están basadas en la teoría de valor trabajo, la cual pone el valor del trabajo como la medida real del valor de todos los bienes según lo expuesto por Gabriel y Manganelli(2010) "valor trabajo establece que es la cantidad de bienes que el trabajo produce lo que determina su valor real y no la cantidad de bienes que son entregados al trabajador como recompensa por su labor; además, considera que los precios relativos de los bienes dependen de la cantidad de trabajo empleada para producirlos.”(p. 3). Gottfried en la década de los 30 replantea ambas teorías (ventaja comparativa y absoluta) en términos de costo de oportunidad, en donde se

\footnotetext{
${ }^{1}$ Universidad Nacional Autónoma de México. Principales Teorías sobre Comercio Internacional. Recuperado de http://www.economia.unam.mx/secss/docs/tesisfe/mcam/1.pdf
} 
mide la producción de un bien frente a otros, es decir cantidad que se debe dejar de producir de un bien para permitir la producción de otro (Rameles,M. 2013).

La teoría de Heckscher - Ohlin nos da un nuevo enfoque respecto a las teorías anteriores. Este modelo nos indica que los factores productivos (como la tierra, trabajo, capital, entre otros) de una nación, los cuales pueden ser abundantes o escasos, son distintos frente a otras naciones, lo cual brinda una ventaja comparativa en un bien donde la producción utiliza intensivamente el factor productivo abundante ${ }^{2}$. Según esta teoría, el libre comercio beneficia a los países comerciantes permitiendo que su producción sea menos costosa y más eficiente y logrando que las naciones se complementen en sus diferencias y escasez.

La teoría de la Disponibilidad por Kravis en 1956 indica que el comercio se origina de las diferencias existente entre países en los recursos naturales y las innovaciones tecnológicas. Un país importara bienes solo cuando no es capaz de producir debido a que su oferta es rígida o porque su producción es insuficiente debido a que la oferta es inelástica, es decir ante el aumento de la producción los costos de estas son muy elevados. Mientras que para exportar se debe mostrar una oferta elástica que sobrepase las necesidades locales (De la Hoz, A., 2013, pp. 29-30).

El economista sueco Linder (1961) desarrollo la teoría de la Demanda Representativa, según De la Hoz, A.(2013) en esta intenta explicar el comercio existente entre naciones similares. Además, indica cuando un bien será exportado, la cual depende en un principio de la demanda interna de este producto que permite generar economías de escala y mejoras en el bien (innovación) (p. 30). También se evalúa la existencia de mercados con características parecidas al mercado interno, es decir que cuente con gustos, ingresos y nivel de vida muy similares.

La teoría del Ciclo del Producto explica por qué algunas compañías se mueven a otro país que tenga un menor coste de producción. En esta teoría se establecieron tres fases en la vida del bien, iniciando por el lugar de producción, la madurez del producto y estandarización. En un inicio la demanda del producto es baja, por lo que la exportación es una opción viable. Posterior a esto,

\footnotetext{
${ }^{2}$ Universidad Nacional Autónoma de México. Principales Teorías sobre Comercio Internacional. Recuperado de http://www.economia.unam.mx/secss/docs/tesisfe/mcam/1.pdf
} 
la demanda por el producto empieza a crecer y la innovación sufre una difusión tecnológica, lo cual da inicio a la distribución del bien en otros países con un nivel de desarrollo intermedio. Por último, la producción y el producto se encuentran estandarizados, por lo que las compañías recurren a mejorar sus costos y movilizar su producción a países que cuenten con trabajo no cualificado y barato para lograr una producción en masa (De la Hoz, 2013, pp. 31-32).

\section{Exportación}

Es la salida legal de algún producto o servicio, nacional o nacionalizado, desde un territorio aduanero hacia otro ${ }^{3}$. Dicha salida puede ser de plazo temporal o definitivo. En este último caso, el producto o servicio no está afecto al pago de ningún tributo. Además, para concretar la salida del producto o servicio, puede llegar a otro territorio aduanero mediante el transporte marítimo, ferroviario, carretero, multimodal o aéreo.

Para realizar una exportación existen dos formas con las que el proveedor puede llegar al cliente final y tres modalidades en las que el producto o servicio llega al cliente final.

\subsection{Tipos de exportación}

Para seleccionar un tipo de exportación, dependerá del acuerdo entre el vendedor y comprador, pero principalmente de la experiencia, responsabilidad y riesgo que quiera tomar el exportador. A continuación se explican los dos tipos de exportación.

\subsubsection{Exportación Directa}

En este tipo de exportación no existen intermediarios entre los agentes productores y compradores finales o intermediarios del destino. Ello implica que el productor asigne capital humano para el contacto con el exterior. La principal ventaja de este tipo se encuentra en el mayor potencial de venta por un mayor volumen de negociación debido a que se tiene contacto directo con

\footnotetext{
${ }^{3}$ MINCETUR (2009), El ABC del Comercio Exterior: Guía de Capacidades Gerenciales de Comercio Exterior.
} 
el comprado “(...) dicho conocimiento le permitirá a la empresa local, adaptarse a los cambios y requerimientos de los mercados de destino", ( MINCETUR, 2009, p. 18).

\subsubsection{Exportación Indirecta}

En este tipo de exportación la empresa productora le vende la producción a otra empresa de su mismo país, la que se encargará de la comercialización de ésta de forma independiente(Minagri, 2015). La ventaja de este tipo de exportación se encuentra en bajos niveles requeridos de inversión dado que no ejecuta la exportación y mitiga los riesgos asociados. Sin embargo, se constituye una desventaja sustancial en la cadena de suministro dado que depende directamente de la empresa intermediadora.

\subsection{Modalidades de Exportación}

Para seleccionar una modalidad de exportación, debe enfocarse en el uso final que se le quiere dar al producto. A continuación, se explican las 03 modalidades de exportación.

\subsubsection{Exportación Definitiva}

Teniendo una descripción exacta de exportación definitiva de bienes, la podemos describir como el "régimen aduanero que permite la salida del territorio aduanero de las mercancías nacionales o nacionalizadas para su uso o consumo definitivo en el exterior. La exportación definitiva no está afecta a ningún tributo” (SUNAT, 2008, Cap. I Art. 60)

\subsubsection{Exportación Temporal}

La SUNAT (2008) refiere sobre esta modalidad:

"Régimen aduanero que permite la salida temporal del territorio aduanero de mercancías nacionales o nacionalizadas con la finalidad de reimportarlas en un plazo determinado, sin haber experimentado modificación alguna, con excepción del deterioro normal por su uso. No podrá incluirse en este régimen las mercancías cuya salida del país 
estuviera restringida o prohibida, salvo que estén destinadas a exposiciones o certámenes de carácter artístico, cultural, deportivo o similar y que cuente con la autorización del sector competente." (Cap. II,Art. 64)

\subsubsection{Exportación Sin Valor Comercial}

Este tipo se refiere a las operaciones que involucren menor cuantía lo que involucra las maletas, menaje, enseres, etc. El valor FOB de las mercancías no deberá superar US\$2,000.

\subsection{Logística Internacional}

Es el área que se enfoca en evaluar la cadena de suministro global, movimiento de bienes, correspondencia y documentación, y diversas actividades que constituyen la base para las actividades y operaciones de exportación e importación, para ellos se señala lo siguiente: " $L a$ logística internacional es el proceso de planeación, implementación y control del flujo y almacenaje de bienes, servicios e información relacionada entre el punto de origen y el punto de consumo ubicado en un país diferente” (David, 2016, p. 44).

El conjunto de actividades inherentes al proceso de logística internacional requieren de la intervención de un conjunto de operadores logísticos para garantizar el traslado de una determinada mercancía. Al respecto, existe un conjunto de ofertas y alternativas de solución para las gestiones correspondientes.

El transporte internacional es una variable relevante en el proceso logístico y está conformado por un conjunto de actividades: carga y transporte en el lugar de origen, proceso aduanero de exportación, estiba en vehículo de traslado internacional, transporte internacional, desestiba en lugar de destino, despacho aduanero de importación e impuestos, transporte y descarga en el destino final. La eficiencia de la gestión logística incide significativamente sobre los costos y la percepción final del cliente (plazo de entrega, costo total, calidad del producto.

\footnotetext{
${ }^{4}$ SUNAT (2008), Ley General de Aduanas.
} 


\section{Operador logístico}

En el marco de optimizar los procesos de aprovisionamiento, producción y distribución de mercancías se ha consolidado un tipo de persona jurídica con una amplia oferta de prestación de servicios:

\begin{tabular}{ll} 
- & Servicios de distribución \\
- & Almacenaje \\
- & Gestión de stocks \\
\hline & Facturación
\end{tabular}

\section{Medios de Transporte Internacional}

El transporte representa una parte importante en la cadena logística internacional. Según su etimología significa "traslado", es decir tiene relación con la movilización de personas y bienes, y los medios utilizados para llevar a cabo esta acción. El transporte sirve para poder enlazar los productos con los centros de ventas, el transporte de personas a diversos puntos geográficos, la unificación de pueblos, ciudades y estados, contribuye a la economía del país.

El transporte internacional traslada de un punto de origen a otro punto de destino según la naturaleza del objeto a personas o mercancías, por su ámbito geográfico (urbano, nacional o internacional), por el medio de transporte utilizado terrestre, marítimo, aéreo, ferroviario y multimodal y por su grado de identificación sea público o privado. Uno de los medios de transporte más importantes y utilizados es el transporte marítimo, esto debido a su bajo costo frente a otros medios, su gran capacidad de almacenaje, sus diversos medios físicos de transporte y su adaptación por los diversos barcos adaptados para cualquier tipo de carga. El transporte marítimo tiene como modalidades de transporte "Línea Regular" que es para servicios constantes de rutas similares y tarifas pre acordadas; y de "Régimen deFletamentos" donde se contrata el espacio total o parcial de un buque para una cierta cantidad de viajes o por un periodo de tiempo ${ }^{5}$.

\footnotetext{
${ }_{5}^{5}$ Ministerio de Comercio Exterior y Turismo(2009). Guía de orientación al usuario del transporte Acuático. Recuperado de http://www.siicex.gob.pe/siicex/documentosportal/188937685rad43065.pdf
} 
En el proceso del transporte marítimo se encuentran diversos operadores participantes en el proceso, entre estos tenemos a el Transportista (Porteador Efectivo), las Agencias Generales (Agencia de Carga y Agencia de Fletamento), Agencias Marítimas, el Estibador y Fletador, el Embarcador, Consignatario, entre otros (Dorta, P., 2013, p. 32).

El transporte terrestre es uno de los medios más accesibles y versátiles para las empresas, puede transportar casi en su totalidad cualquier tipo de producto a un costo relativamente bajo y de forma rápida. Entre los modos de contratación está el envío de una carga por una ruta determinada, y el envió de cargas agrupadas la cual está compuesta de diversos cargadores. Los principales tipos de vehículos utilizados en el comercio internacional son los vehículos rígidos, vehículos articulados, plataformas porta vehículos, plataformas portacontenedores, tautliner, graneles y cisternas (Molins, A., 2011, p. 47).

Otro de los medios de transporte utilizados es el Ferroviario, esta modalidad está tomando una gran importancia por el concepto del "Desarrollo Sostenible". Entre sus principales deficiencias esta la capacidad del vagón, las dimensiones del transporte, las conexiones o destinos de las vías. A pesar de lo antes mencionado, este transporte cuenta con una variedad de vagones para los diversos productos, entre estos tenemos los vagones cerrados, silos, tolva, cisterna, plataforma portacontenedores, plataforma portavehiculos, entre otros.

El transporte aéreo internacional es aquella actividad en donde se realiza el traslado de productos de un punto de origen a un punto de destino fuera del territorio nacional. El transporte aéreo internacional es el modo de transporte más rápido, pero también el más caro; en gran parte por este medio se transporta carga perecible y de alto valor ${ }^{6}$. Este modo de transporte cuenta con diversas ventajas debido a su rapidez, entre estas tenemos un menor costo de seguro, menor tiempo de entrega, fácil control y seguimiento, seguridad entre otros. También, este medio de transporte cuenta con ciertas desventajas que son su restricción en dimensiones, límite de peso y el costo elevado por utilizar este medio de transporte internacional. Los operadores que interactúan y

\footnotetext{
${ }^{6}$ Ministerio de Comercio Exterior y Turismo (2009). Guía de orientación al usuario del transporte aéreo. Recuperado de http://www.siicex.gob.pe/siicex/documentosportal/188937685radB4C00.pdf
} 
participan en el proceso del transporte aéreo son la compañía aérea, la agencia de carga internacional, agencia de aduanas, terminal aeroportuario, deposito temporal entre otros.

El modo de transporte multimodal es realizado por un operador (Operadores de Transporte Multimodal, OTM) que realiza el envío de mercaderías utilizando dos o más modos de transporte. Entre los principales beneficios está la disminución del costo, la reducción en tiempos de entrega, un mejor seguimiento de la mercadería, menor cantidad de incidencias y simplicidad en la documentación.

\section{Transporte Aéreo}

El transporte aéreo es el medio que utiliza aeronaves y permite el traslado de mercancías entre dos puntos garantizando las condiciones de seguridad pertinentes. Éste es el medio de transporte más reciente y se constituye como uno de los servicios más usados (luego del transporte marítimo) para el comercio internacional. La principal característica de este medio de transporte es la rapidez: por ello se constituye como un medio frecuente para el transporte de mercancías. Asimismo, la utilización del servicio es más sencilla y el proceso logístico es menos complejo que en el transporte marítimo.

En los últimos años, la globalización y el desarrollo del comercio mundial han impulsado el crecimiento del transporte aéreo, alcanzando a movilizar en términos de carga sólo el 1\% con un valor aproximadamente del $40 \%$ del comercio mundial. Es preciso resaltar que en este medio de transporte no se cuenta con vehículos especializados por tipo de carga, por lo que para alcanzar un aspecto especializado se recurre a medios auxiliares en el transporte (contenedores, embalaje, entreotros).

"Los tipos de servicio que ofrece la industria de carga aérea se definen por la naturaleza de la demanda y el tipo de mercancía. La carga aérea es particularmente adecuada para mercancías que tienen una alta proporción entre valor y peso, o son perecedera, rápidamente obsoletas, se requieren con poco tiempo o es costoso manejarlas o almacenarlas. Hacer envíos por aire también es atractivo cuando la demanda es 
impredecible, infrecuente, sobrepasa la oferta local o es de temporada” (David, 2006, p. 354).

Los productos usualmente enviados por este medio dependen de cada región; sin embargo, éstos guardan características en común como: perecibilidad, alta rotación, urgencia, seguridad, manejo adaptado, alto valor, etc.

\section{Agencias de Carga}

Los agentes de carga internacional son un operador del comercio exterior que se encargan de gestionar el transporte de mercancías tanto en el ámbito nacional como internacional, así como en la exportación e importación. Esta es definida por la Ley General de Aduanas en el artículo $\mathrm{N}^{\circ}$ 2 del Decreto Legislativo $\mathrm{N}^{\circ} 1053$ de la siguiente forma:

"Persona que puede realizar y recibir embarques, consolidar, y desconsolidar mercancías, actuar como operador de transporte multimodal sujetándose a las leyes de la materia y emitir documentos propios de su actividad, tales como conocimientos de embarque, carta de porte aéreo, carta de porte terrestre, certificados de recepción y similares" (SUNAT, 2008).

A través del tiempo sus funciones se han amplificado con respecto a los servicios que ofrece, según Glass, D. (1989) citado por Guzman, J, (2005) nos indica:

"el agente de carga actúa como un intermediario entre el remitente o el consignatario y los transportadores, almacenadores, autoridades aduaneras y otras personas en la cadena de transporte con quienes el cliente de otra manera tendría que tratar. De este modo, tradicionalmente su rol principal ha sido celebrar los contratos con aquellas personas en nombre de su cliente. Adicionalmente, los agentes de carga con frecuencia asesoran en relación con rutas, proveen información cobre importaciones y exportaciones, y preparan y diligencian la documentación necesaria para que los bienes lleguen a su destino.”. 
Es decir, el agente de carga internacional no solo sirve de intermediador con los transportistas sino también con otros operados dentro de la cadena logística, como el embalaje de la carga, el transporte local al almacén autorizado, el almacenamiento de mercadería y otros más. Según la FIATA (Federación Internacional de Asociaciones de Transitarios y Asimilados) citado por la Secretaria de Comunicaciones y transportes del instituto Mexicano de Transporte (1998) las agencias de carga internacional están clasificadas de acuerdo a su especialización en función del medio de transporte. De acuerdo a esto las agencias están clasificadas de la siguiente forma:

“a) Agentes de carga de superficie (Surface freight forwarders), que son aquellos que se especializan en el movimiento de bienes por tierra: ferrocarril, autotransporte y fluvial; b) Agentes de carga marítimos (Ocean freight forwarders), que son los expertos en el movimiento de carga por mar y los Agentes de carga aéreos (Air freight forwarders) quienes se especializan en el movimiento de mercancías por vía aérea."(Instituto Mexicano del Transporte, 1998, p.9).

\section{FODA}

Para realizar el análisis del entorno externo e interno se empleó la matriz FODA (Fortalezas, Oportunidades, Debilidades y Amenazas). Esta es una herramienta estratégica que se utiliza para analizar los factores interno (fortalezas y debilidades) y factores externos (Oportunidades y Amenazas) de la compañía para lograr obtener un diagnóstico sobre la situación actual de la empresa.

Como menciona Ponce H. (2007) "El análisis FODA consiste en realizar una evaluación de los factores fuertes y débiles que, en su conjunto, diagnostican la situación interna de una organización, así como su evaluación externa, es decir, las oportunidades y amenazas".

Según Thompson y Strikland (1998) citado por Ponce H. (2007) “el análisis FODA estima el efecto que una estrategia tiene para lograr un equilibrio o ajuste entre la 
capacidad interna de la organización y su situación externa, esto es, las oportunidades y amenazas".

\section{Matriz MADE Y MADI}

Para realizar el análisis del entorno externo e interno se utilizó la matriz de análisis y diagnóstico interno (MADI) y la matriz de análisis y diagnóstico externo (MADE). EL MADE se utiliza para analizar el entorno especifico, existen dos modelos para su análisis que son las 5 fuerzas competitivas de Porter y el Enfoque Sistémico, también se evalúa el efecto de la influencia del entorno específico en la compañía, el efecto que tiene cada factor en las 4P's (Producto, Precio, Plaza, Promoción) y la importación de un factor frente a los demás ${ }^{7}$.

El MADI se emplea para el análisis interno de la compañía, las teorías para analizar su entorno son el enfoque sistémico y las teorías de recursos y capacidades. En esta también se evalúa la influencia cada factor en la compañía, el efecto que tiene cada factor en las 4P's (Producto, Precio, Plaza, Promoción) y la importación de un factor frente a los demás ${ }^{8}$

\section{Regresión Lineal Múltiple}

Otra herramienta para el análisis de las variables es el modelo de regresión lineal múltiple es una herramienta que se emplea para determinar la relación que existe entre una variable dependiente y un grupo de variables independientes, como menciona María José Rodríguez:

“El Análisis de Regresión Lineal Múltiple nos permite establecer la relación que se produce entre una variable dependiente $Y$ y un conjunto de variables independientes $(X 1, X 2, \ldots$ $X K)$. El análisis de regresión lineal múltiple, a diferencia del simple, se aproxima más a situaciones de análisis real puesto que los fenómenos, hechos y procesos sociales, por definición, son complejos y, en consecuencia, deben ser explicados en la medida de lo posible por la serie de variables que, directa e indirectamente, participan en su concreción” (Rodriguez, 2001, p. 3)

\footnotetext{
${ }^{7}$ Universidad Peruana de Ciencias Aplicadas (2013). Unidad 4: Análisis del Entorno Valoración Cuantitativa

${ }^{8}$ Universidad Peruana de Ciencias Aplicadas (2013). Unidad 5: Análisis del Interno Valoración Cuantitativa
} 
Este modelo también se encarga de determinar la multicolinealidad entre variables independientes, como mencionan Gujarati \& Porter (2010) “designaba una relación lineal “perfecta” o exacta entre algunas o todas las variables explicativas de un modelo de regresión”( $p$. 321).

\section{ANOVA.}

El Análisis de Varianza o también conocido como ANOVA (Analysis of Variance) es un modelo estadístico que se encarga de comparar las varianzas de las medias para determinar si pertenecen a una sola población. También se menciona que:

"El análisis de varianza (ANOVA) de un factor nos sirve para comparar varios grupos en una variable cuantitativa. Esta prueba es una generalización del contraste de igualdad de medias para dos muestras independientes. Se aplica para contrastar la igualdad de medias de tres o más poblaciones independientes y con distribución normal.” (Bakieva, M., González Such, J. y Jornet, J, 2012)

El análisis de varianza según el software estadístico Minitab 18(2017) “prueba la hipótesis de que las medias de dos o más poblaciones son iguales. Los ANOVA evalúan la importancia de uno o más factores al comparar las medias de la variable de respuesta en los diferentes niveles de los factores"

\section{Durbin - Watson}

Es un indicador desarrollado por Durbin y Watson, la cual se utiliza para contrastar la presencia de autocorrelación entre los residuos de una regresión.

Al respecto se menciona: “(...) la gran ventaja de este estadístico se debe a que se basa en la estimación de residuos. Aunque ahora se usa de forma rutinaria, es importante tener en cuenta las suposiciones adyacentes del estadístico”. Gujarati (2004) 


\section{Multicolinealidad}

Se puede determinar la presencia de multicolinealidad entre dos variables cuando dos variables independientes están relacionadas entre sí. Esto representa un problema muestral en una ecuación de regresión en la medida en que no es posible determinar con precisión la significancia de variables explicativas altamente correlacionadas con la variable objetivo. Al respecto, Novales (2010) manifiesta: "En la mayoría de los modelos de regresión que nos encontramos, las variables explicativas tienen correlación no nula. Esto se debe a que los datos económicos no proceden de un diseño experimental, como pueda suceder en otro tipo de ciencias." 


\section{CAPÍTULO II: PLAN DE INVESTIGACIÓN}

\section{El problema}

La compañía ha tenido una reducción de sus ingresos comparado a los años anteriores, lo cual no ha permitido superar las metas establecidas de forma eficiente. Durante este tiempo se han realizado capacitaciones al personal y mejora de costos por embarques, pero estos esfuerzos no han logrado incrementar los ingresos de la forma esperada.

Con los resultados obtenidos por la compañía en los últimos meses, se puede concluir que debido al débil flujo de información existente en el proceso de exportación aérea no se ha logrado mejorar el servicio al cliente. De igual forma, la poca búsqueda de clientes potenciales no ha permitido incrementar los ingresos de la empresa y contar con una mayor cartera de exportadores.

Por otra parte, la cantidad de sobrecostos o reprocesos generados durante la operación han generado la perdida de embarques y clientes debido a la demora y costos adicionales no incluidos en la cotización.

\section{Hipótesis}

Ho: El proceso de exportación aérea no aporta al incremento de los ingresos a través de mejoras en las variables analizadas.

H1: El proceso de exportación aérea aporta al incremento de los ingresos a través de mejoras en las variables analizadas.

\section{Objetivo General}

- Identificar las variables que afectan al ingreso de la compañía y plantear mejoras en el proceso de exportación aérea de la Agencia de Carga para el incremento en los ingresos. 


\section{Objetivos Específicos}

- Identificar las variables que afectan el crecimiento de los ingresos.

- Reducir el monto de facturas por servicios asumidas por la compañía.

- Mejorar el tiempo de la operación de exportación aérea. 


\section{CAPÍTULO III. METODOLOGÍA DE TRABAJO}

La presente tesis fue desarrollada con información primaria con la que se pudo mostrar los detalles de la situación actual de la Agencia de Carga. Adicional a ello contamos con información secundaria que complementó nuestro trabajo, no solo enfocado en la Agencia de Carga estudiada, sino también en el sector y teniendo presente la situación actual del Comercio Exterior en el Perú.

Debido principalmente a la situación actual del Comercio Exterior en el Perú y los factores internos de la Agencia de Carga, utilizamos las herramientas MADE y MADI para realizar una evaluación de cada uno de los factores que afectan de manera positiva o negativa a la Agencia de Carga. Con una evaluación detallada, elaboramos el FODA CRUZADO para proponer estrategias que mejoran la situación actual. Al contar con estrategias definidas, seleccionamos variables independientes y una dependiente que deseábamos mejorar, todas relacionadas al proceso de exportación aérea. Nuestro análisis se enfocó en describir y mostrar la relación entre las variables, con ellas modelamos una regresión lineal múltiple que además son explicadas mediante el uso del SPSS.

Sumadas todas las fuentes de información mencionada y mediante un análisis total de dichas fuentes, se pudo dar a esta tesis un enfoque cuantitativo. Ello nos permitió tener una visión real y clara en la que se propuso plasmar mejoras numéricas al proceso de exportación. 


\section{CAPÍTULO IV. DESARROLLO}

\section{Análisis del Entorno}

Desde el 2015, América Latina en conjunto ha tenido una tarea difícil para recuperarse de la recesión. Es por ello que el Fondo Monetario Internacional indica en su Artículo de Actualidad que "La cifra de crecimiento económico en América Latina y el Caribe en 2016 fue la tercera peor en 30 años”. Sin embargo, las perspectivas de recuperación de la economía de América Latina son optimistas para el presente año; según el informe anual del organismo, "Perspectivas del Comercio Internacional de América Latina y el Caribe, 2017”, las importaciones de la región se recuperarían y se espera que crezcan un 7\% para este año. Esta recuperación estaría impulsado por países asiáticos (principalmente China), seguida del comercio a Estados Unidos y la región.

Los cambios más relevantes del panorama regional se manifestaron en los países como Argentina, que espera la reactivación del consumo, gasto público y exportaciones. Asimismo. Brasil vislumbra un horizonte de crecimiento luego de dos años de recesión debido a mejores precios en unos de sus cultivos de mayor producción (soja), estímulos en el consumo, y mayor dinamismo en las negociaciones con otros países. En el caso de la Alianza del Pacífico, conformada por Chile, Colombia, México y Perú; aún no se ha logrado la integración completa entre sus miembros; sin embargo, existe un gran potencial de desarrollo y representa una oportunidad para dinamizar el comercio nacional y regional. Uno de los principales factores con incidencia sobre la conectividad entre los integrantes de la Alianza se encuentra en la regulación de los esquemas de transporte (marítimo y aeroespacial).

En línea con las políticas de Profundización Económica Comercial, en el año 2016, el Perú firmó tres acuerdos que involucran compromisos en materia de Comercio de Servicios, Inversiones, Contratación Pública y Solución de Controversias. Éstos buscarían promover el 
comercio internacional. Cabe precisar que Brasil representa uno de los principales socios en intercambio comercial y de exportaciones.

Las exportaciones en el Perú han crecido un 27.7\% en el primer semestre del $2017^{9}$, según comunicó el Ministro Eduardo Ferreyros del Ministerio de Comercio Exterior y Turismo (MINCETUR) y se prevé que las exportaciones del Perú a fines de 2017 crecerán en un 15\%. Asimismo, resaltó que este crecimiento se debe al mayor dinamismo de los sectores agro y pesca. $\mathrm{Si}$ bien los precios de los minerales son altamente dependientes del entorno internacional, actualmente estos muestran una perspectiva estable. La evolución anual del valor de las exportaciones de los años 2015 - 2016 se muestran en el siguiente gráfico.

Figura 1 Exportaciones $2016-2015$

\section{Exportaciones 2016 - 2015}

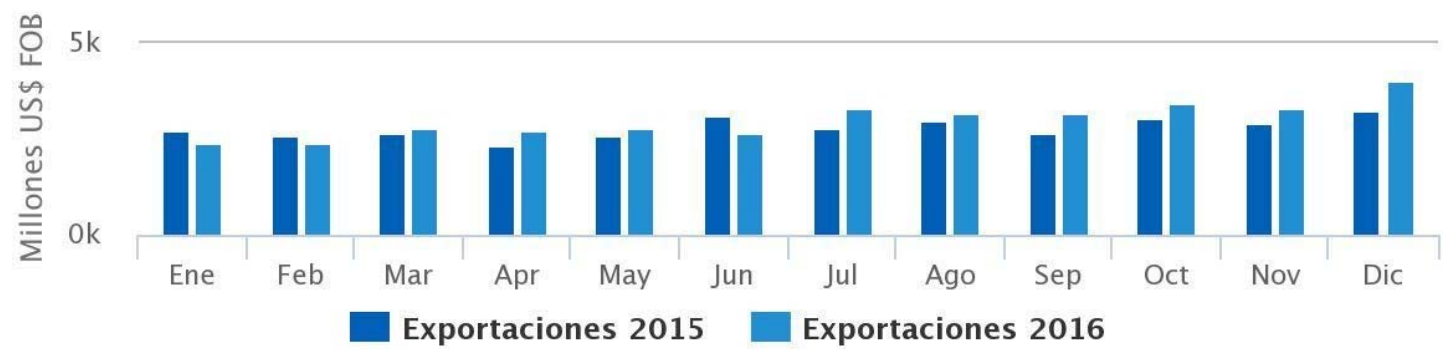

Fuente: Adex Data Trade

En ese sentido, con el fin de fortalecer las políticas que asegurarán el ritmo de crecimiento de la actividad de comercio internacional del país, el Estado a través de PROMPERU, creó la Dirección de Promoción de Inversión Productiva para proyectos de desarrollo productivo; además modificó el proceso de importación realizado por SUNAT implementando el despacho anticipado y se implementó el Observatorio de Logística de Comercio Exterior. Adicionalmente, SUNAT ha organizado jornadas de orientación en temas especializados a usuarios del comercio exterior.

Las condiciones del sector externo para el comercio exterior son favorables y las políticas para dinamizar el comercio son atractivas; sin embargo, debido al retraso en la expansión del

9 Diario Gestion: http://gestion.pe/economia/mincetur-proyecta-que-exportaciones peruanas-creceran-15-20172197662 
Aeropuerto Internacional Jorge Chávez el país enfrenta un gran limitante logístico para competir con países de la región como Colombia y Chile; los cuales ya han implementado la infraestructura necesaria anticipándose estratégicamente al dinamismo del comercio internacional, y han desplazado al Perú en su papel de hub comercial de Latinoamérica hacia el mundo.

La información recopilada del mercado confirma que las expectativas sobre el desempeño de las exportaciones en el país reflejan un gran potencial de crecimiento. Por lo tanto, resulta prioritario haber establecido medidas logísticas que permitan reducir los obstáculos con el fin de mejorar la atención a todos los participantes de la cadena logística de exportación del país.

\section{MADE}

Al tener una visión más clara del entorno externo en el que se desenvuelve la Agencia de Carga estudiada, nos permitimos evaluar los factores más relevantes que afectar de alguna manera a la Agencia de Carga. Para su análisis usamos la herramienta MADE en el que se plasmaron 10 factores que se muestran en el siguiente cuadro:

Figura 2 MADE

\section{MATRIZ DE ANÁLISIS Y DIAGNOSTICO EXTERNO (MADE)}

\begin{tabular}{|c|c|c|c|c|c|c|c|c|c|c|c|c|c|c|}
\hline \multirow{2}{*}{\multicolumn{2}{|c|}{$\begin{array}{l}\text { E. Especifico: } \\
\text { Organización: }\end{array}$}} & Enfoque Sistemico & \multicolumn{9}{|c|}{ Indicador de Djagnóstico Extemo: } & 0.11 & & \multirow{2}{*}{$\frac{100.00 \%}{10}$} \\
\hline & & & & & $\overline{54 P}$ & $\overline{\mathrm{SM}}$ & & $\overline{E Y A}$ & L. Fi & $\overline{\text { ACT }}$ & $\overline{\text { ORES }}$ & Tot. Fact & tores & \\
\hline $\mathbf{n}$ & Tipo_Entom & Variable & Factor & PO & $\mathrm{PE}$ & $\mathbf{P A}$ & & M & NT & 0 & 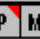 & W & Valor & Total \\
\hline 1 & E. Especifico & Competencia & $\begin{array}{l}\text { Capacitacion de la Sunat a los usuarios del Comercio } \\
\text { Exterior }\end{array}$ & $x$ & $x$ & & & & & & $x$ & $8.89 \%$ & 1 & 0.0889 \\
\hline 2 & E. Especifico & Proveedores & Aeropuerto saturado con segundo terminal y pista & $x$ & $x$ & $x$ & & $\mathbf{x}$ & & & & $15.56 \%$ & -2 & -0.3111 \\
\hline 3 & E. General & Tecnológico & $\begin{array}{l}\text { Sunat implementa el Observatorio de Logistica de } \\
\text { Comercio Exterior - fomenta la transparencia de } \\
\text { tarifas de servicios logisticos }\end{array}$ & & $x$ & & & & & r & $x$ & $13.33 \%$ & 1 & 0.1333 \\
\hline 4 & E. Especifico & Agente Regulador & Programa de seguro de credito para Pymes & $x$ & $x$ & & & & & & $x$ & $4.44 \%$ & 2 & 0.0889 \\
\hline 5 & E. General & Económico & $\begin{array}{l}\text { Creacion de la Direccion de Promocion de Inversion } \\
\text { Productiva de PROMPERU }\end{array}$ & $x$ & & s & $x$ & & & & $x$ & $13.33 \%$ & 1 & 0.1333 \\
\hline 6 & E. General & Pollico & $\begin{array}{l}\text { Firma de tres acuerdo comerciales con Brasil para la } \\
\text { liberacion y flujo comercial entre los dos paises. }\end{array}$ & & $x$ & & $x$ & & & & $x$ & $2.22 \%$ & 1 & 0.0222 \\
\hline 7 & E. General & Polfíco & Incorporacion de la Defensoria del exportador para & & & & $\mathbf{x}$ & & & & $x$ & $8.89 \%$ & 1 & 0.0889 \\
\hline 8 & E. General & Polfíco & Expectabiva de crecimiento de exportaciones en un & $x$ & & & $\bar{x}$ & & & & $x$ & $6.67 \%$ & 2 & 0.1333 \\
\hline 9 & E. General & Social & Sobreregulación en los esquemas de transporte de & $x$ & $x$ & $x$ & & & $x$ & & & $11.11 \%$ & -1 & -0.1111 \\
\hline 10 & E. Especifico & Competencia & Gran cartidad de competidores lo cual genera & & $x$ & 3 & $\bar{x}$ & & $x$ & & & $15.56 \%$ & -1 & -0.1556 \\
\hline 11 & & & & & & & & & & & & $0.00 \%$ & N.N & N.N \\
\hline
\end{tabular}


Figura 3 Reporte MADE

\section{REPORTE FINAL DE LA MATRIZ DE ANÁLISIS Y DIAGNÓSTICO EXTERNO}

\begin{tabular}{|c|c|c|c|}
\hline INDICADOR DE DIAGNOSTICO EXTERNO: & 0.11 & ENTORNO FAHORABLE & Fecha Actualiración: \\
\hline OPORTUNDADES: & 0.69 & & 29 de Octubre de 2017 \\
\hline
\end{tabular}

Las 3 Factores del entono que más afectan a la Qmanización:
\begin{tabular}{|c|l|c|c|c|}
\hline N & Factores Importantes: & Valor & 少 & OR \\
\hline $\mathbf{1}$ & d.eropuerto saturado con segundo teminal y pista que & -0.3111 & $53.64 \%$ & AMENAZA \\
\hline $\mathbf{2}$ & Gran cantidad de competidores lo cual genera variaci & -0.1556 & $26.82 \%$ & AMENAZA \\
\hline $\mathbf{3}$ & Expectativa de crecimiento de exportaciones en un 1 & 0.1333 & $19.32 \%$ & OPORTUNDAD \\
\hline
\end{tabular}

\begin{tabular}{|l|c|}
\hline Muy Positivo & 2 \\
\hline Positivo & 1 \\
\hline Neutro & 0 \\
\hline Negativo & -1 \\
\hline Wuy negativo & -2 \\
\hline
\end{tabular}

Las 3 Variables dé entono que más afectan a la Organización:
\begin{tabular}{|c|l|c|c|c|}
\hline N & \multicolumn{1}{|c|}{ Variables Importantes: } & Oportunidad & Riesgo & Valor Final \\
\hline $\mathbf{1}$ & Proveedores & 0.0000 & -0.31111 & -0.3111 \\
\hline $\mathbf{2}$ & Político & 0.2444 & 0 & 0.2444 \\
\hline $\mathbf{3}$ & Tecnológico & 0.2444 & 0 & 0.2444 \\
\hline
\end{tabular}

Efecto de Emono en las 4 P's ded Marketing:
\begin{tabular}{|c|l|c|c|c|c|c|}
\hline $\mathbf{N}$ & Las 4P's & Oportunidad & qo & Riesgo & 嵒 & Valor Final \\
\hline $\mathbf{1}$ & Producto & 0.3111 & $42.42 \%$ & -0.4222 & $57.58 \%$ & 0.7333 \\
\hline $\mathbf{2}$ & Precio & 0.4667 & $44.68 \%$ & -0.5778 & $55.32 \%$ & 1.0444 \\
\hline $\mathbf{3}$ & Plaza & 0.1333 & $24.00 \%$ & -0.4222 & $76.00 \%$ & 0.5556 \\
\hline $\mathbf{4}$ & Promoción & 0.3778 & $70.83 \%$ & -0.1556 & $29.17 \%$ & 0.5333 \\
\hline
\end{tabular}

Distribución de imaacto: ¿A quien afecta más?

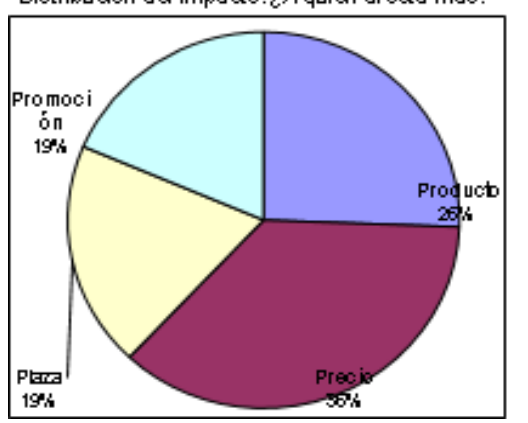

Dependencia e independencia de las Qoontunidades y Amenazas:

\begin{tabular}{|l|c|c|c|l|}
\cline { 2 - 4 } \multicolumn{1}{c|}{} & Total & 20\% Factores & I & \\
\hline Oportunidades: & 7 & 2 & 0.39 & INDEPENDIENTE \\
\hline amenazas: & 3 & 1 & 0.54 & IMDEPENDIENIE \\
\hline
\end{tabular}

Analisis de Resultados:

Luego de analizadas los 10 factores del MADE, tenemos un resultado con una puntuación de Oportunidades de 0.69 y Amenazas de -0.58, las cuales nos brindan un resultado de Entorno Favorable con una puntuación final de 0.11. Este dato final se contrastó con el resultado que nos brinda el MADI.

\section{MADI}

$\mathrm{Al}$ analizar el entorno interno en la que trabaja el personal de contacto de la Agencia de Carga estudiada, evaluamos al igual que el Made los factores más relevantes que afectar a la 
Agencia de Carga. Para ello ahora mostramos el MADI donde se insertaron 15 factores que se muestran en el siguiente cuadro:

Figura 4 MADI

\begin{tabular}{|c|c|c|c|c|c|c|c|c|c|c|c|c|}
\hline \multirow{3}{*}{\multicolumn{2}{|c|}{ 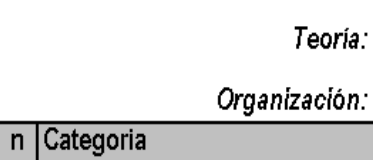 }} & \multirow{3}{*}{\begin{tabular}{|l|} 
Recuros Y Capacidades \\
\\
Factor \\
\end{tabular}} & \multicolumn{7}{|c|}{ Indicador de Diag. Interno: } & -0.07 & & \multirow{3}{*}{\begin{tabular}{|c|}
$100.00 \%$ \\
15 \\
Total \\
\end{tabular}} \\
\hline & & & \multicolumn{3}{|c|}{ LAS 4 P'S MKT } & \multicolumn{4}{|c|}{ EVAL. FACTORES } & \multicolumn{2}{|c|}{ Tot. Factores: } & \\
\hline & & & & & A $\mathrm{P}$ & $\sqrt[M N]{M}$ & $\mathrm{~N}$ & \begin{tabular}{l|l}
0 & $P$ \\
\end{tabular} & MP & W & Valor & \\
\hline 1 & Carencias & Proceso de exportación aérea de carga seca no actualizado & $\mathrm{x}$ & & & & $\mathrm{x}$ & & & $11.43 \%$ & -1 & -0.1143 \\
\hline 2 & Recursos & Mejora en los programas(herramientas) de comunicación interna & $x$ & & & & & $\mathrm{x}$ & & $2.86 \%$ & 1 & 0.0286 \\
\hline 3 & Recursos & Estaciones en otros paises & $\mathrm{x}$ & $x$ & $x$ & & & & $\mathrm{x}$ & $1.90 \%$ & 2 & 0.0381 \\
\hline 4 & Incapacidades & Bajo nivel de consolidación de carga & $\mathrm{x}$ & $x$ & & & $\mathrm{x}$ & & & $8.57 \%$ & -1 & -0.0857 \\
\hline 5 & Capacidades & Tiene diversos productos para envió de carga & $\mathrm{x}$ & $\mathrm{x}$ & $x$ & & & $\mathrm{x}$ & & $3.81 \%$ & 1 & 0.0381 \\
\hline 6 & Incapacidades & Poca comunicación(fllujo de informacion) entre áreas & $x$ & & & & $\mathrm{x}$ & & & $10.48 \%$ & -1 & -0.1048 \\
\hline 7 & Carencias & Analisis limitado en el proceso de exportacion aerea & $\mathrm{x}$ & $x$ & & & $\mathrm{x}$ & & & $9.52 \%$ & -1 & -0.0952 \\
\hline 8 & Incapacidades & Elevada generación de sobrecostos & $\mathrm{x}$ & $x$ & & & $\mathrm{x}$ & & & $5.71 \%$ & -1 & -0.0571 \\
\hline 9 & Recursos & KPI'S que evaluan el desarrollo de la operación & $\mathrm{x}$ & $x$ & & & & $\mathrm{x}$ & $x$ & $8.57 \%$ & 1 & 0.0857 \\
\hline 10 & Incapacidades & Bajo nivel en busqueda de clientes potenciales & $\mathrm{x}$ & $x$ & & & $\mathrm{x}$ & & & $11.43 \%$ & -1 & -0.1143 \\
\hline 11 & Recursos & Cuenta con un area de seguridad y resiliencia operativa eficaz & $\mathrm{x}$ & $\mathrm{x}$ & $x$ & & & $\mathrm{x}$ & $x$ & $0.95 \%$ & 1 & 0.0095 \\
\hline 12 & Capacidades & Personal operativo instruido para la operación & $\mathrm{x}$ & $x$ & & & & $\mathrm{x}$ & $x$ & $8.57 \%$ & 1 & 0.0857 \\
\hline 13 & Recursos & Capacitaciones periodicas y actualizaciones de procesos para el & $\mathrm{x}$ & & & & & $\mathrm{x}$ & $x$ & $2.86 \%$ & 1 & 0.0286 \\
\hline 14 & Capacidades & Equipo para el asesoramiento y captacion de mypimes & $\mathrm{x}$ & $\mathrm{x}$ & $x$ & & & $\mathrm{x}$ & $x$ & $7.62 \%$ & 1 & 0.0762 \\
\hline 15 & Recursos & Atto poder de negociación con proovedores & $\mathrm{x} \mid \mathrm{z}$ & $x$ & & & & & $\mathrm{x}$ & $5.71 \%$ & 2 & 0.1143 \\
\hline
\end{tabular}


Figura 5 Reporte MADI

\begin{tabular}{|c|c|c|c|c|c|c|c|}
\hline \multicolumn{8}{|c|}{ REPORTE FINAL DE LA MATRIZ DE ANÁLISIS Y DIAGNÓSTICO INTERNO } \\
\hline \multicolumn{3}{|c|}{ INDICADOR DE DIAGNOSTICO INTERNO: } & -0.07 & \multirow{4}{*}{\multicolumn{2}{|c|}{ ORGANIZACIÓN EN CRISIS }} & \multicolumn{2}{|c|}{ Fecha Actualización: } \\
\hline & & \multirow{2}{*}{$\begin{array}{r}0 \text { INTERNO } \\
\text { FORTALEZA } \\
\text { DEBILIDAD }\end{array}$} & 0.50 & & & \multicolumn{2}{|c|}{16 de Octubre de 2017} \\
\hline & & & -0.57 & & & & \\
\hline \multicolumn{4}{|c|}{ Los 3 Factores que más afectan a la Organización: } & & & Muy Positivo & 2 \\
\hline $\mathrm{N}$ & Factores Importantes: & Valor & $\%$ & OIR & & Positivo & 1 \\
\hline 1 & Alto poder de negociación con proovedores & 0.1143 & $22.86 \%$ & FORTALEZA & & Neutro & 0 \\
\hline 2 & Bajo nivel en busqueda de clientes potenciales & -0.1143 & $20.05 \%$ & DEBILIDAD & & Negativo & -1 \\
\hline 3 & Proceso de exportación aérea de carga seca no actua & -0.1143 & $20.05 \%$ & DEBILIDAD & & Muy negativo & -2 \\
\hline \multicolumn{8}{|c|}{ Las 3 Categoria interna que más afectan a la Organización: } \\
\hline $\mathbf{N}$ & Categoría & Fortaleza & Debilidad & Valor Final & & \multicolumn{2}{|c|}{ Indicador } \\
\hline 1 & Incapacidades & 0.0000 & -0.3619 & -0.3619 & & \multirow{3}{*}{\begin{tabular}{|l} 
Independencia: \\
Dependencia:
\end{tabular}} & $(0,0.7)$ \\
\hline 2 & Recursos & 0.3048 & 0 & 0.3048 & & & $(0.7,1)$ \\
\hline 3 & Carencias & 0.3048 & 0 & 0.3048 & & & \\
\hline
\end{tabular}

Efecto en las 4P's del Marketing:
\begin{tabular}{|c|l|c|c|c|c|c|}
\hline $\mathbf{N}$ & \multicolumn{1}{|c|}{ Las 4P's } & Fortaleza & $\%$ & Debilidad & $\%$ & Valor Final \\
\hline $\mathbf{1}$ & Producto & 0.5048 & $46.90 \%$ & -0.5714 & $53.10 \%$ & 1.0762 \\
\hline $\mathbf{2}$ & Precio & 0.4381 & $55.42 \%$ & -0.3524 & $44.58 \%$ & 0.7905 \\
\hline $\mathbf{3}$ & Plaza & 0.1619 & $100.00 \%$ & 0.0000 & $0.00 \%$ & 0.1619 \\
\hline $\mathbf{4}$ & Promoción & 0.2762 & $100.00 \%$ & 0.0000 & $0.00 \%$ & 0.2762 \\
\hline
\end{tabular}

Distribución del impacto: ¿A quien afecta más?

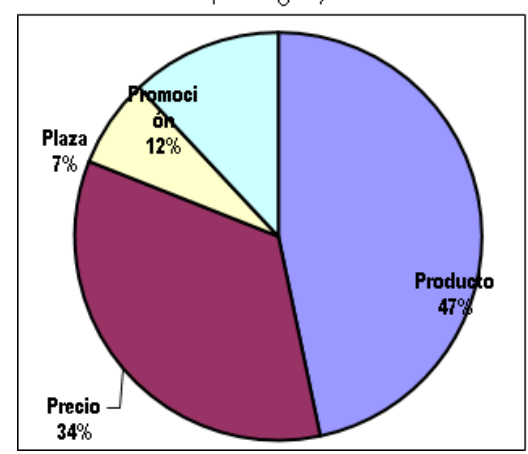

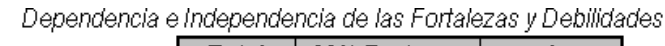

\begin{tabular}{|l|c|c|c|l|}
\cline { 2 - 4 } \multicolumn{1}{c|}{} & Total & $\mathbf{2 0} \%$ Factores & I & \multicolumn{1}{c|}{} \\
\hline Fortaleza: & 9 & 2 & 0.40 & INDEPENDIENTE \\
\hline Debilidad: & 6 & 2 & 0.40 & INDEPENDIENTE \\
\hline
\end{tabular}

Análisis de Resultados:

Luego de analizadas los 15 factores incluidos en el MADI, tenemos un resultado con una puntuación de Fortalezas de 0.50 y Debilidades de -0.57 , las cuales nos brindan un resultado de Organización en Crisis con una puntuación final de -0.07. Este dato final se contrastó con el resultado que nos brinda el MADE.

\section{Grafico Resultado MADE y MADI}

Luego de obtener los resultados en los análisis MADE (0.11) y MADI (-0.07), procedimos a ubicar los puntos en el siguiente cuadrante: 
Figura 6 Estrategia MADE y MADI

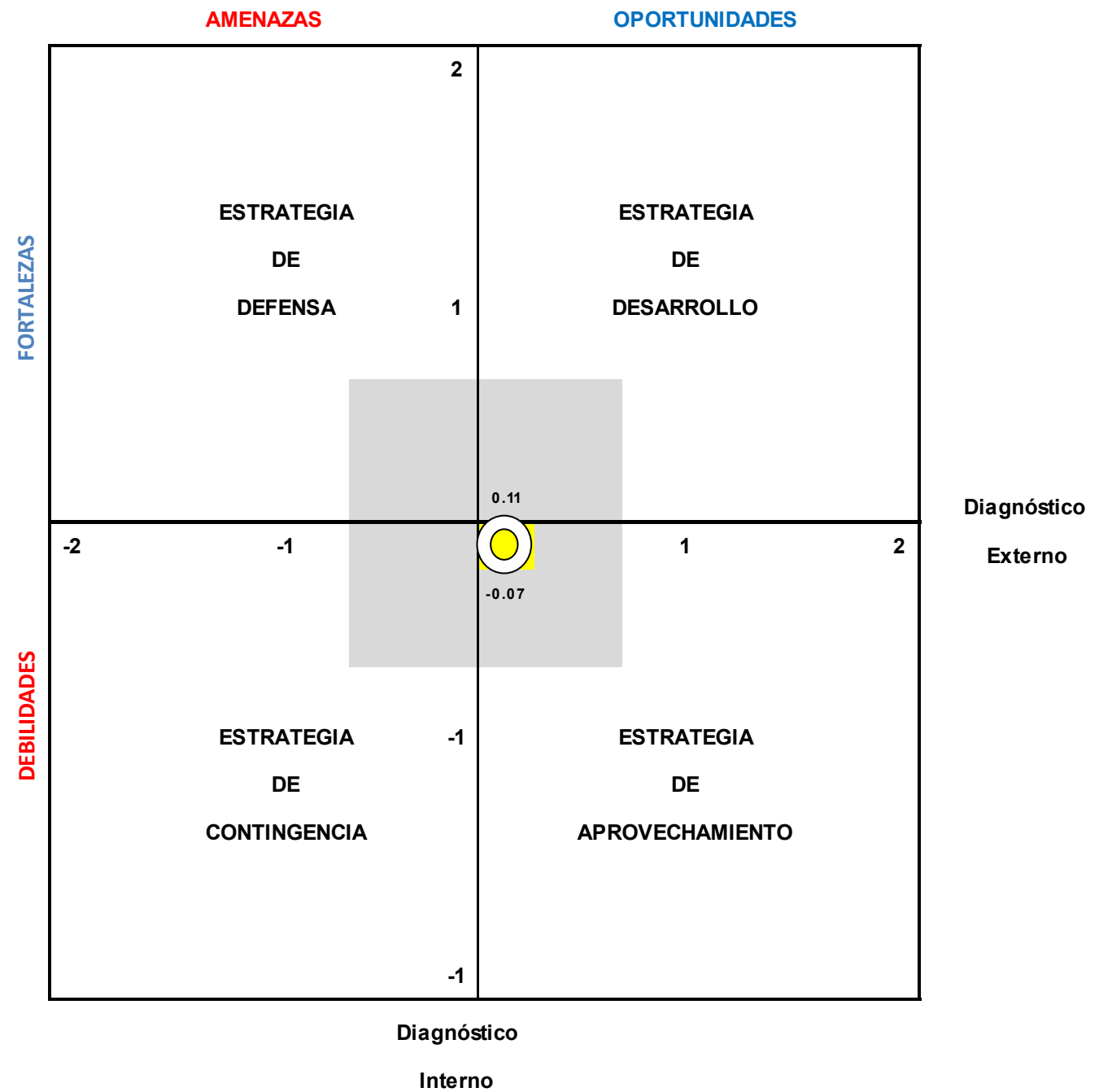

Según el cuadro final, la Agencia de Carga debe aplicar una Estrategia de Aprovechamiento, en ella vemos que la empresa cuenta con una cantidad de debilidades pero el entorno es favorable. Por ello deben hacerse cambios dentro de la empresa. 


\section{Matriz Foda Cruzado}

\begin{tabular}{|c|c|c|}
\hline & OPORTUNIDADES & AMENAZAS \\
\hline & $\begin{array}{l}\text { 1) Capacitación de la Sunat a los usuarios del Comercio Exterior. } \\
\text { 2) Sunat implementa el Observatorio de Logística de Comercio } \\
\text { Exterior, fomenta la transparencia de tarifas de servicios } \\
\text { logísticos. } \\
\text { 3) Impulso para la creación de plataformas logísticas. } \\
\text { 4) Firma de tres acuerdos comerciales con Brasil para la } \\
\text { liberación y flujo comercial entre los dos países. } \\
\text { 5) Incorporación de la Defensoría del exportador para facilitar } \\
\text { procesos de exportación con mayor información. } \\
\text { 6) Expectativa de crecimiento de exportaciones en un } 15 \% \text {. }\end{array}$ & $\begin{array}{l}\text { A) Aeropuerto saturado con segundo terminal y pista que finalizan en } \\
\text { el } 2022 \text {. } \\
\text { B)Sobrerregulación en los esquemas de transporte de exportación en } \\
\text { la Alianza del Pacifico (México, Chile, Colombia y Perú). } \\
\text { C) Gran cantidad de competidores. }\end{array}$ \\
\hline \multicolumn{3}{|l|}{ FORTALEZAS } \\
\hline $\begin{array}{l}\text { 1) Mejora de las herramientas de comunicación interna en la } \\
\text { compañía. } \\
\text { 2) Estaciones en otros países (presencia a nivel global). } \\
\text { 3) Diversos servicios para envió de carga. 4)KPI'S que } \\
\text { evalúan el desarrollo de la operación } \\
\text { 5) Cuenta con un área de seguridad y resiliencia } \\
\text { operativa eficaz. } \\
\text { 6) Personal operativo capacitado para la operación. } \\
\text { 7) Capacitaciones periódicas y actualizaciones de } \\
\text { procesos para el manejo de carga. } \\
\text { 8) Equipo para la captación y asesoramiento de nuevos clientes } \\
\text { (pymes). } \\
\text { 9) Alto poder de negociación con proveedores. }\end{array}$ & $\begin{array}{l}\text { (2,6) Elaborar estrategias logísticas con las estaciones de principales } \\
\text { destinos. }(3,6) \text { Desarrollar los servicios que tiene la compañía para } \\
\text { captar nuevos clientes. } \\
(6,1) \text { Reforzar conocimientos del personal a través la SUNAT, para } \\
\text { asesorar al cliente y mejorar el proceso de exportación. } \\
(8,5) \text { Brindar conocimientos e información obtenida de la } \\
\text { Defensoría del Exportador al equipo de captación de clientes. } \\
(9,6) \text { Fortalecer nuestras relaciones con los proveedores logrando } \\
\text { mejorar nuestro poder de negociación. }\end{array}$ & $\begin{array}{l}\text { (1, A) Optimizar uso de las herramientas de comunicación para } \\
\text { afrontar el congestionamiento en el aeropuerto. } \\
\text { (2, A) Establecer rutas alternas para diversificar y optimizar } \\
\text { servicios. (2, B) Consolidar información (regulaciones y } \\
\text { procesos de importación) y transmitir entre estaciones. } \\
\text { (3, C) Mejorar la variedad de servicios frente a la competencia. } \\
\text { (4, C) Integrar la revisión de KPI’s específicos para clientes estratégicos } \\
\text { como servicio complementario. } \\
\text { (5, C) Integrar el servicio adicional de seguridad de la carga haciendo } \\
\text { frente a la gran cantidad de competidores. } \\
\text { (7, B) Capacitaciones y actualizaciones periódicas de los procesos } \\
\text { para manejo de carga en diversos destinos. }\end{array}$ \\
\hline \multicolumn{3}{|l|}{ DEBILIDADES } \\
\hline $\begin{array}{l}\text { A) Proceso de exportación aérea de carga seca no } \\
\text { actualizado. } \\
\text { B) Bajo nivel de consolidación de carga. } \\
\text { C) Poca comunicación (flujo de información) entre áreas. } \\
\text { D) Análisis limitado del proceso de exportación aérea. } \\
\text { E) Elevada generación de sobrecostos. } \\
\text { F) Bajo nivel en búsqueda de clientes potenciales. }\end{array}$ & $\begin{array}{l}\text { A,6) Desarrollar nuevo flujograma que permita optimizar los } \\
\text { procesos operativos y captar nuevos clientes y rutas. } \\
\text { B,2) Mejorar tarifas para destinos potenciales permitirá el } \\
\text { crecimiento de cargas consolidadas. } \\
\text { B,4) Brindar un servicio logístico competitivo para el destino Brasil. } \\
\text { B,6) Mapeo de procesos para mejora de servicios a principales } \\
\text { destinos de exportación: } \\
\text { D,6) Analizar proceso logístico de exportación para determinar } \\
\text { errores. E,5) Entidad permite minimizar error en el proceso de } \\
\text { exportación por parte del cliente. } \\
\text { E,1) Capacitación a la agencia de carga en temas logísticos. } \\
\text { F,6) Reforzar conocimientos sobre la cadena logística para } \\
\text { un mejor desempeño. }\end{array}$ & $\begin{array}{l}\text { C, A) Identificar información relevante para mitigar retrasos en el } \\
\text { proceso de exportación. } \\
\text { C, C) Reforzar uso de herramientas de comunicación para } \\
\text { mejorar flujo de información sobre embarques y rutas. } \\
\text { E, A) Especificar requisitos para las diversas mercancías de exportación } \\
\text { reducirá los sobrecostos y tiempo de la operación. }\end{array}$ \\
\hline
\end{tabular}




\subsection{Estrategia Fortalezas - Oportunidades}

\section{$(2,6)$ Elaborar estrategias logísticas con las estaciones de principales destinos.}

Para beneficiarse del crecimiento de las exportaciones en el Perú, se requiere gestionar reuniones con las estaciones de los principales destinos de exportación, tomando como base nuestra presencia a nivel global, para iniciar un trabajo conjunto en la elaboración de estrategias logísticas que incluyan proveedores, almacén, venta, canales de distribución, entre otros. Esto permitirá ofrecer a los clientes servicios competitivos que cubran toda la operación, así como el seguimiento y comunicación constante a través de todo el proceso de exportación, es decir desde el recojo en origen hasta la entrega de la carga en el almacén del importador.

\section{$(3,6)$ Desarrollar los servicios que tiene la compañía para captar nuevos clientes.}

Tomando en cuenta que contamos con niveles de servicio en base a las diversas necesidades de los clientes, ya sea temas de tarifa, T/T, rutas entre otros, nos enfocaremos en dar a conocer a profundidad los productos que se ajusten a los diversos clientes para de esta manera lograr ganar clientes a los que aún no hemos podido captar.

$(6,1)$ Reforzar conocimientos del personal a través la SUNAT, para asesorar al cliente y mejorar el proceso de exportación.

El personal es capacitado sobre procesos operativos de la compañía mas no sobre la regularidad operativa en el país, por lo que es importante enviar personal a las capacitaciones realizar por SUNAT sobre las actualizaciones y cambios en el proceso exportador. Posterior a esto, organizar reuniones de capacitación donde la información obtenida sea retransmitida al resto del personal, para así para lograr un proceso de exportación más fluido y minimizar los errores.

$(8,5)$ Brindar conocimientos e información obtenida de la Defensoría del Exportador al equipo de captación de clientes.

El equipo encargado de captar nuevos clientes será capacitado respecto al proceso de exportación aérea, esto para contar con un conocimiento actualizado sobre el actual proceso y poder tomar las mejores decisiones respecto a que información (requisitos, documentación) requiere el cliente para el traslado de su mercancía. Esto permitirá orientar a los clientes de una manera eficaz, logrando minimizar las demoras y/o inconvenientes que puedan presentarse a lo largo del proceso. 
$(9,6)$ Fortalecer nuestras relaciones con los proveedores logrando mejorar nuestro poder de negociación.

Actualmente, la compañía cuenta con buena relación con sus proveedores, pero el mejorar este vínculo nos permitirá incrementar el poder de negociación, dando como resultados mayores beneficios tanto para los clientes, así como para la empresa, ya que esto nos ayudara a obtener tarifas competitivas así como diversificación de rutas. De esta manera podremos ofrecer a los clientes una mayor gama de opciones de producto frente a la competencia.

\section{$(9,2)$ Mejorar tarifas tomando como base la información del Observatorio de}

\section{Comercio Exterior.}

La compañía cuenta con tarifas competitivas para diversos destinos debido a la buena relación con proveedores, este beneficio permite tener una ventaja frente al resto de competidores. Con la finalidad de orientar a los exportadores, SUNAT ha implementado un Observatorio de Logistica de comercio exterior, con el cual darán a conocer a las empresas exportadoras (principalmente a las pequeñas y nuevas empresas) los precios referenciales de los servicios logísticos y de comercio exterior. De esta manera, estas empresas podrán tener una referencia para realizar sus operaciones y evitar costos inflados del servicio ofrecido por empresas que se aprovechan de la desinformación y desconocimiento. Debido a que estos costos son referenciales se encuentran al nivel de los precios de mercado, por lo que se encontrarían más elevados que los precios ofrecidos por la empresa, en este punto podríamos dar a conocer y resaltar las tarifas competitivas con las que cuenta la empresa para lograr captar clientes potenciales resaltando no solo las tarifas sino también el servicio completo y diferenciado que podrá obtener con nuestra empresa.

\subsection{Estrategia Fortalezas - Amenazas}

(1,1) Optimizar el uso de las herramientas de comunicación para afrontar el congestionamiento en el aeropuerto.

Como es de conocimiento, las obras de ampliación del aeropuerto Jorge Chavez tienen como fecha tentativa de término el año 2023, esto ocasiona que se presente congestión tanto para el traslado de carga como de pasajeros. En temas de transporte de carga, se generan ciertas limitaciones debido a la baja capacidad de vuelos, así como de destinos directos, ya que la salida puede verse demorada por cancelaciones de vuelos o incremento de equipaje pasajero 
adicional a esto la carga debe conectar dos veces o incluso más dependiendo el destino de la misma y en algunos casos las conexiones demoran.

En la actualidad, contamos con herramientas de comunicación que nos permiten estar interconectados con nuestras estaciones, pero estas no se están aprovechando de la manera correcta, lo cual genera que la comunicación entre países en algunos casos no sea tan fluida. Pero debido a la situación actual y tomando como base esta ventaja, debemos optimizar el uso de estas herramientas lo cual nos permitirá un intercambio de información más directo y fluido con las estaciones así como el planteamiento de rutas estratégicas para evitar demoras en la llegada de la carga a su destino final.

\section{$(2,1)$ Establecer rutas alternas para diversificar y optimizar servicios.}

Como se mencionó en el punto anterior, la coordinación entre estaciones se ha venido desarrollando en un nivel de comunicación bastante básico, por lo que es necesario mejorar este punto y desarrollar medidas estrategias, como ampliar nuestras rutas mediante la consolidación en aeropuertos HUB logrando así llegar a destinos a los cuales no podríamos acceder de manera directa y también manteniendo una tarifa mucho más competitiva. Así también logramos ofrecer a los clientes diferentes alternativas de ruta para un mismo destino, partiendo de la necesidad y premura que tenga este para trasladar su carga.

\section{$(2,2)$ Consolidar información (regulaciones y procesos de importación) y transmitir} entre estaciones.

Cada país cuenta con diferentes regulaciones para el ingreso de carga a su territorio y esta se viene actualizando periódicamente, en algunos casos las regulaciones cambian y los clientes no llegan a informarse oportunamente y al momento de realizar sus operaciones presentan demoras por alguna documentación adicional que se le solicita. En este caso, como contamos con presencia global y las estaciones se encuentran interconectadas, se realiza el envío de comunicaciones a todas las estaciones con las que realizan operaciones dando a conocer alguna actualización, cambio o nueva regulación en dicho país; logrando de esta manera poder prevenir algún inconveniente por el no conocimiento de un proceso. El contar con esta información de manera anticipada nos permite informarle al cliente sobre dichos cambios para que pueda realizar sus trámites con anticipación y no vea demorada la operación.

\section{$(3,3)$ Diversificar servicios para hacer frente a la competencia}


La aparición de agencias de carga se ha visto bastante incrementada en los últimos años y los clientes se han distribuido en base a esa gran cantidad de forwarder que ofrecen variados rangos de tarifas, así como de servicios. Contamos en la actualidad con diversos servicios en base a la demanda y requerimientos de los clientes, pero con el paso del tiempo los clientes han incrementado sus necesidades, es por ellos que de igual manera necesitamos mantener en constante actualización dichos servicios, para así lograr de esta manera hacer frente a la competencia. Adicional a esto nos apoyamos en las ventajas con las que contamos como la fluida comunicación con nuestras estaciones, relaciones con los proveedores lo cual refuerza nuestro poder de mercado y la fijación de rutas alternas, esto a su vez nos permite ofrecer un servicio diferenciado y variado logrando así hacer frente a la competencia, la cual viene incrementándose con el tiempo.

\section{$(4,3)$ Integrar la revisión de KPI's específicos para clientes estratégicos como servicio} complementario.

Las agencias de carga del mercado, principalmente las pequeñas y medianas ofrecen un servicio bastante estandarizado y básico, los cuales incluyen servicio de transporte internacional, transporte interno e incluso agenciamiento de aduana. Son pocas las empresas que se encargan de ofrecer servicios adicionales, por ejemplo nuestra compañía cuenta con servicios adicional para mantener esa diferenciación con la competencia. En el mercado existen ciertos clientes que requieren de un mayor control y seguimiento de la operación, esto con la finalidad de saber en qué se puede mejorar y lograr disminuir errores, así como extra costos. Para estos casos, contamos con la medición de algunas variables como el T/T, el tiempo de respuesta frente a alguna inquietud, tiempo de liberación en destino, salida a tiempo de la carga, entre otros, de esta manera el cliente y la empresa puede determinar los puntos de mejora y lograr un mejor trabajo conjunto, actualmente solo se aplica para un pequeño grupo de clientes, pero puede ofrecerse para todo cliente que desee parametrizar su proceso.

\section{$(5,3)$ Integrar el servicio adicional de seguridad de la carga haciendo frente a la gran} cantidad de competidores.

Como ya mencionado, los servicios adicionales marcan una diferencia entre las agencias de carga y las elecciones de los clientes. Actualmente se viene desarrollando el servicio de brindar seguridad a la carga, esto es muy importante ya que se trata del seguimiento de la misma desde que parte del almacén del cliente hasta su llegada a destino. Para el transporte interno se realiza el rastreo vía satélite, logrando tener el conocimiento de la ubicación de la 
carga en todo momento hasta la llegada al almacén de la línea, ya en el proceso de transporte internacional nos apoyamos del seguimientos de las aerolíneas las cuales nos indican si la carga se entregó en buen estado y completa; una vez nacionalizada la carga en destino si nuestra empresa realiza el transporte también se cuenta con un monitoreo de la unidad encarga de entregar la carga al consignatario.

Adicional a esto si en caso se presenta alguna falta o daño de los productos, se realizan las investigaciones respectivas con la finalidad de determinar la responsabilidad con lo cual el cliente tendrá la seguridad de que en caso de algún siniestro la empresa se encargará de responder frente a este. Esto genera confianza por parte del exportador de colocar su carga bajo nuestra responsabilidad

\section{$(7,2)$ Capacitaciones y actualizaciones periódicas de los procesos para manejo de} carga en diversos destinos.

Las regulaciones de importación a nivel mundial se encuentran en constante actualización, es por ello que los operadores de carga internacional deben encontrarse informados de estos cambios con el fin de evitar errores en origen y por consiguiente retrasos en la importación de las cargas. Actualmente se desarrollan capacitaciones con respecto al manejo de carga pero no se ha llegado a tocar el tema de actualizaciones en las regulaciones, por lo que capacitar al personal con respecto a esta información es necesario y de suma importancia puesto que es responsabilidad de la compañía de mantener a su personal capacitado e informado de cada una de estas actualizaciones, como por ejemplo en el caso de la Alianza del pacifico en donde las regulaciones se han visto incrementadas, es necesario que el personal tenga conocimiento de los requerimientos que se han incrementado y puede obtener información adicional tomando contacto con las estaciones de destino para que estas nos indiquen alguna información adicional y así poder indicarle al cliente con exactitud que nuevos procedimientos o regulaciones se requiere y su operación se desarrolle.

\subsection{Estrategia Debilidades - Oportunidades}

A,6) Desarrollar nuevo flujograma que permita optimizar los procesos operativos y captar nuevos clientes y rutas. 
La compañía cuenta con un proceso de exportación Aérea no actualizado, el cual no permite cubrir de forma óptima los actuales requerimientos del mercado. La revisión y evaluación del proceso de exportación aérea nos permitirá identificar las principales falencias del proceso y elaborar un nuevo flujograma que nos permita optimizar los procesos, redefinir las funciones mediante la elaboración del description job y minimizar el tiempo de la operación. Estos cambios permitirán una mejora en el servicio brindado y respaldaran la oferta del servicio frente a nuevos clientes.

\section{B,2) Mejorar tarifas para destinos potenciales permitirá el crecimiento de cargas} consolidadas.

La creación del Observatorio de Logística de Comercio Exterior permitirá contar con transparencia en la información de fletes, esto servirá como soporte para dar a conocer las tarifas competitivas con las que cuenta la compañía para diversos destinos. Esta información dará la oportunidad de captar nuevos clientes que generarán una mayor cantidad de embarques para ciertos destinos, los cuales podrán ser consolidados y retribuir una mayor ganancia a la compañía.

\section{B,4) Brindar un servicio logístico competitivo para el destino Brasil.}

El actual nivel de comercio con Brasil en la compañía es bajo respecto a otros destinos. La firma de acuerdos entre Perú y Brasil para mejor el flujo de mercancías es una gran oportunidad para la captación de nuevos clientes y mejora en las rutas de exportación hacia este país. Para lograr un incremento de embarques, la compañía debería realizar un análisis sobre su situación actual respecto a los principales destinos de este país y medir cuál es su participación frente al mercado. Con esta información se podrá identificar la cantidad de clientes potenciales y el nivel de volumen comercializado a partir del cual se estimaría el posible crecimiento real que podría tener la compañía.

Para lograr gestionar un servicio de calidad y ofrecer nuestros productos a los actuales clientes y potenciales clientes se deberá realizar una coordinación logística con las estaciones de destino para determinar las mejores opciones para movilizar la carga, es decir establecer los principales aeropuertos (HUB) para la distribución de la mercancía, generar tarifas estandarizadas competitivas en el mercado, determinar los tiempos de entrega y salida de las mercancías en origen así como el tiempo de tránsito y liberación del embarque para su entrega al cliente final. Esto nos servirá como base para la obtención de nuevos clientes con un servicio 
diferenciado a estos destinos, lo cual nos permitirá incrementar el nivel de consolidación de nuestros embarques y generar mayores ingresos a la compañía.

\section{B,6) Mapeo de procesos para mejora de servicios a principales destinos de} exportación:

La compañía tiene un bajo nivel de consolidación embarques. Para incrementar la consolidación se realizará un mapeo de procesos con el fin de identificar los principales errores y reprocesos que tenemos dentro de la operación. Los resultados de esta investigación nos permitirán plantear medidas correctivas que mejoren el servicio brindado. Esta investigación se realizará en base a los principales mercados potenciales que tiene el país.

\section{D,6) Analizar proceso logístico de exportación para determinar errores.}

Actualmente se realizan mediciones al proceso de exportación, pero estos indicadores no abarcar la totalidad del mismo. Por lo cual, realizar el análisis de la información obtenida de los embarques realizados en los últimos años, permitirá detectar la cantidad de clientes perdidos, así como la cantidad rutas que han sufrido una disminución o pérdida total del tráfico de mercancías. Esto ayudara a tener una mejor visibilidad de la situación actual de la empresa y a determinar qué acciones se debe tomar para lograr obtener participación en el crecimiento esperado de las exportaciones en el Perú.

\section{E,5) Entidad permite minimizar error en el proceso de exportación por parte del} cliente.

La Defensoría del exportador permitirá, mediante la publicación de información referente al comercio internacional, que los clientes puedan minimizar los errores en los procesos de exportación como el mal embalaje de la carga, la identificación de carga peligrosa, etiquetado y rotulado inadecuado de la mercancía, entre otras actividades que generar sobrecostos y extiende el tiempo en el proceso del embarque. Esta iniciativa complementara el asesoramiento ya realizado por parte de la compañía a los clientes.

\section{E,1) Capacitación a la agencia de carga en temas logísticos.}

La capacitación al personal de la compañía en las diversas partes del proceso de exportación ayudara a minimizar los errores que puedan producirse por una inadecuada gestión de la mercadería. Las capacitaciones no solo permiten tener un flujo rápido de la mercancía, sino que también nos ayudara a prevenir posibles dificultades en el proceso, esto a través de la 
trasmisión de información al cliente logrando mejorar el manejo de la carga para futuras exportaciones.

\section{F,6) Reforzar conocimientos sobre la cadena logística para un mejor desempeño.}

El equipo de ventas no se encuentra totalmente informado del proceso de exportación aérea, lo cual representa un limitante al momento de ofrecer los servicios de la compañía a los clientes. Es por esto que, realizar una capacitación constante y detallada sobre el proceso de exportación a los vendedores permitirá obtener una mejor visión y entendimiento del mercado que aportará a la elaboración de un speech de venta que logre transmitir los objetivos de la compañía y así poder afianzar la relación con los actuales y nuevos clientes.

\subsection{Estrategia Debilidades - Amenazas}

\section{C,1) Identificar información relevante para mitigar retrasos en el proceso de exportación.}

En diversos embarques se generan reprocesos debido al bajo nivel de identificación y flujo de información relevante en la operación, generando sobrecostos y mayor uso de horahombre. Para disminuir este inconveniente, es importante el poder identificar qué información es relevante en cada embarque para así lograr tener una acción de respuesta rápida y efectiva. Es por esto, que es de vital importancia entrenar al personal para establecer procesos en el flujo de información y reforzar la comunicación entre las aéreas involucradas en la operación. Esto nos dará como resultado una uniformización de la comunicación y un proceso mucho más eficiente.

\section{C,3) Reforzar uso de herramientas de comunicación para mejorar flujo de información sobre embarques y rutas.}

Es importante el poder capacitar al personal en las herramientas de comunicación con las que cuenta la compañía, el conocer los beneficios de estas y su forma de uso brindara un mejor desarrollo de la operación frente a posibles contingencias. El eficaz flujo de información nos brindara la oportunidad de tener respuestas rápidas y eficientes para nuestros clientes en diversos temas relaciones al embarque, como el transito del mismo, cotización, rápido contacto con clientes, actualización de datos de la mercancía, entre otros. Generando así mantener la 
confianza en el proceso implementado por la empresa por parte de los clientes actuales y logrando también captar potenciales clientes quienes podrán apreciar que nuestro proceso se encuentra bien ejecutado.

\section{E,1) Especificar requisitos para las diversas mercancías de exportación reducirá los} sobrecostos y tiempo de la operación.

Algunas áreas de la compañía que participan en el proceso de exportación aérea no tienen un conocimiento absoluto sobre los requisitos de las diversas mercancías generando retrasos en el proceso, por lo que estandarizar la información respecto a los diversos requisitos que requieren cada tipo de mercancía y compartir a las distintas áreas es importante. Esta información servirá como soporte de prevención para evitar los reprocesos y la generación de sobrecostos en la operación. El definir si la carga es peligrosa, restringida o general, el tipo de embalaje que necesita, las dimensiones permitidas por la línea, los documentos necesarios para su ingreso a almacén, entre otros tipos de contingencias, no solo facilitara el proceso de la compañía sino también para el cliente.

A partir de todo lo analizado en el FODA Cruzado, se identificó cuatro variables que permiten mejorar el proceso de exportación aérea de la compañía para poder incrementar el ingreso actual. La variable "Embarques" se determinó a partir de las estrategias $(2,6),(3,6)$, $(8,5),(\mathrm{A}, 6),(\mathrm{B}, 2),(\mathrm{B}, 4),(\mathrm{B}, 6),(2, \mathrm{~A}),(3, \mathrm{C})$ y $(\mathrm{E}, \mathrm{A})$ las cuales tienen como objetivo reducir el tiempo de duración del proceso de exportación aérea y mejorar los servicios ofrecidos por la compañía, esto con la finalidad de aumentar la cantidad de embarques con que cuenta la compañía en la actualidad.

La variable "Toneladas” fue elegida a partir de las estrategias $(2,6),(9,6),(\mathrm{A}, 6),(2, \mathrm{~B})$, $(\mathrm{B}, 2),(\mathrm{B}, 6),(1, \mathrm{~A})$ y $(2, \mathrm{~A})$ las cuales quieren aumentar la cantidad de toneladas movilizadas por la compañía. Esto se logrará mediante una mejor relación con los proveedores de los diversos servicios que ofrece la compañía y una mejor coordinación y negociación con las aerolíneas para poder mitigar la falta de espacio en los vuelos y mejorar las tarifas.

Otra de las variables resultantes a partir de las estrategias elaboradas es la variable "Embarques Prepagados", la cual se eligió por las estrategias $(3,6),(6,1),(A, 6),(B, 4),(D, 6)$, $(\mathrm{E}, 1),(\mathrm{F}, 6),(3, \mathrm{C}),(4, \mathrm{C}),(5, \mathrm{C})$ y $(\mathrm{C}, \mathrm{A})$ que tienen como objetivo mejorar el servicio de 
exportación aérea y capacitar a su personal para minimizar errores, esto con el fin de incrementar la cantidad de clientes potenciales que manejen embarques prepagados.

Por último, se eligió la variable "Facturas por Servicios Asumidos por la Compañía" a partir de las estrategias $(6,1),(\mathrm{A}, 6),(\mathrm{D}, 6),(\mathrm{E}, 5),(\mathrm{E}, 1),(\mathrm{F}, 6),(2, \mathrm{~B}),(7, \mathrm{~B}),(\mathrm{C}, \mathrm{A}),(\mathrm{C}, \mathrm{C}) \mathrm{y}$ (E,A). Estas estrategias están enfocadas en mejorar la recolección y flujo de información para el manejo de embarques, así como en la capacitación de las diversas aéreas involucradas para un mejor desempeño. Esto con el fin de minimizar los errores durante el proceso y reducir los costos asumidos por la compañía.

\section{Desarrollo Regresión Lineal Múltiple SPSS}

\subsection{Definición de las variables}

\subsubsection{Variable Dependiente}

- Ingresos:

Es la cantidad de dinero expresado en miles de dólares americanos que percibe la compañía a cambio de los servicios de exportación aérea ofrecidos a empresas con ventas internacionales.

\subsubsection{Variables Independientes}

\section{- Embarques:}

Es la cantidad de embarques de exportación aérea que tiene la compañía durante un mes. Es importante la medición de esta variable para determinar el nivel de circulación de carga que tiene la compañía, así como el beneficio obtenido por cantidad de embarques.

\section{- Toneladas:}


Es el peso total de las mercancías de exportación aérea durante un mes expresado en toneladas. Esta variable permite poder negociar mejores precios con los proveedores.

\section{- Embarquess Prepagados:}

Cantidad de embarques que son pagados a la compañía antes del vuelo de la carga expresados en miles de dólares americanos. La variable nos permite identificar la cantidad de dinero en efectivo con la que cuenta la compañía respecto a los embarques trabajados en ese periodo de tiempo. Permite que la compañía cuente con mayor liquidez.

\subsection{Proceso de Regresión Lineal Múltiple en el SPSS}

Las variables mencionadas anteriormente fueron sometidas a un análisis estadístico de Regresión Lineal Múltiple en la herramienta de análisis SPSS Statistics en donde la variable dependiente es el valor sobre el cual se trabajaron las demás variables independientes para determinar si son correlacionadas, la base de datos de las variables se muestran en el Anexo A. El procedimiento paso a paso de todos los datos usados se muestra en el Anexo B. 


\section{CAPÍTULO V: ANÁLISIS DE RESULTADOS}

\section{RESULTADOS}

Los resultados obtenidos con las herramientas estadísticas para la variable independiente Embarques y la variable dependiente Ingresos muestran un R cuadrado de ,788, es decir la variable dependiente es explicada en un $78.8 \%$ por la variable independiente.

Tabla 1 Durbin-Watson

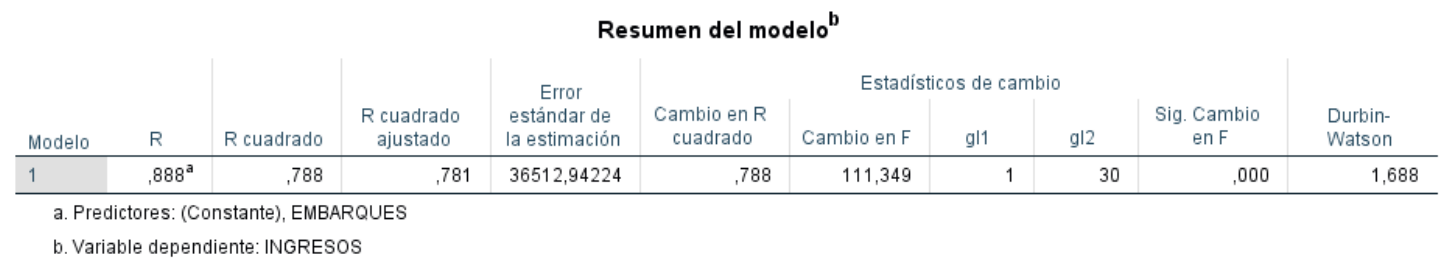

El modelo también nos muestra un resultado de 1.688 en el Durbin Watson.

Para determinar si las variables no son auto correlacionales se realizó el siguiente análisis basado en la tabla del estadístico de Durbin Watson a un nivel de significancia del 5\% (Anexo C):

Figura 7 Autocorrelación

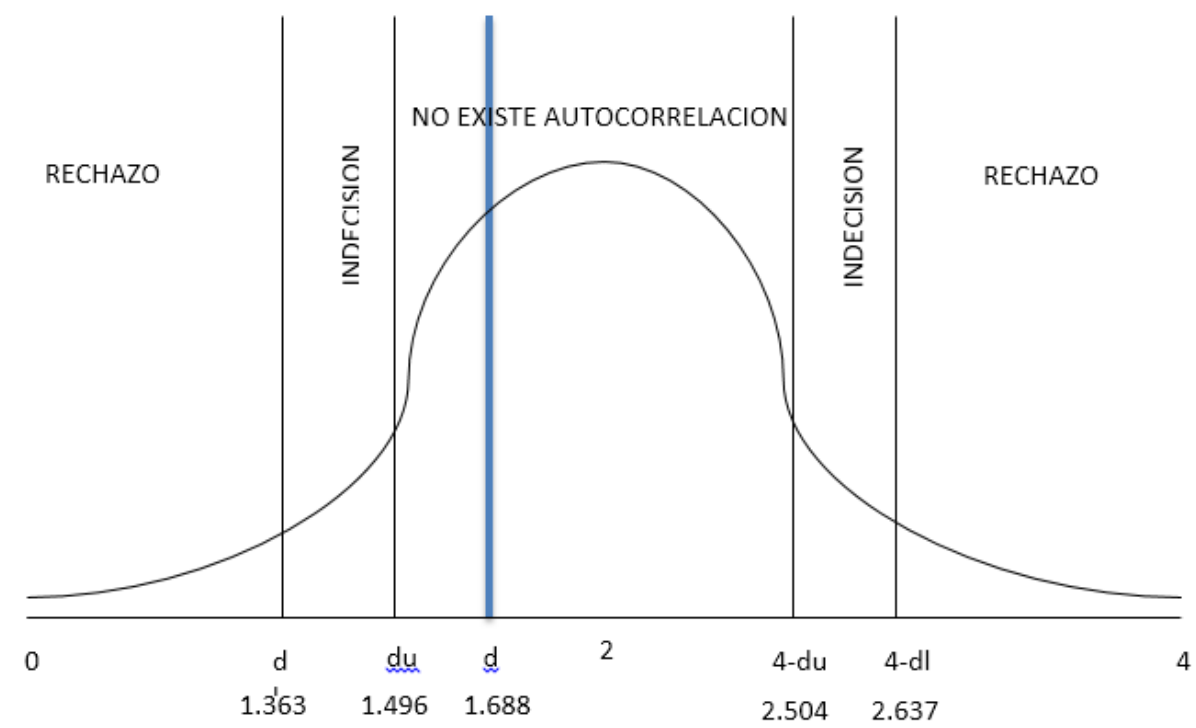


Se trabajó con $\mathrm{n}=31$ observaciones y 1 variable explicativa a un nivel de significancia del 5\%, lo cual nos da como $\mathrm{dl}=1.363$, un $\mathrm{du}=1.496$, un $4-\mathrm{du}=2.504$ y un $4-\mathrm{dl}=2.637$.

El valor resultante del modelo es 1.688, el cual se encuentra ubicado dentro del rango $\mathrm{du}<\mathrm{d}<4$-du $(1.496<1.688<2.504)$. Mostrando que no existe auto correlación entre las variables.

El Análisis de Varianzas (ANOVA), nos muestra un valor de Sig. de ,000. Esto nos permite concluir que, si el valor de Sig. es menor a 0,05 , la hipótesis nula (Ho) es rechazada y la hipótesis alternativa $\left(\mathrm{H}_{1}\right)$ se acepta.

\section{Tabla 2 ANOVA}

\begin{tabular}{|c|c|c|c|c|c|c|}
\hline \multicolumn{7}{|c|}{ ANOVA $^{a}$} \\
\hline \multicolumn{2}{|c|}{ Modelo } & $\begin{array}{l}\text { Suma de } \\
\text { cuadrados }\end{array}$ & gl & $\begin{array}{c}\text { Media } \\
\text { cuadrática }\end{array}$ & $\mathrm{F}$ & Sig. \\
\hline \multirow[t]{3}{*}{1} & Regresión & $1,699 E+11$ & 4 & $4,247 E+10$ & 61,816 &, $000^{b}$ \\
\hline & Residuo & $1,855 E+10$ & 27 & 687092544,8 & & \\
\hline & Total & $1,884 E+11$ & 31 & & & \\
\hline
\end{tabular}

a. Variable dependiente: INGRESOS

b. Predictores: (Constante), FACTURAS POR SERVICIOS ASUMIDOS POR LA COMPAÑIA, EMBARQUES, EMBARQUES PREPAGADOS, TONELADAS

En la tabla "Coeficientes" se expresa la relación entre la variable dependiente con las variables independientes. Esta tabla muestra una constante de 17483,732 y que por cada embarque que tenga la compañía se tendrá un ingreso de 837.400.

Además, la variable embarque muestra un coeficiente estandarizado del ,888.

Tabla 3 Coeficientes

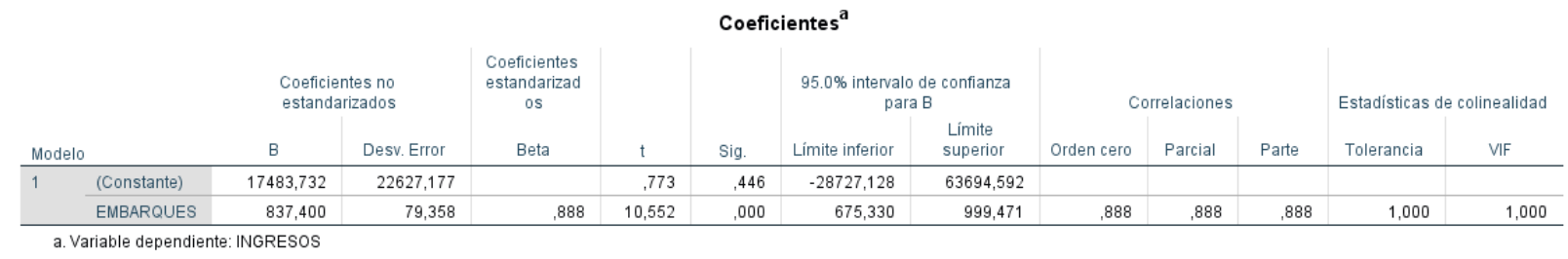

También se realizó un análisis estadístico a la variable dependiente Ingresos con las variables independientes Embarques y Toneladas. 
Este análisis nos dio un coeficiente de determinación del ,898 lo cual indica que la variable dependiente es explicada en un $89.8 \%$ por las variables independientes.

Tabla 4 Durbin Watson 2

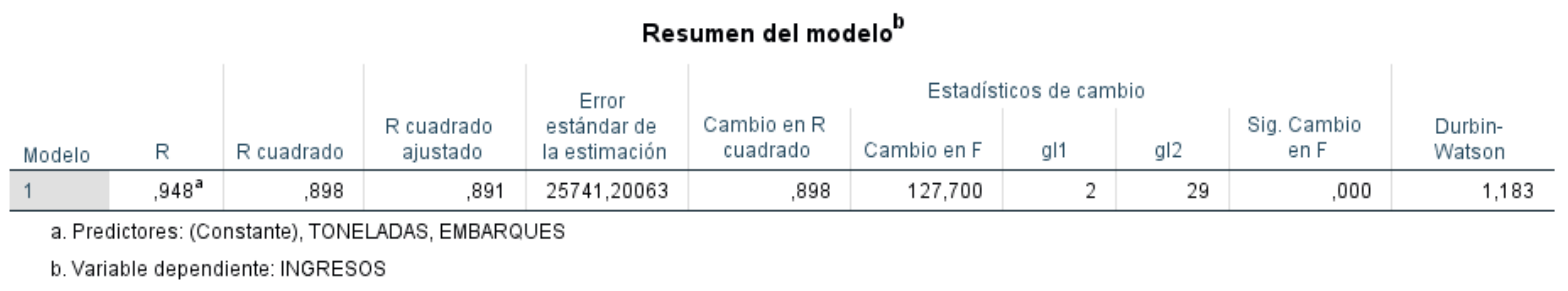

La Tabla 4 también nos muestra un resultado del 1,183 en el Durbin Watson.

Para determinar si las variables no son auto correlacionales se realizó el siguiente análisis:

Figura 8 Autocorrelación 2

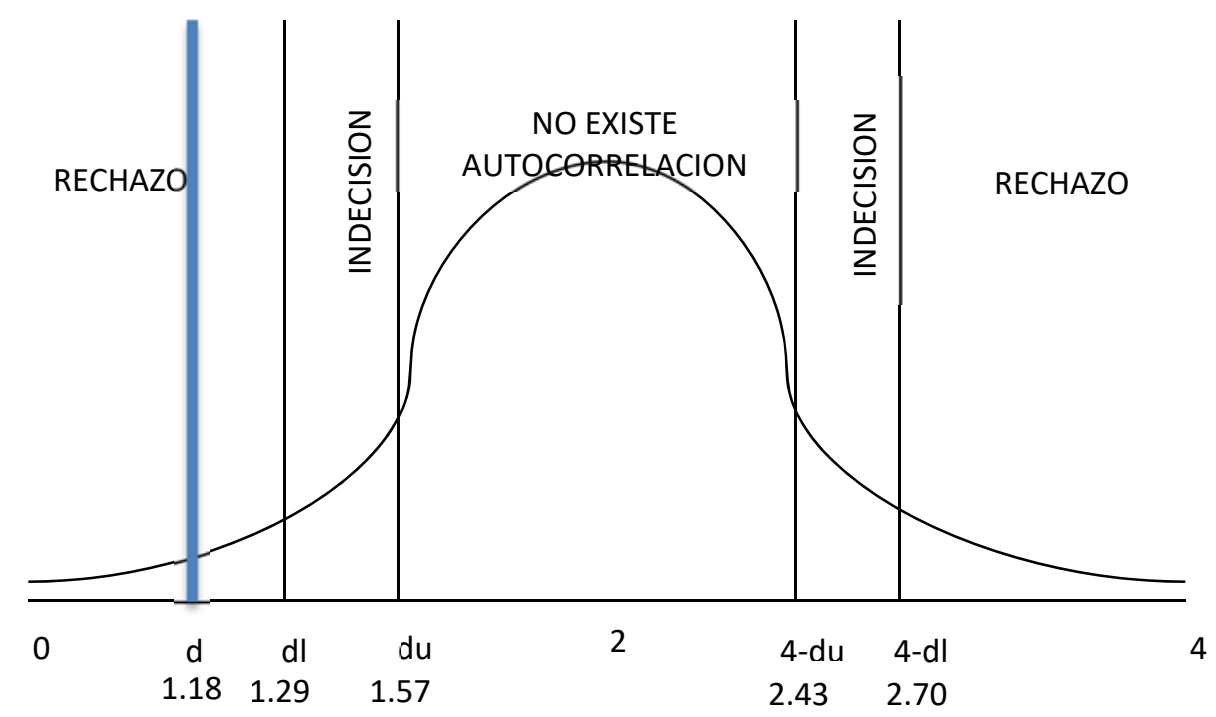

Se trabajó con $n=31$ observaciones y 2 variables explicativas a un nivel de significancia del $5 \%$, lo cual nos da un $\mathrm{dl}=1.297$, un $\mathrm{du}=1.570$, un $4-\mathrm{du}=2.43$ y un $4-\mathrm{dl}=2.703$.

El valor resultante del modelo es 1.183, el cual se encuentra ubicado fuera del rango du $<\mathrm{d}<4$-du, por lo que se rechaza este modelo estadístico.

A partir del resultado anterior se corrió un nuevo modelo estadístico con la variable dependiente Ingresos y las variables independientes Embarques y Embarques Prepagados. 
Este análisis nos dio como resultado un coeficiente de determinación de ,789, lo cual nos muestra que la variable dependiente es explicada en un $78.9 \%$ por las variables independientes.

Tabla 5 Durbin Watson 3

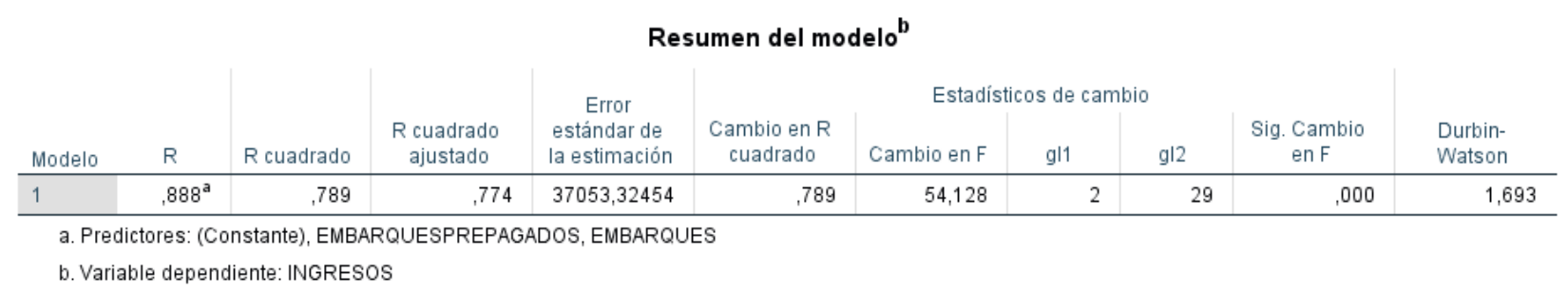

La Tabla 5 nos muestra un resultado del 1.693 en la herramienta Durbin Watson.

Para determinar si las variables no son auto correlacionales se realizó el siguiente análisis:

Figura 9 Autocorrelación 3

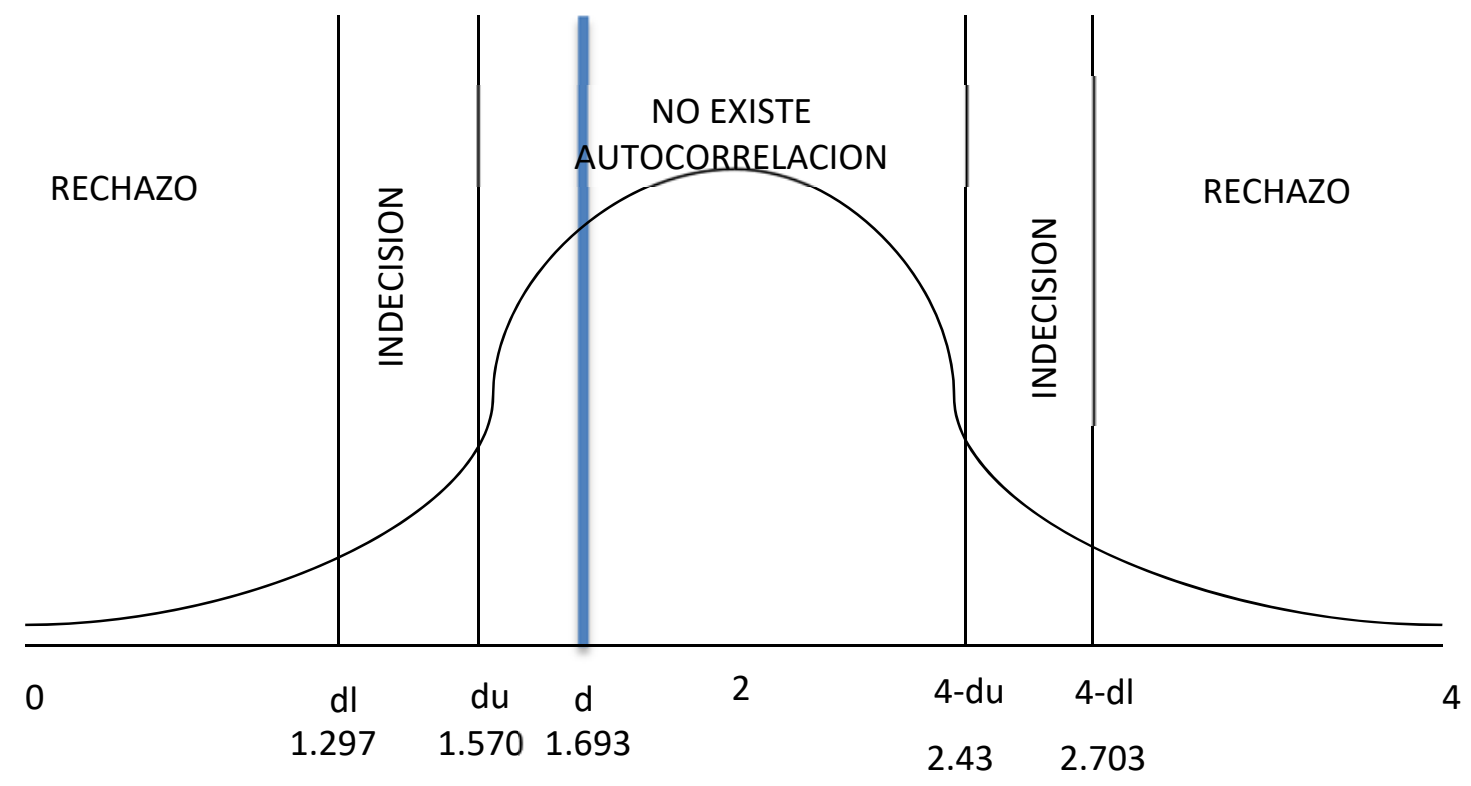

Se trabajó con $n=31$ observaciones y 2 variables explicativa a un nivel de significancia del $5 \%$, lo cual nos da un $\mathrm{dl}=1.297$, un $\mathrm{du}=1.570$, un $4-\mathrm{du}=2.43$ y un $4-\mathrm{dl}=2.703$.

El valor resultante en el modelo del Durbin-Watson es 1.693, el cual se encuentra ubicado dentro del rango $\mathrm{du}<\mathrm{d}<4$-du $(1.570<1.693<2.43)$. Mostrando que no existe auto correlación entre las variables. 
El Análisis de Varianzas (ANOVA) tiene un valor de Sig. de ,000. Esto nos permite concluir que la hipótesis nula $(\mathrm{Ho})$ es rechazada y la hipótesis alternativa $\left(\mathrm{H}_{1}\right)$ se acepta. Debido a que el valor de Sig. es menor a 0,05 .

Tabla 6 ANOVA 2

\begin{tabular}{|c|c|c|c|c|c|c|}
\hline \multicolumn{7}{|c|}{ ANOVA $^{\mathrm{a}}$} \\
\hline Modelo & & $\begin{array}{l}\text { Suma de } \\
\text { cuadrados }\end{array}$ & $\mathrm{gl}$ & $\begin{array}{c}\text { Media } \\
\text { cuadrática }\end{array}$ & $\mathrm{F}$ & Sig. \\
\hline \multirow[t]{3}{*}{1} & Regresión & $1,486 \mathrm{E}+11$ & 2 & $7,432 \mathrm{E}+10$ & 54,128 &, $000^{b}$ \\
\hline & Residuo & $3,982 \mathrm{E}+10$ & 29 & 1372948859 & & \\
\hline & Total & $1,884 E+11$ & 31 & & & \\
\hline
\end{tabular}

En la tabla "Coeficientes" se expresa la relación entre la variable dependiente con las variables independientes. Esta tabla muestra una constante de 14490.212, además muestra que por cada embarque que tenga la compañía se tendrá un ingreso de 801.182 y por cada embarque prepagado que obtenga la compañía generar un ingreso de 197,945.

Además, muestra el coeficiente estandarizado de la variable embarques el cual es ,849 lo cual indica que la variable tiene una importancia relativa en el modelo, es decir que mientras más embarques se tengan, mayor serán los ingresos de la compañía.

Con respecto a la variable Embarques Prepagados, muestra un coeficiente estandarizado de, 049 , lo cual indica que la variable no tiene un nivel de importancia tan representativo como la variable Embarques, pero aun así aporta al incremento de los ingresos de la compañía.

Tabla 7 Coeficientes 2

\begin{tabular}{|c|c|c|c|c|c|c|c|c|c|c|c|}
\hline \multicolumn{12}{|c|}{ Coeficientes $^{a}$} \\
\hline & & \multicolumn{2}{|c|}{$\begin{array}{l}\text { Coeficientes no } \\
\text { estandarizados }\end{array}$} & $\begin{array}{c}\text { Coeficientes } \\
\text { estandarizad } \\
\text { os } \\
\text { Beta }\end{array}$ & $t$ & Sig. & \multicolumn{3}{|c|}{ Correlaciones } & \multicolumn{2}{|c|}{ Estadisticas de colinealidad } \\
\hline \multirow[t]{3}{*}{1} & (Constante) & 14490,212 & 24402,488 & & .594 & 557 & & & & & \\
\hline & EMBARQUES & 801,182 & 128,344 & 849 & 6,242 & .000 & 888 & .757 & .533 & 394 & 2,540 \\
\hline & $\begin{array}{l}\text { EMBARQUESPREPAGAD } \\
\text { OS }\end{array}$ & 197,945 & 546,179 & .049 &, 362 & .720 & .710 & .067 & .031 & 394 & 2,540 \\
\hline
\end{tabular}

Según el análisis estadístico realizado las variables Embarques y Embarques Prepagados son relevantes para la variable dependiente ingresos. A pesar de este resultado, la variable toneladas sigue siendo un punto importante de analizar con respecto a los ingresos de 
las Agencias de Carga, esto debido a que representa un componente importante para la generación de ingresos así como también es una variable que es medible en la compañía analizada de forma global. 


\section{SOLUCIÓN}

El actual flujograma de la compañía está basado en un proceso de exportación aérea directo y simplificado, es decir no se aporta seguimiento, asesoría y verificación de la información durante el proceso para evitar posibles errores durante la operación. Tal como se muestra a continuación: 
Figura 10 Flujograma Actual

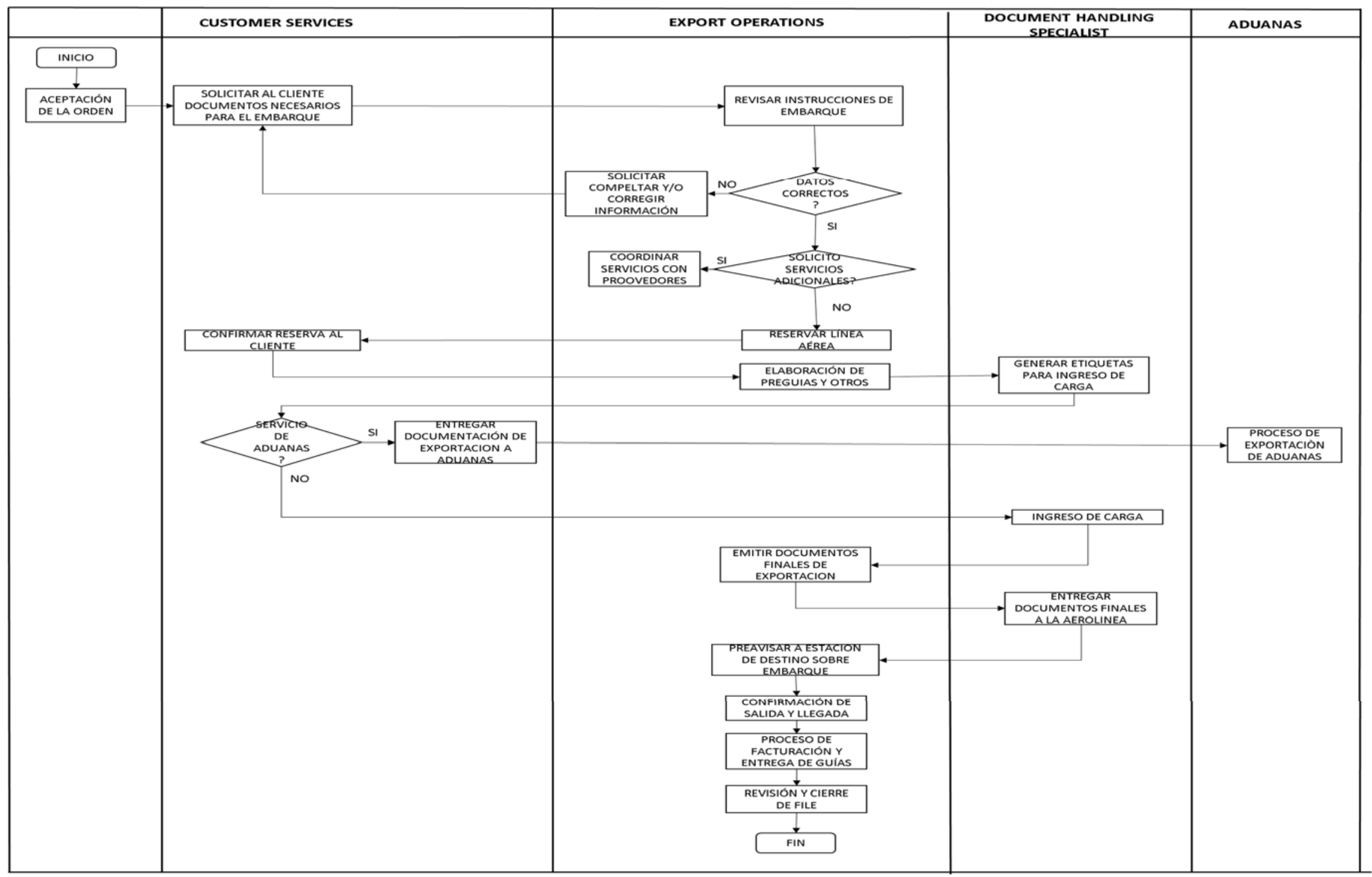


Es por ello, que basándonos en las cuatro variables resultantes del FODA Cruzado, planteamos una reestructuración y mejora al flujograma actual para lograr un proceso de exportación aérea eficiente.

\section{Variable Embarques}

Para aumentar la cantidad de embarques se implementó nuevos procesos que permiten disminuir los tiempos de operación durante el proceso de exportación aérea. Para lograr este objetivo se realizarán las siguientes modificaciones.

Posterior a la aceptación de la cotización el área de ventas entrega un pequeño instructivo al cliente que informe los requerimientos básicos para el correcto ingreso de la carga. En este instructivo se detallará los siguientes puntos:

- Las cajas del embarque deben ser resistentes y estar en buen estado.

- Las cajas deben ser de un tamaño adecuado al de la mercancía, para evitar que el embalaje colapse.

- Cajas con dimensiones menores a $18 \times 15 \times 15$ cm deberán ser colocados dentro de una caja más grande para su correcto manejo en el ingreso a almacén.

- Las cajas y mercancías deben estar correctamente embaladas para su adecuado manejo.

- La mercancía debe estar debidamente rotulada y etiquetada para su rápida identificación y correcto tratamiento durante su envió.

- Retire todas las etiquetas de la caja que no tengan relación con la mercadería.

- Las cajas y mercancías deben estar correctamente selladas para evitar daños, fugas o derrames del producto.

- Los pallets utilizados para el embarque deben contar con tratamiento térmico y estar certificadas por SENASA.

- El embarque debe estar debidamente enzunchado y envuelto con stretch film si se utiliza pallets.

- Brindar descripción, clase y composición exacta de la mercancía; esta información es esencial para determinar el adecuado manejo del embarque.

De tener alguna duda respecto a las características o requerimientos de ingreso para su embarque no dude en contactarse con nosotros. 
Posterior a esto, el vendedor transfiere información del cliente al Team Leader de Costumer Services para la asignación de un Customer Service Specialist. El Customer Service Specialist solicita información y documentos sobre el embarque al cliente con las siguientes indicaciones adicionales:

- Llenar la información solicita en los recuadros asignados.

- Ingresar destino final del embarque.

- Ingresar términos del embarque (incoterm).

- Colocar datos del embarcador y consignatario completos.

- Indicar descripción del producto de manera específica y general.

- Ingresar cantidad de bultos exacto, dimensiones y peso cercanas a lo real.

- Cualquier duda o consulta respecto a la información solicitada no dude en comunicarse con nosotros.

Posterior a esto, el Customer Service Specialist envía esta información al Team Leader de Operaciones el cual asigna el embarque a un Export Operations Specialist. Este se encarga de verificar que la información este completa e identificar si se requiere mayor información o documentos del embarque, si la cotización coincide con la información del cliente, si cuenta con la aerolínea a utilizar y si se cuenta con otros embarques con el mismo destino para poder consolidar.

Adicional a esto, se verifica si se solicitó algún servicio adicional para el embarque, de ser así se procede a coordinar el mismo. En este punto también se verificará que la carga tenga aprobación del departamento de Seguridad y si el cliente cuenta con crédito.

Una vez se tenga la información correcta para la operación, se procede a asignar un numero de AWB (airway bill), de HAWB (house airway bill) y hacer la reserva con la aerolínea. Luego se envía la información a Costumer Service Specialist con las siguientes indicaciones:

- El embarque debe contar con un correcto embalaje

o Cajas resistentes. 
o Rotulado y etiquetado adecuado.

o Strech film, zunchos, esquineros, pallet certificado de ser necesario.

o El producto tiene estar totalmente cubierto, no debe ser visible.

o Si es mercancía peligrosa, el embalaje debe cumplir con lo indicado en el Manual de Mercancías Peligrosas.

- Indicar fecha y hora de ingreso del embarque.

- Enviar documentos de transporte (tarjeta de propiedad y licencia de conducir) y datos de personal de estiba (Nombre completo y DNI) previo al recojo de la carga.

En el mes de Agosto de 2016, la empresa obtuvo 204 embarques. En el mes de Agosto de 2017, el cual fue el último mes registrado sin dar inicio a la aplicación de las mejoras, la empresa obtuvo 209 embarques atendidos.

Para el último año mencionado, el promedio mensual de embarques atendidos fue de 207. Luego de aplicar la mejora propuesta para la variable Embarques, basada en instructivos e indicaciones para la reducción de tiempos, el número de embarques realizados en el mes de Noviembre es de 238.

Dicho número representa un incremento del $15 \%$ respecto al promedio mensual de embarques atendidos en el 2017

\section{Variable Toneladas}

La variable Toneladas es un elemento importante en el proceso de exportación aérea en una Agencia de Carga, además de ser un elemento medible en la compañía para su constante evaluación.

Esta variable fue descartada en el modelo estadístico debido a ser auto correlacional con la variable embarque, a pesar de esto es una variable que debe ser mejorada para el incremento en ingresos de la compañía.

Para lograr la mejora de esta variable es esencial el poder conseguir nuevos proveedores y lograr afianzar nuestra relación con los proveedores actuales (aerolínea, embaladores, 
especialista mercancía peligrosa, transporte), esto con el fin de mejorar nuestro servicio y obtener precios competitivos en el mercado.

Mejorar nuestra relación con las aerolíneas y tener reuniones de negociación permite que la compañía cuente con tarifas negociadas competitivas para diversos destinos, mejorando nuestras cotizaciones de venta y aumentando nuestras ganancias. Las negociaciones también nos permiten poder contar con espacios reservados en los vuelos, de acuerdo a la cantidad de toneladas proyectadas en el mes, esta información se obtiene mediante la data histórica de los clientes y su potencial de exportación al año.

Por otra parte, generar nuevas relaciones con otras aerolíneas también beneficia a la compañía, puesto que brinda una gran variedad de alternativas para movilizar la carga a diversos destinos. Esto permite mejorar las tarifas y contar con planes de contingencia para los diversos problemas que puedan surgir durante el proceso de exportación, además de poder movilizar grandes volúmenes de embarque sin problemas de reprogramación y poder consolidar más embarques, lo cual incrementa los ingresos a la compañía.

Respecto a los servicios de transporte, embalado y de mercancía peligrosa, es importante el poder contar con más proveedores. Con esto se logra una mejora en los precios del servicio, por lo cual se elaboran tarifarios estandarizados para los distintos servicios que aplican para todos los proveedores. Esto también permite continuar con la operación si alguno de los proveedores no cuenta con el tiempo o insumos suficientes para realizar el servicio.

También permitirá mejorar los tiempos de respuestas al cliente, esto debido a que se tendrá rápido acceso al tarifario de los servicios, así como una rápida respuesta por parte de los proveedores. El contar con más de un proveedor por servicio nos permite minimizar el riesgo y mejorar los tiempos en el proceso de exportación. 
Figura 11 Flujograma Variable Toneladas

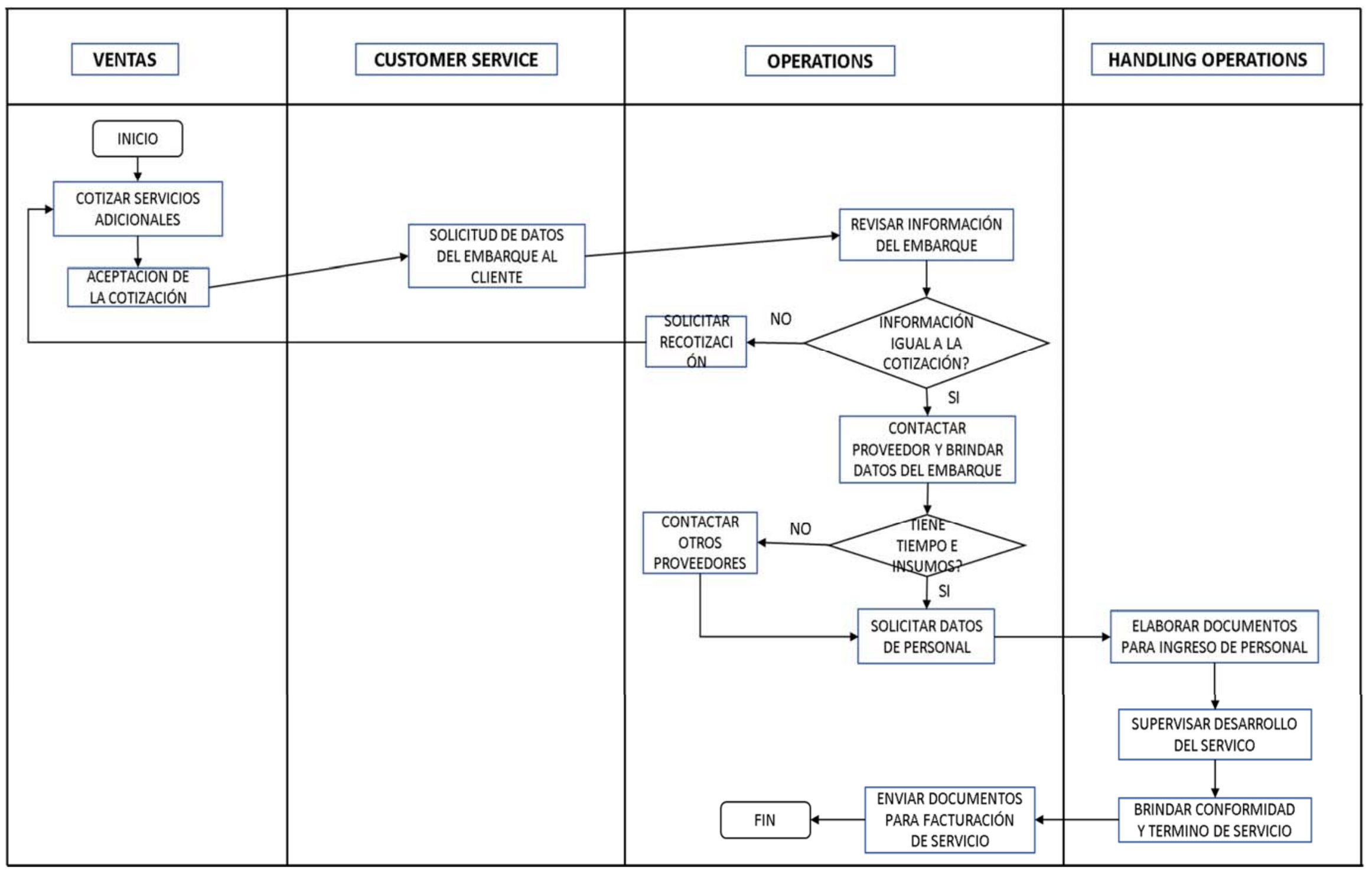


Este flujograma permite mejorar el tiempo de respuesta a la solicitud de servicios adicionales, la disponibilidad de espacios en los vuelos y la rápida acción frente a problemas durante la operación.

En el mes de Agosto de 2016, la empresa obtuvo 74.16 Toneladas atendidas. En el mes de Agosto de 2017, el cual fue el último mes registrado sin dar inicio a la aplicación de las mejoras, la empresa obtuvo 68.48 Toneladas atendidas.

Para el último año mencionado, el promedio mensual de toneladas atendidas fue de 96.60. Luego de aplicar la mejora propuesta para la variable Toneladas, la cantidad de Toneladas atendidas en el mes de Noviembre es de 104.33.

Dicho número representa un incremento del $8 \%$ respecto al promedio mensual de Toneladas atendidas en el 2017.

\section{Variable Embarques Prepagados}

Se realizó una investigación para poder identificar a los clientes potenciales (nuevos y actuales) que cuenten con una gran cantidad de embarques al año, principalmente prepagados. Para lograr obtener estos embarques se realizó un flujograma de exportación diferente, el cual busca ofrecer una mayor interacción y comunicación con el cliente.

Para estos clientes se manejará un tarifario previamente negociado lo cual reducirá el tiempo de respuesta por parte del Customer Service Specialist VIP (CSSV) personal capacitado en temas operativos y de ventas. Si el cliente enviara una instrucción de embarque para un destino no incluido en su tarifario, el CSSV solicitara la cotización al aérea de Pricing, el cual enviara el tarifario a Ventas para su formalización y solicitud de aprobación al cliente. Una vez CSSV cuente con la aprobación, procederá a revisar que la información y documentación del embarque este correcto, de no ser así solicita información al cliente; luego verificara si existe solicitud de servicios adicionales, de ser así procede a coordinar. Luego se procede a enviar la información a Operaciones para la elaborar la guía y demás documentos. 
Operaciones envía la información de ingreso a CSSV el cual transfiere dicha información al cliente. CSSV solicita al cliente fecha de ingreso de la carga, documentos de transporte para su ingreso al almacén y si la carga vuela con documentos originales. Una vez se tenga esta información se envía a Operaciones para coordinar con el Document Handling Specialist (DHS) el ingreso del embarque. DHS elabora las etiquetas, ingresa el embarque al almacén y supervisa que se realice de forma adecuada los servicios adicionales solicitados por el cliente. Una vez finalizado el ingreso, DHS envía el ticket balanza a Aduanas y a Operaciones para elaborar la guía con datos finales. Operaciones envía la guía a CSSV para solicitar la aprobación del cliente, si el cliente tiene alguna corrección se indica a Operaciones para su actualización.

Una vez CSSV cuente con la aprobación, Operaciones procede a emitir los documentos finales y enviar a DHS para su entrega en la aerolínea. Cuando la carga allá volado, se notificará al cliente de la salida de su embarque, así como al agente de aduanas para que proceda con el recojo de la guía. Adicional a esto CSSV verificara que se realice de forma correcta la facturación del embarque. Una vez realizado el pago total de los costos del embarque, se procede a cerrar en el sistema de la compañía.

Estas modificaciones requieren de un nuevo puesto "Customer Service Specialist VIP”, el cual se asignó a un Customer Service Specialist que paso por un proceso de capacitación en el área Operativa y de Ventas, por lo que no se incurrió en la contratación de un nuevo personal y solo se invirtió en las capacitaciones realizadas.

En el mes de Agosto de 2016, la empresa obtuvo 45 Embarques Prepagados. En el mes de Agosto de 2017, el cual fue el último mes registrado sin dar inicio a la aplicación de las mejoras, la empresa obtuvo 31 Embarques Prepagados.

Para el último año mencionado, el promedio mensual de Embarques Prepagados fue de 51. Luego de aplicar la mejora propuesta para la variable Embarques Prepagados, la cantidad de Embarques Prepagados en el mes de Noviembre es de 57.

Dicho número representa un incremento del $11 \%$ respecto al promedio mensual de Embarques Prepagados en el 2017. 
Figura 12 Flujograma Variable Embarques Prepagados

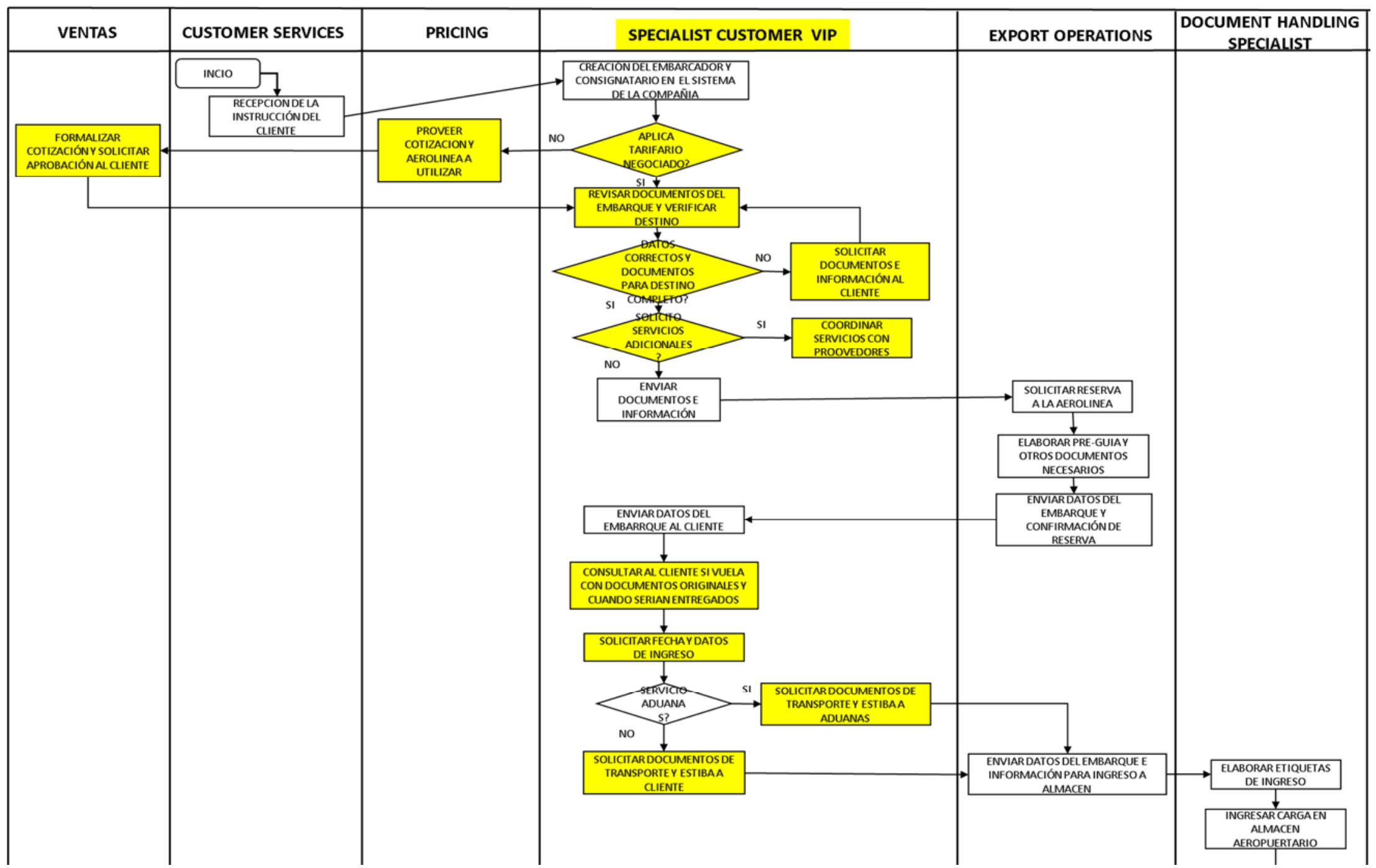




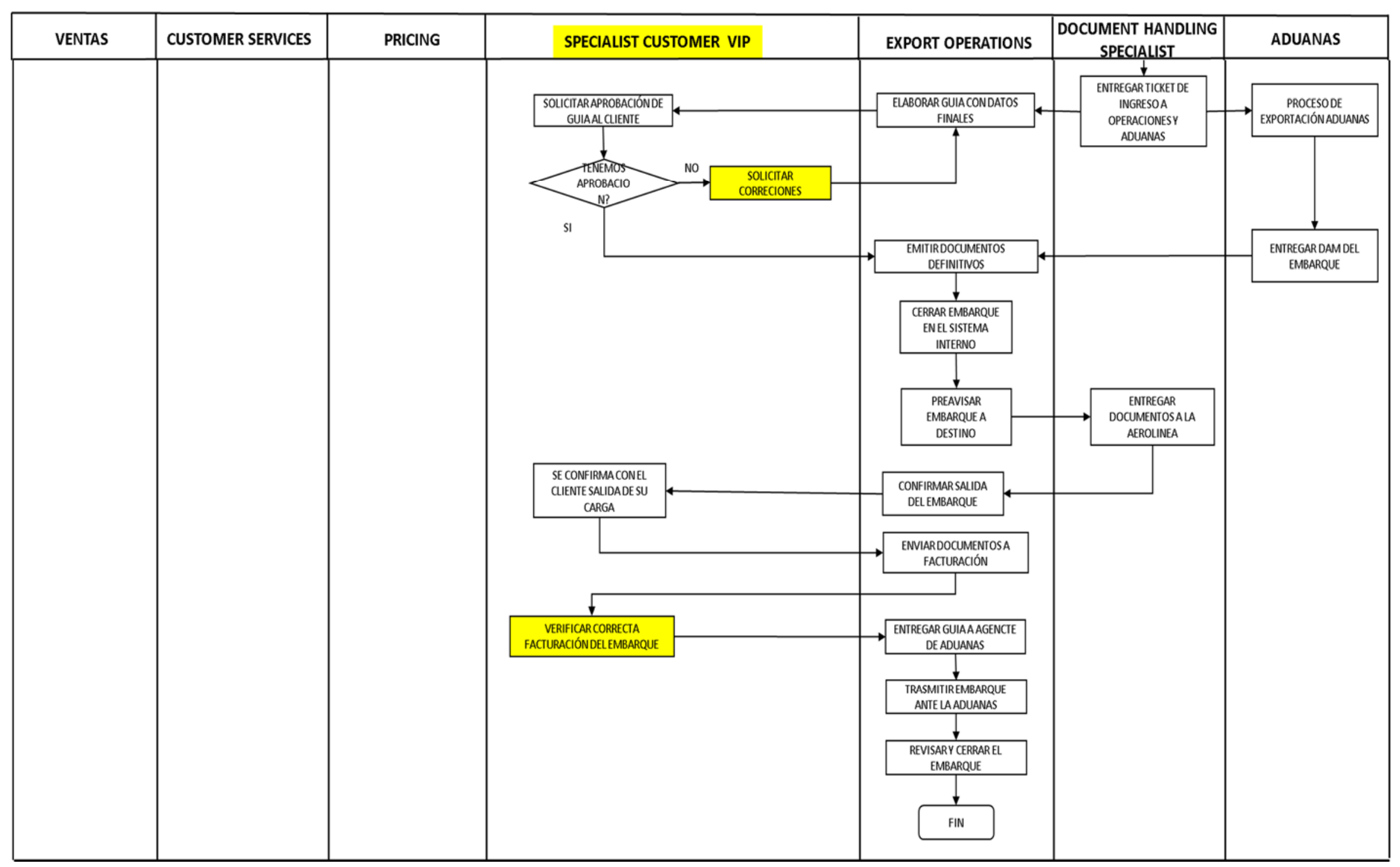




\section{Variable Facturas por Servicios Asumidos por la Compañía}

Para poder disminuir la cantidad de facturas por servicios asumidos por la Compañía se trabajó en mejorar la recolección de información del embarque y el correcto traspaso de la información entre aéreas.

Para iniciar un adecuado proceso de exportación, se capacito al personal de Ventas en temas operativos, esto con la finalidad de que el vendedor logre identificar de forma oportuna la información relevante para el embarque detallado en las cotizaciones, como por ejemplo los servicios especiales de transporte internacional y los servicios adicionales. Toda esta información debe ser trasmitida de forma adecuada al resto de aéreas involucradas.

Cuando el área de Operaciones tenga la información del embarque debe revisar que todos los datos sean correctos y se cuente con la documentación e información necesaria según el tipo de carga, destino y aerolínea a utilizar. Adicional a ello, se solicita información sobre el embalaje para verificar que este correcto. Una vez se tenga todo lo necesario se procede a enviar los datos del ingreso al aérea de Document Handling Specialist (DHS).

En esta área se procede a elaborar las etiquetas del embarque, coordinar con el transporte el ingreso al almacén y verificar la correcta elaboración de documentos para su ingreso, esto para evitar sobrecostos como la movilización de carga, el uso de espacio de desconsolidación del almacén entre otras actividades que encarecen el proceso y reducen los ingresos de la compañía.

Otro proceso que aporta con la reducción de facturas por servicios asumidos por la compañía es la coordinación que se realiza con Pricing y la aerolínea previa al ingreso del embarque. Esto sirve para prevenir situaciones donde la aerolínea no cuente con vuelos para ese destino, no tenga espacios para los próximos vuelos o algún otro suceso que afecte el proceso de exportación; lo cual permite coordinar con Pricing nuevas opciones de vuelo que no afecten al cliente con retrasos o mayores costos.

En el mes de Agosto de 2016, el monto por facturas de servicios asumidos por la compañía es de 682.18. En el mes de Agosto de 2017, el cual fue el último mes registrado sin 
dar inicio a la aplicación de las mejoras, la compañía asumió el monto de 461.18 por facturas de servicios.

Para el último año mencionado, el monto promedio mensual de facturas de servicios asumidos por la compañía es de 329.66. Luego de aplicar la mejora propuesta para la variable de facturas de servicios asumidos por la compañía, la compañía solo asumió el monto de 59.33 por facturas de servicios en el mes de Noviembre.

Dicho número representa una reducción del $82 \%$ respecto al monto promedio mensual de facturas de servicios asumidos por la compañía en el 2017. 
Figura 13 Flujograma Variable Facturas por Servicios Asumidos por la Compañía

\begin{tabular}{|c|c|c|c|c|}
\hline VENTAS & CUSTOMER SERVICES & PRICING & EXPORT OPERATIONS & $\begin{array}{c}\text { DOCUMENT HANDLING } \\
\text { SPECIALIST }\end{array}$ \\
\hline & 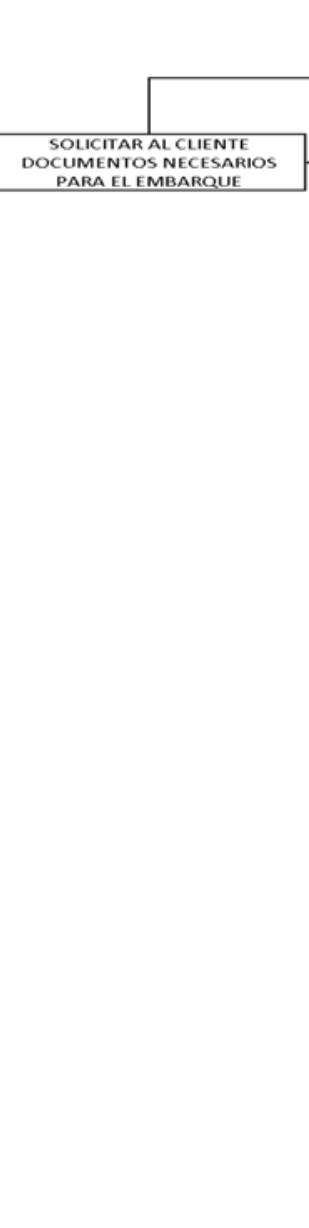 & 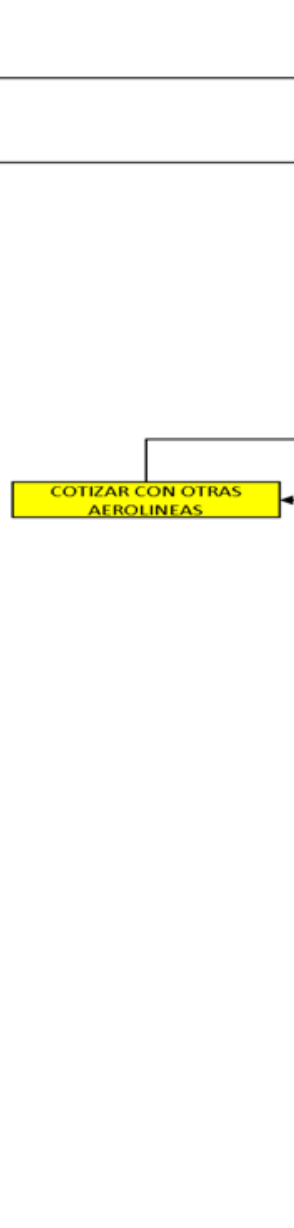 & 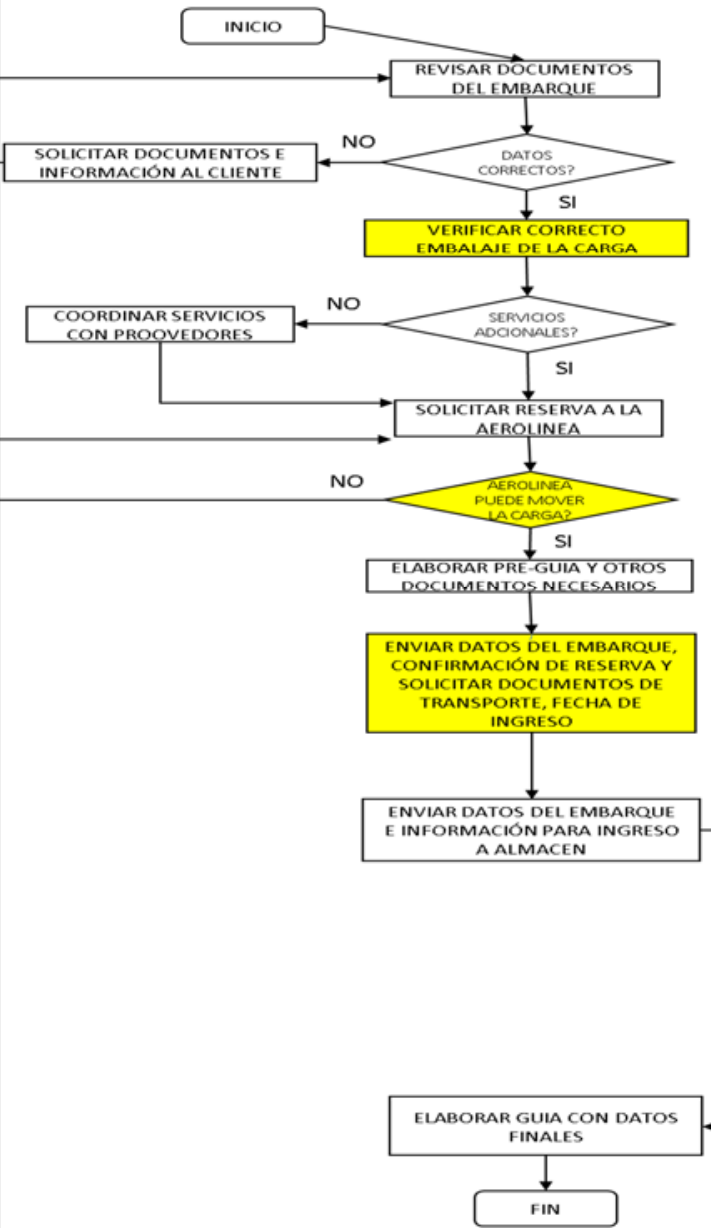 & 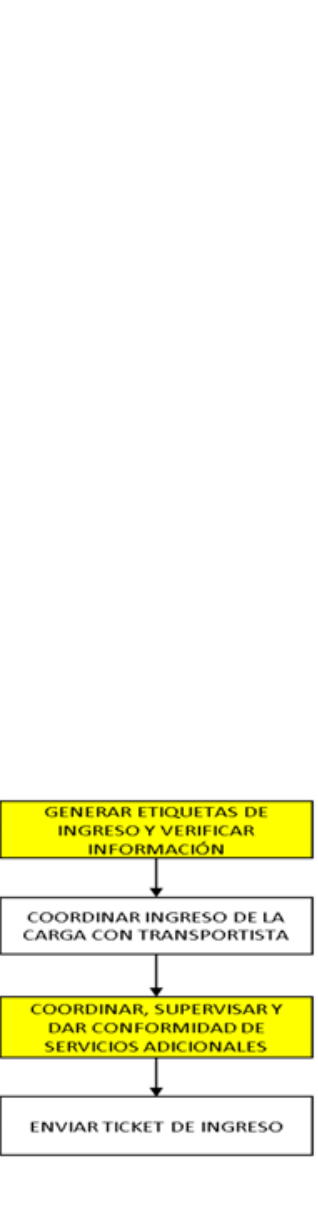 \\
\hline
\end{tabular}


A partir de las soluciones propuestas respecto a las variables relacionadas al proceso de exportación aérea se elaboró un nuevo flujograma general actualizado.

En el mes de Agosto de 2016, la empresa obtuvo Ingresos por 215,369.99. En el mes de Agosto de 2017, el cual fue el último mes registrado sin dar inicio a la aplicación de las mejoras, la empresa obtuvo 147,727.44 en Ingresos.

Para el último año mencionado, el promedio mensual en Ingresos fue de 188,005.81. Luego de aplicar las mejoras propuestas, el Ingreso total en el mes de Noviembre es de $247,959.43$.

Dicho número representa un incremento del $31.89 \%$ respecto al promedio mensual en Ingresos el 2017.

De igual forma, las mejoras planteadas en la compañía lograron reducir el tiempo de la operación en la exportación.

Inicialmente, el tiempo promedio de exportación es de tres días, operando el primer día la coordinación e ingreso del embarque del cliente. En el segundo día se coordina la generación de documentos aduaneros y comerciales que el embarque requiera. En el tercer día se entrega documentos en la línea para cumplir su vuelo según itinerario brindando por la aerolínea.

A partir de las mejoras planteadas, se logró minimizar esta operación en un promedio de dos días. En donde el primer día se coordina y gestiona en ingreso del embarque en el almacén aeroportuario así como la generación y entrega de documentos comerciales y aduaneros que requiera la carga. En el segundo día se realiza la entrega de documentos en la línea para su vuelo según itinerario. 
Figura 14 Flujograma Final Propuesto

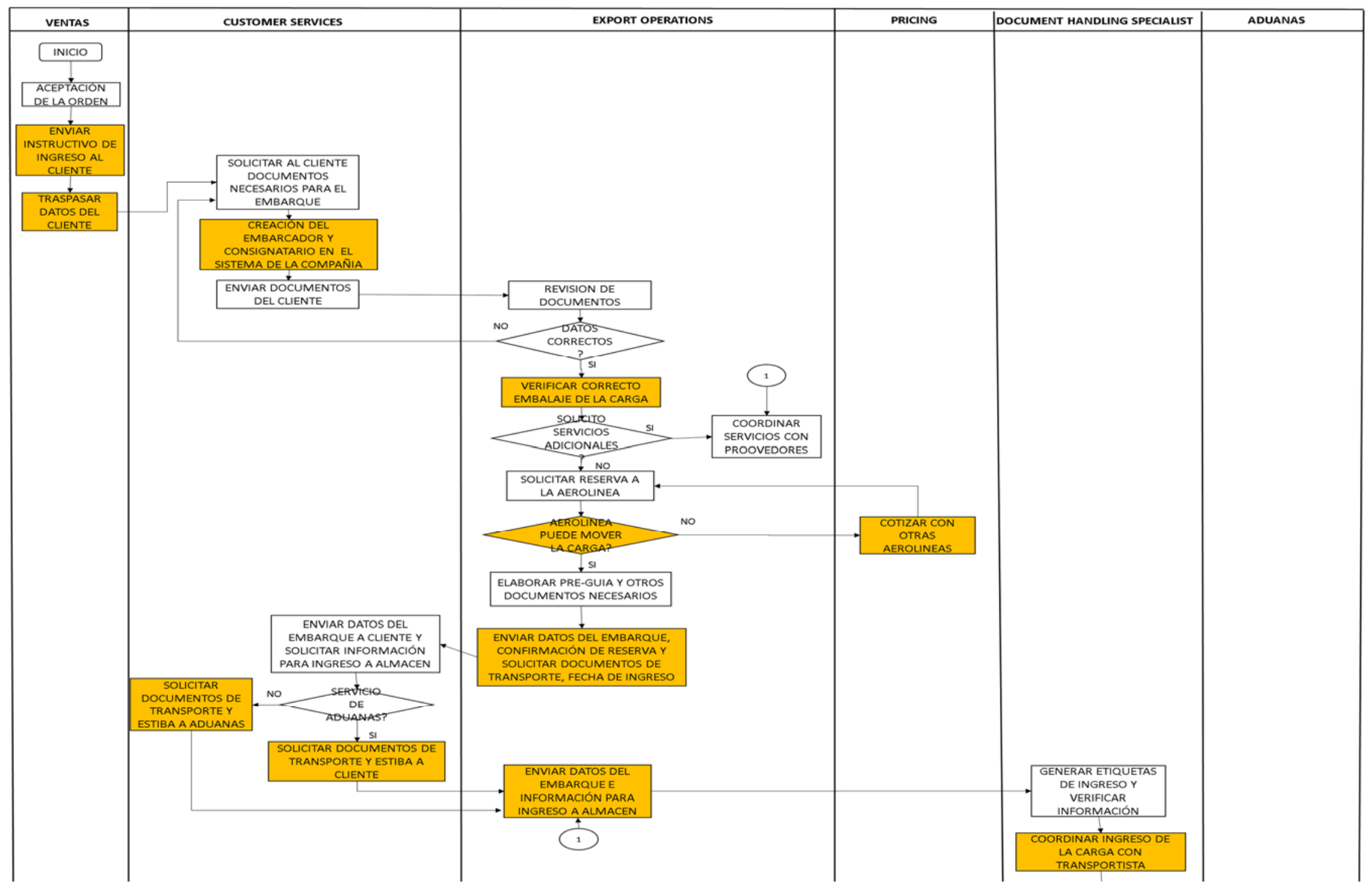




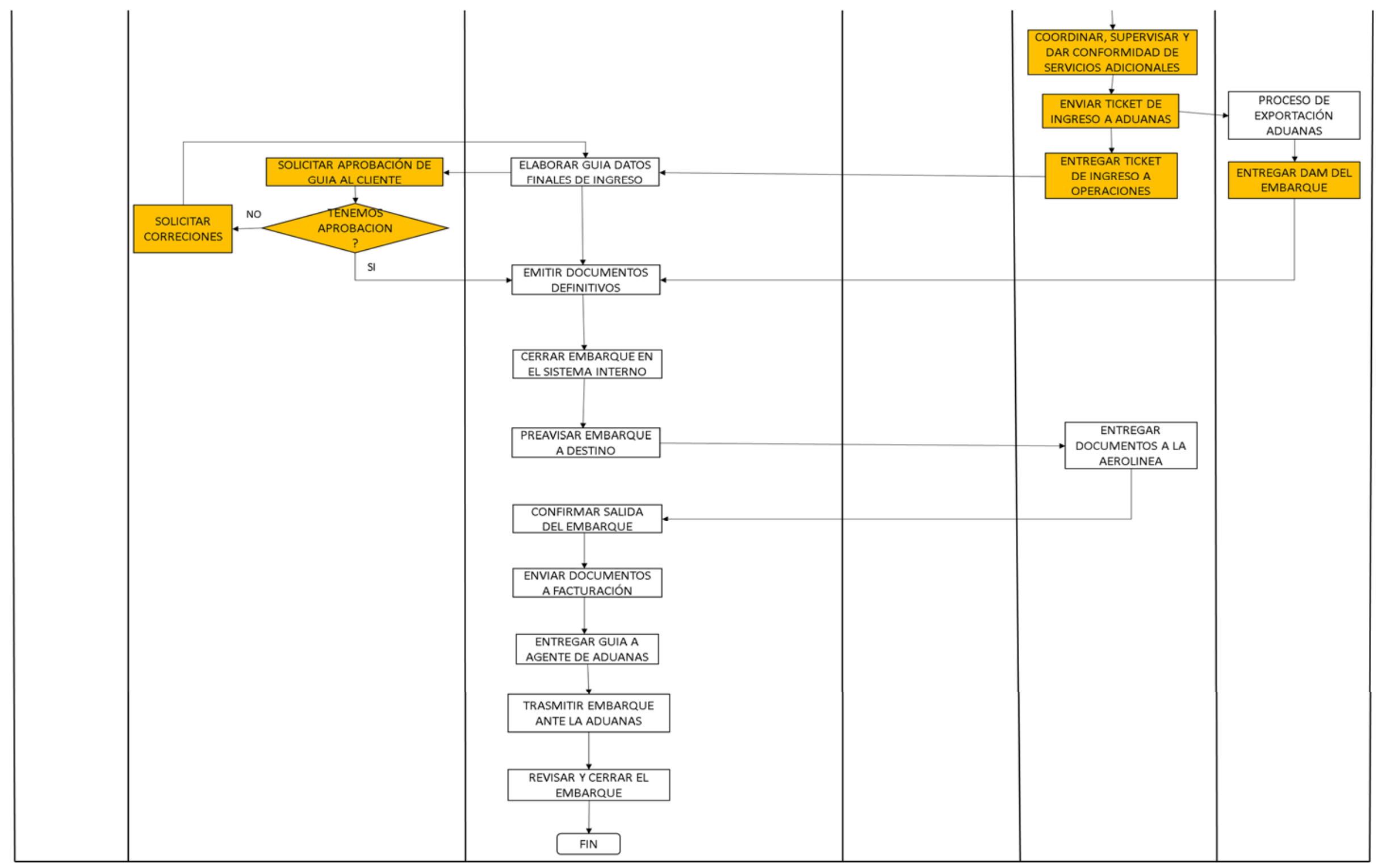




\section{CAPITULO VI : CONCLUSIONES Y RECOMENDACIONES}

\section{CONCLUSIONES}

Los ingresos de la compañía incrementan en un 31.89\% mensual con las mejoras realizadas en el proceso de exportación aérea, basadas en las variables Embarque, Toneladas, Embarques Prepagados y Facturas por servicios asumidos por la Compañía.

Las facturas por servicios asumidos por la compañía generados en el proceso de exportación aérea tienen un impacto negativo en los ingresos de la compañía. El análisis realizado en este trabajo, nos muestra que estas facturas se generan por falta de información del embarque, una mala coordinación para su ingreso o errores generados en la documentación emitida por la compañía, lo cual provoca que se incurran en reprocesos que ralentizan y encarecen la exportación. Los servicios generados a partir de los errores antes mencionados son la movilización de carga en almacén, el re embalaje del embarque y el uso del espacio de desconsolidación. Se implementó mejoras en el flujo de información durante el proceso de exportación para reducir los errores operativos, lo cual dio como resultado una disminución del $82 \%$ de facturas.

Los embarques generan un impacto positivo en los ingresos de la compañía. Mientras más embarques tenga la compañía, mayores serán los ingresos de esta. Para lograr mejorar esta variable se realizaron cambios en el proceso de exportación aérea donde se consiguió reducir el tiempo el operativo del proceso. Esto ha permitido que los embarques crezcan en un $15 \%$.

La comunicación y flujo de información representan una debilidad en la compañía, esto debido a la falta de conocimiento sobre el proceso de exportación y la información necesaria para el proceso de exportación aérea del embarque. Estas acciones impiden el crecimiento de la variable Embarques Prepagados. La elaboración de un nuevo flujograma dirigido a clientes potenciales ha mejora el flujo de información y ha logrado incrementar los embarques en un en un $11 \%$. 
El contar con pocos o únicos proveedores para los servicios que ofrece la compañía dificulta el proceso de exportación y no permiten la mejora de la variable Toneladas. Esta situación genera que los precios de los servicios ofertados no sean competitivos en el mercado, además de no tener una respuesta rápida frente a solicitudes o problemas que puedan surgir durante la operación, debido a que no se cuenta con disponibilidad inmediata por parte del proveedor. A través de las mejoras desarrolladas en el proceso de exportación y la coordinación con los proveedores han dado como resultado un incremento del $8 \%$ en toneladas.

El contar con una amplia red global de estaciones en distintos países permite a la compañía ofrecer un mejor servicio de exportación. Esto debido a la información y seguimiento que se puede realizar a los embarques durante todo el proceso, es decir desde el almacén del exportador hasta el almacén del consignatario, lo cual ofrece mayor seguridad y confianza al cliente. Esto permite ser competitivo y ofrecer mejores tarifas en comparación a otras agencias de carga

El asesoramiento realizado a los clientes por parte de ventas y customer service durante la operación no reducen la cantidad de reprocesos y sobrecostos generados en el proceso de exportación. El no indicar la información y documentos que requiere el tipo de embarque, verificar la información remitida por el cliente y no solicitar lo necesario para una correcta operación reducen los ingresos de la compañía. Otro factor importante a considerar en este proceso es tener en cuenta la falta de conocimiento que podría tener el cliente en cuento a la naturaleza de su carga y la información necesaria para realizar la operación.

\section{RECOMENDACIONES}

Para mejorar el flujo de información relevante y esencial para el proceso de exportación de los diversos embarques entre las distintas áreas involucradas se debe realizar una capacitación. La capacitación brindara información sobre las funciones que desempeñan las diversas áreas participantes, esto con la finalidad de entender las funciones y responsabilidades de otras aéreas y comprendan que documentos o información son esenciales para no retrasar o encarecer el servicio brindado. Además, permitirá afianzar la comunicación entre áreas y generar nuevas ideas que permitan mejorar el proceso. 
Para mejorar el asesoramiento brindando a los clientes por parte del área de Ventas y Customer Service, se elaborará un instructivo básico que brindara información importante al cliente sobre los requisitos que debe cumplir su mercancía para lograr un proceso de exportación fluido, esto sería enviado por el área de ventas. Por otra parte, cuando el área de Customer Service tome contacto con el cliente para la solicitud de información sobre el embarque, adicional al envió de la instrucción de embarque para su respectivo llenado se enviará al cliente algunas indicaciones que permitirán mejorar la recolección de información. Esto no solo permitirá reducir el nivel de incidencias, sino que mejorará la relación con el cliente y desarrollará confianza y fidelidad hacia la compañía.

La diversificación de proveedores para los diversos servicios que ofrece la compañía brinda mayores oportunidades para mejorar el servicio y obtener una mayor cantidad de toneladas. Esta medida permite mejorar nuestros precios y ofrecer tarifas competitivas, además de reducir los tiempos de repuesta frente a las solicitudes de servicios adicionales. También nos brinda la oportunidad de crear una tarifario estandarizado para los diversos requerimientos que nos permitan cubrir nuestro valor de venta, utilizando cualquiera de los proveedores asociados sin afectar al cliente con modificaciones en el precio.

Capacitar a un personal de Costumer Service en temas Operativos y de Ventas para mejorar el servicio brindando a los clientes potenciales. Esta capacitación permite realizar un mejor seguimiento del proceso de exportación del embarque además de contar con mayor información sobre el status de la carga y mejorar la comunicación con el cliente. Esto permite mejorar la confianza del cliente hacia la compañía e incrementar la cantidad de embarques promedio en el mes, así como un mejor análisis de la operatividad con la información recolectada.

Tener reuniones de negociación con las aerolíneas permite mejorar las tarifas para diversos destinos, además de contar con espacios reservados durante el mes. Esto debido a la proyección de toneladas por destino que maneja la compañía, lo cual permite realizar reservas de espacio con tiempo de anticipación y evitar reprogramaciones o tiempos de espera de confirmación durante el proceso de exportación. 


\section{CRONOGRAMA DE ACTIVIDADES - Diagrama de Gantt}

Para lograr los resultados de esta tesis, se elaboró un cronograma de actividades que permitieran el desarrollo de las soluciones de forma correcta. A continuación se detallan las actividades y los tiempos empleados durante la implementación de las mejoras del proceso:

Actividad 1: Capacitación al Personal de Ventas, Costumer Services y Operaciones sobre las funciones y responsabilidades de cada aérea durante el proceso de exportación y que información es relevante para el proceso de exportación.

Actividad 2: Programar reuniones de negociación con las aerolíneas más frecuentes y solicitar mejoras en la cotización de los proveedores actuales sobre los diversos servicios de la compañía. Realizar la búsqueda de nuevos proveedores y aerolíneas potenciales.

Actividad 3: Se realiza una investigación para determinar a los clientes potenciales con mayor número de embarques prepagados.

Actividad 4: Elaboración de instructivo con requerimientos básicos de la carga para el proceso de exportación aérea.

Actividad 5: Solicitar reuniones de negociación con los nuevos proveedores y aerolíneas potenciales.

Actividad 6: Elaborar flujograma con funciones de nuevo puesto Customer Service VIP.

Actividad 7: Mejoras a las plantillas de solicitud de información al cliente y plantillas de transferencia de información entre áreas.

Actividad 8: Semana de reuniones con aerolíneas y proveedores.

Actividad 9: Selección de un personal de Customer Service para su capacitación sobre las funciones, responsabilidades y procesos de las áreas de Ventas y Operaciones. Esta persona ocupara el puesto de Customer Service VIP.

Actividad 10: Elaborar tarifas estandarizadas por diversos servicios y se transfiere información de los proveedores a Operaciones.

Actividad 11: Elaborar un flujograma con nuevas funciones y responsabilidades para las diversas áreas involucradas en el proceso.

Actividad 12: Actualizar tarifa compra de las aerolíneas y transferir información de nuevas líneas a las diversas aéreas involucradas en el proceso de exportación. 
Actividad 13: Reasignación de clientes potenciales al Customer Service VIP, y redistribución de sus clientes al resto del personal de Customer Service.

Actividad 14: Planificar con la aerolínea la reserva de espacios para los próximos meses según la proyección de toneladas por destino que se estima mover.

Actividad 15: Capacitar al personal de Ventas sobre temas operativos para mejorar el reconocimiento de información relevante para el proceso de exportación.

Actividad 16: Se elabora un nuevo flujograma sobre solicitud de servicios adicionales. Se asigna y remarca procesos a las áreas involucradas para la reducción de errores y reprocesos. 
Figura 15 Diagrama de Gantt

\begin{tabular}{|c|c|c|c|c|c|c|c|c|c|c|c|c|c|c|c|c|c|c|c|c|c|c|c|c|}
\hline $\mathbf{N}^{\circ}$ ACTIVIDAD & INICIO & FINAL & $\begin{array}{l}\text { न } \\
\text { ó } \\
\text { ơ } \\
\text { ปे }\end{array}$ & $\begin{array}{l}\text { ने } \\
\text { ò } \\
\text { ơ } \\
\text { ơ }\end{array}$ & 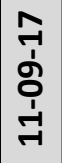 & $\begin{array}{l}\text { ने } \\
\text { ơ่ } \\
\text { ค่ }\end{array}$ & ح- & 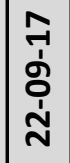 & $\begin{array}{l}\text { ने } \\
\text { ઠิ่ } \\
\text { ஸे }\end{array}$ & $\begin{array}{l}\text { f. } \\
\text { જ่ } \\
\text { જે } \\
\text { ริ่ }\end{array}$ & 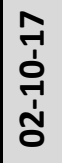 & $\begin{array}{l}\text { ने } \\
\text { ó } \\
\text {-1 } \\
\text { ó }\end{array}$ & $\begin{array}{l}\text { fิ } \\
\text { ó } \\
\text { 엉 }\end{array}$ & 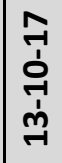 & 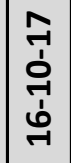 & f. & $\begin{array}{l}f \\
\dot{y} \\
\grave{1} \\
\dot{y} \\
\dot{n}\end{array}$ & $\begin{array}{c}\text { ने } \\
\text { ó } \\
\text { ने } \\
\text { సે }\end{array}$ & $\begin{array}{l}\text { f } \\
\text { ó } \\
\text {-1 } \\
\text { ò }\end{array}$ & 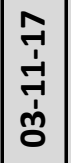 & $\begin{array}{l}\mathcal{A} \\
\stackrel{1}{1} \\
\stackrel{1}{1} \\
\dot{8}\end{array}$ & 곡 & $\begin{array}{l}\mathcal{F} \\
\stackrel{-}{-} \\
\vec{g} \\
\stackrel{-}{-}\end{array}$ & 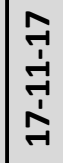 \\
\hline ACT 1 & 04-09-17 & 15-09-17 & & & & & & & & & & & & & & & & & & & & & & \\
\hline АCT 2 & 04-09-17 & $15-09-17$ & & & & & & & & & & & & & & & & & & & & & & \\
\hline АCT 3 & $11-09-17$ & $15-09-17$ & & & & & & & & & & & & & & & & & & & & & & \\
\hline ACT 4 & $18-09-17$ & $22-09-17$ & & & & & & & & & & & & & & & & & & & & & & \\
\hline ACT 5 & $18-09-17$ & $22-09-17$ & & & & & & & & & & & & & & & & & & & & & & \\
\hline АCT 6 & $18-09-17$ & $29-09-17$ & & & & & & & & & & & & & & & & & & & & & & \\
\hline ACT 7 & \begin{tabular}{|l|}
$25-09-17$ \\
\end{tabular} & \begin{tabular}{|l|}
$29-09-17$ \\
\end{tabular} & & & & & & & & & & & & & & & & & & & & & & \\
\hline АCT 8 & $02-10-17$ & $06-10-17$ & & & & & & & & & & & & & & & & & & & & & & \\
\hline АCT 9 & 02-10-17 & \begin{tabular}{|l|}
$13-10-17$ \\
\end{tabular} & & & & & & & & & & & & & & & & & & & & & & \\
\hline ACT 10 & 09-10-17 & \begin{tabular}{|l|}
$13-10-17$ \\
\end{tabular} & & & & & & & & & & & & & & & & & & & & & & \\
\hline ACT 11 & $09-10-17$ & $20-10-17$ & & & & & & & & & & & & & & & & & & & & & & \\
\hline ACT 12 & $16-10-17$ & $20-10-17$ & & & & & & & & & & & & & & & & & & & & & & \\
\hline ACT 13 & $16-10-17$ & $20-10-17$ & & & & & & & & & & & & & & & & & & & & & & \\
\hline ACT 14 & $23-10-17$ & $03-11-17$ & & & & & & & & & & & & & & & & & & & & & & \\
\hline ACT 15 & $23-10-17$ & $03-11-17$ & & & & & & & & & & & & & & & & & & & & & & \\
\hline АCT 16 & $06-11-17$ & 17-11-17 & & & & & & & & & & & & & & & & & & & & & & \\
\hline
\end{tabular}

ACTIVIDAD DE VARIABLE EMBARQUES ACTIVIDAD DE VARIABLE TONELADAS ACTIVIDAD DE VARIABLE EMBARQUES PREPAGADOS ACTIVIDAD DE VARIABLE FACTURAS POR SERVICIOS ASUMIDOS POR LA COMPAÑÍA 


\section{Referencias Bibliográficas}

13 medidas para mejorar competitividad del comercio exterior (29 de Agosto de 2017). Diario Gestión. Recuperado de https://gestion.pe/economia/13-medidas-mejorar-competitividad$\underline{\text { comercio-exterior-142597 }}$

Andrade, C. (2015). Gestión Logística en las Operaciones del Transporte Internacional para el desarrollo del comercio en el puerto del Callao. Recuperado de http://cybertesis.unmsm.edu.pe/bitstream/cybertesis/4488/1/Andrade_mc.pdf

Asociación de Exportadores (ADEX). (Setiembre 2017). Exportaciones cerrarían con un $\begin{array}{llllll}\text { incremento de } & 15.2 \% & \text { este } & \text { año. }\end{array}$ http://www.adexperu.org.pe/notadeprensa/exportaciones-cerrarian-con-un-incremento-de-152-este-ano/

DAVID, PIERRE A. (2016), Logística Internacional La Administración de las Operaciones de Comercio Internacional.

De la Hoz, A. (2013). Generalidades de Comercio Internacional. Recuperado de http://www.colmayorbolivar.edu.co/files/generalidadesdecomerciointernacional.pdf

Diario Gestión. (Agosto 2017). Mincetur proyecta que las exportaciones peruanas crecerán $15 \%$ el 2017. Recuperado de http://gestion.pe/economia/mincetur-proyecta-queexportaciones-peruanas-creceran-15-2017-2197662

Dorta, P. (2013). Transporte y Logística Internacional. Recuperado de https://www2.ulpgc.es/hege/almacen/download/7101/7101787/transporte y logistica interna cional 2013.pdf 
Editorial: Involución Aeroportuaria (11 de Octubre de 2017). Diario Gestión. Recuperado de https://gestion.pe/opinion/editorial-involucion-aeroportuaria-220502

Exportaciones Peruanas crecerán 15\% este año, afirma el Mincetur (14 de Agosto de 2017). Diario La República. Recuperado de http://larepublica.pe/economia/1073937-exportacionesperuanas-creceran-15-este-ano-afirma-el-mincetur

García, Maximiliano (2009), La Nueva Teoría del Comercio Internacional en la posmodernización de la economía global. Recuperado de http://www.utm.mx/edi_anteriores/temas037/E3-.pdf

Guzman Escobar, J. (2005). El agente de carga. Revista e-Mercatoria, 4(1), 4

Mincetur (2009), El ABC del Comercio Exterior: Guía de Capacidades Gerenciales de Comercio Exterior. Recuperado de https://www.mincetur.gob.pe/wpcontent/uploads/documentos/comercio_exterior/Sites/Pecex/lecturas_complementarias/03_G UIA_DEL_EXPORTADOR.pdf

Mincetur: Las 4 mejores propuestas sobre comercio exterior (11 de agostode de 2016). Diario El Comercio. Recuperado de https://elcomercio.pe/economia/peru/mincetur-4-mejorespropuestas-comercio-exterior-222738

Ministerio de Comercio Exterior y Turismo (2009). Guía de orientación al usuario del transporte aéreo. Recuperado de http://www.siicex.gob.pe/siicex/documentosportal/188937685radB4C00.pdf

Ministerio de Comercio Exterior y Turismo (Mincetur). (2013) Guía 8 Transporte y Logística Internacional.

Molins, A. (2011). Logística Internacional. Recuperado de http://api.eoi.es/api_v1_dev.php/fedora/asset/eoi:75375/componente75373.pdf 
Perú y Brasil firman acuerdos para aumentar comercio exterior (29 de Abril de 2016). Diario El Comercio. Recuperado de https://elcomercio.pe/economia/peru/peru-brasil-firmanacuerdos-aumentar-comercio-exterior-216073

Ponce Talancón, Humberto(2007). La Matriz Foda: Alternativa de Diagnóstico y Determinación de Estrategias de Intervención en Diversas Organizaciones.

Ramales, M. (2013). Economía Internacional Apuntes Introductorios. Recuperado de http://www.eumed.net/libros-gratis/2013a/1291/1291.pdf

Steimberg, F. (2004) La nueva teoría del comercio internacional y la política comercial estratégica. Recuperado de http://www.adizesca.com/site/assets/e-la nueva teoria comercio internacional -y la politica comercial estrategica-fs.pdf

Sunat (26 de Junio de 2008) Articulo 64 [titulo III]. Ley General de Aduanas [1053]

Sunat: Operadores económicos autorizados agilizaron exportaciones por más de US\$ 159 millones (28 de Setiembre de 2017). Diario Gestión. Recuperado de https://gestion.pe/economia/sunat-operadores-economicos-autorizados-agilizaronexportaciones-us-159-millones-144414

Superintendecia Nacional de aduanas y de administración tributaria (2008). Normas Legales GJA-03 Ley General de Aduanas. Recuperado de http://www.sunat.gob.pe/legislacion/procedim/normasadua/gja-03normasoc.htm

Universidad del Cema (2010). TEORÍA DEL VALOR TRABAJO: LOS ENFOQUES DE $\begin{array}{llllll}\text { SMITH } & \text { Y } & \text { RICARDO } & \text { Recuperado de }\end{array}$ http://www.ucema.edu.ar/u/jms/cursos grado y posgrado/historia del pensamiento econo mico/monografias_anteriores/2010_gabriel_manganelli.pdf

Universidad Nacional Autónoma de México (2003). Principales Teorías sobre Comercio Internacional. Recuperado de http://www.economia.unam.mx/secss/docs/tesisfe/mcam/1.pdf

Universidad Peruana de Ciencias Aplicadas (2013). Unidad 4: Análisis del Entorno Valoración Cuantitativa 
Universidad Peruana de Ciencias Aplicadas (2013). Unidad 5: Análisis Interno Valoración Cuantitativa

Villar P. (29 de Agosto de 2017). Conoce las 13 medidas del Gobierno para Fortalecer al $\begin{array}{lllll}\text { Comercio Exterior. Diario } & \text { El }\end{array}$ https://elcomercio.pe/economia/peru/conoce-13-medidas-gobierno-fortalecer-comercioexterior-noticia-454119 


\section{ANEXO}

\section{ANEXO A Data de Variables}

\begin{tabular}{|c|c|c|c|c|c|}
\hline & INGRESOS & EMBARQUES & TONELADAS & $\begin{array}{c}\text { EMBARQUES } \\
\text { PREPAGADOS }\end{array}$ & $\begin{array}{c}\text { FACTURAS } \\
\text { ASUMIDAS } \\
\text { POR LA } \\
\text { EMPRESA }\end{array}$ \\
\hline ene-15 & 306595.18 & 348 & 164.40 & 75 & 406.1 \\
\hline feb-15 & 311024.79 & 346 & 177.66 & 70 & 402.79 \\
\hline mar-15 & 454956.00 & 434 & 285.67 & 85 & 310.84 \\
\hline abr-15 & 303624.18 & 377 & 167.91 & 89 & 397.77 \\
\hline may-15 & 308675.58 & 317 & 165.27 & 78 & 321.13 \\
\hline jun-15 & 343958.00 & 395 & 186.17 & 114 & 267.12 \\
\hline jul-15 & 238646.89 & 365 & 125.98 & 94 & 167.48 \\
\hline ago-15 & 281630.56 & 379 & 145.19 & 77 & 791.53 \\
\hline sep-15 & 291401.92 & 352 & 144.73 & 71 & 180 \\
\hline oct-15 & 287386.89 & 343 & 141.20 & 75 & 41.32 \\
\hline nov-15 & 352428.73 & 341 & 181.01 & 89 & 271.83 \\
\hline dic-15 & 399465.80 & 397 & 180.28 & 70 & 102.16 \\
\hline ene-16 & 275527.84 & 272 & 115.92 & 79 & 85.14 \\
\hline feb-16 & 325610.96 & 337 & 120.35 & 76 & 416.94 \\
\hline mar-16 & 165451.18 & 182 & 60.91 & 51 & 610.28 \\
\hline abr-16 & 172926.90 & 192 & 71.70 & 54 & 281.29 \\
\hline may-16 & 204418.24 & 194 & 74.58 & 86 & 283.41 \\
\hline jun-16 & 203639.24 & 200 & 79.05 & 44 & 158.95 \\
\hline jul-16 & 184287.32 & 228 & 70.67 & 59 & 133.72 \\
\hline ago-16 & 215369.99 & 204 & 74.16 & 45 & 682.18 \\
\hline sep-16 & 174805.00 & 231 & 74.55 & 44 & 699.80 \\
\hline oct-16 & 164962.08 & 223 & 73.32 & 37 & 848.47 \\
\hline nov-16 & 192440.42 & 153 & 76.64 & 44 & 304.91 \\
\hline dic-16 & 219263.10 & 282 & 80.32 & 71 & 302.58 \\
\hline ene-17 & 142331.21 & 188 & 59.64 & 54 & 274.96 \\
\hline feb-17 & 190721.11 & 177 & 86.41 & 54 & 582.77 \\
\hline mar-17 & 248474.92 & 211 & 158.99 & 44 & 223.19 \\
\hline abr-17 & 158215.11 & 177 & 101.72 & 40 & 101.02 \\
\hline may-17 & 175506.82 & 203 & 81.91 & 52 & 581.72 \\
\hline jun-17 & 227579.37 & 236 & 96.82 & 64 & 222.08 \\
\hline jul-17 & 213490.53 & 252 & 118.87 & 68 & 189.87 \\
\hline ago-17 & 147727.45 & 209 & 68.48 & 31 & 461.68 \\
\hline
\end{tabular}




\section{ANEXO B Proceso de Regresión Lineal Múltiple en el SPSS}

Las variables serán sometidas a un análisis estadístico de Regresión Lineal Múltiple en la herramienta de análisis SPSS Statistics en donde la variable dependiente es el valor sobre el cual se trabajarán las demás variables independientes para determinar si son correlacionadas. El primer paso es el ingreso de la información en la herramienta estadística.

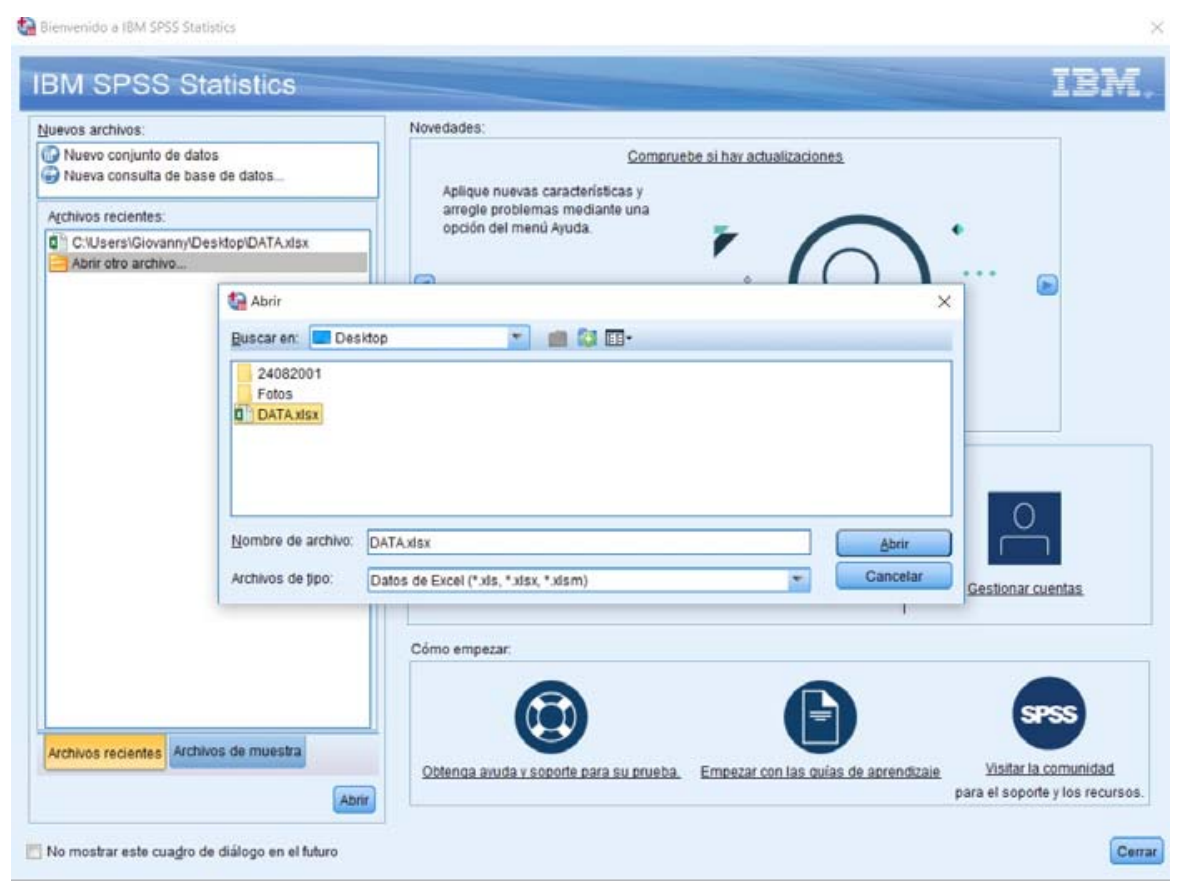

Posterior a la apertura de la base de datos, en la pestaña "Vista de Variables" se procede a asignar su medida que en este caso es "escala" debido a que son datos numéricos, colocar las etiquetas, cantidad de decimales en la base de datos.

Posterior a esto, ya se contaría con la base de datos lista para proceder con la herramienta estadística en la pestaña "Vista de datos". 


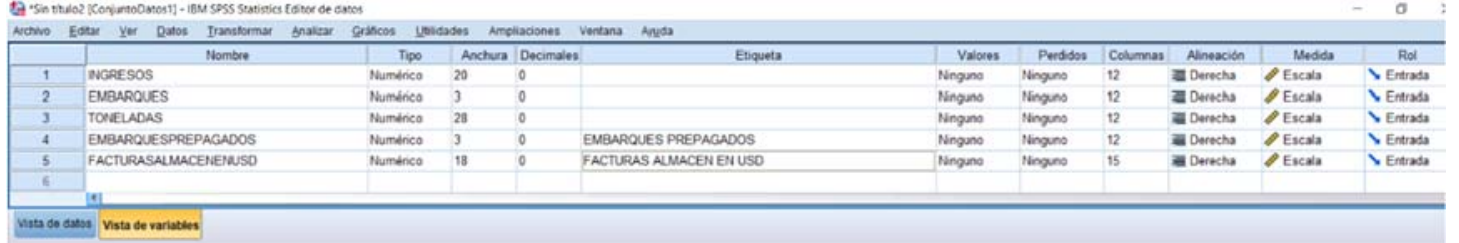

\begin{tabular}{|c|c|c|c|c|c|c|c|c|c|c|c|c|c|c|c|c|}
\hline 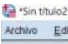 & 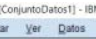 & 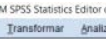 & $\begin{array}{l}\text { Ide catos } \\
\text { thar graticos y }\end{array}$ & ymataseses Amplasionen & nes Vertanas Anda & & & & & & & & & & & \\
\hline 1. WGREESOS & 306595.1 & 79947368 & & & & & & & & & & & & & nasole & 105 sariatle: \\
\hline & INGRESOS & EMBarques & TONELADAS & $\begin{array}{l}\text { EMBARQUESP } \\
\text { REPAGADOS }\end{array}$ & $\begin{array}{l}\text { FACTuRasalmaC } \\
\text { ENENUSD }\end{array}$ & var & at & $=$ & art & wor & at & 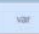 & $=$ & var & ar & 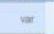 \\
\hline 1 & 306595 & 348 & 164 & 75 & 406 & & & & & & & & & & & \\
\hline 2 & 311025 & 346 & 178 & 70 & ${ }^{403}$ & & & & & & & & & & & \\
\hline 3 & 454956 & 434 & 236 & 25 & 311 & & & & & & & & & & & \\
\hline 4 & $\begin{array}{l}303624 \\
30075 \\
3\end{array}$ & 377 & 168 & 69 & 398 & & & & & & & & & & & \\
\hline 5 & $\begin{array}{l}306676 \\
\text { 3asese }\end{array}$ & 317 & 165 & 78 & 321 & & & & & & & & & & & \\
\hline 6 & $\begin{array}{l}349358 \\
239647\end{array}$ & $\begin{array}{l}395 \\
365\end{array}$ & $\begin{array}{l}{ }_{196}^{126} \\
126\end{array}$ & 114 & $\begin{array}{l}267 \\
167 \\
167\end{array}$ & & & & & & & & & & & \\
\hline 8 & $\begin{array}{l}2366471 \\
281531\end{array}$ & 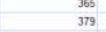 & $\begin{array}{l}126 \\
145 \\
145\end{array}$ & $\pi$ & $\begin{array}{l}167 \\
792 \\
792\end{array}$ & & & & & & & & & & & \\
\hline 9 & 291402 & 352 & 145 & 71 & $\begin{array}{l}792 \\
180 \\
180 \\
\end{array}$ & & & & & & & & & & & \\
\hline 10 & 287337 & 343 & 141 & 75 & 41 & & & & & & & & & & & \\
\hline 11 & 352429 & 341 & 181 & 99 & 272 & & & & & & & & & & & \\
\hline 12 & 399466 & 397 & 180 & 70 & 102 & & & & & & & & & & & \\
\hline 13 & 275528 & 272 & 116 & 79 & o5 & & & & & & & & & & & \\
\hline 14 & 325611 & 337 & 120 & 76 & 417 & & & & & & & & & & & \\
\hline 15 & 165451 & 182 & 61 & 51 & 610 & & & & & & & & & & & \\
\hline 16 & 172927 & 192 & 12 & 54 & 281 & & & & & & & & & & & \\
\hline 17 & 204418 & 194 & 75 & 86 & 283 & & & & & & & & & & & \\
\hline 18 & 203639 & 200 & 79 & 4 & 159 & & & & & & & & & & & \\
\hline${ }_{20}^{19}$ & 184287 & 228 & 71 & 59 & 134 & & & & & & & & & & & \\
\hline${ }_{21}^{20}$ & $\begin{array}{l}215370 \\
174055 \\
2\end{array}$ & ${ }_{231}^{204}$ & $\begin{array}{l}74 \\
75 \\
75\end{array}$ & 85 & 682 & & & & & & & & & & & \\
\hline$\frac{21}{22}$ & 186095 & ${ }^{251}$ & $\begin{array}{l}75 \\
73 \\
73\end{array}$ & ${ }^{44}$ & $\begin{array}{l}700 \\
848\end{array}$ & & & & & & & & & & & \\
\hline 23 & $\begin{array}{l}169962 \\
19240\end{array}$ & 153 & $\pi$ & 4 & 305 & & & & & & & & & & & \\
\hline 24 & 219263 & 282 & 30 & 71 & 303 & & & & & & & & & & & \\
\hline & 142331 & 188 & 60 & 54 & 275 & & & & & & & & & & & \\
\hline & 190721 & 177 & & 54 & 563 & & & & & & & & & & & \\
\hline 27 & 248475 & 211 & 159 & 4 & 223 & & & & & & & & & & & \\
\hline 28 & 158215 & 177 & 102 & 40 & 101 & & & & & & & & & & & \\
\hline$\infty$ & $3766 \mathrm{nz}$ & .002 & & & & & & & & & & & & & & \\
\hline
\end{tabular}

也. Sin titulo2 [ConjuntoDatos1] - IBM SPSS Statistics Editor de datos

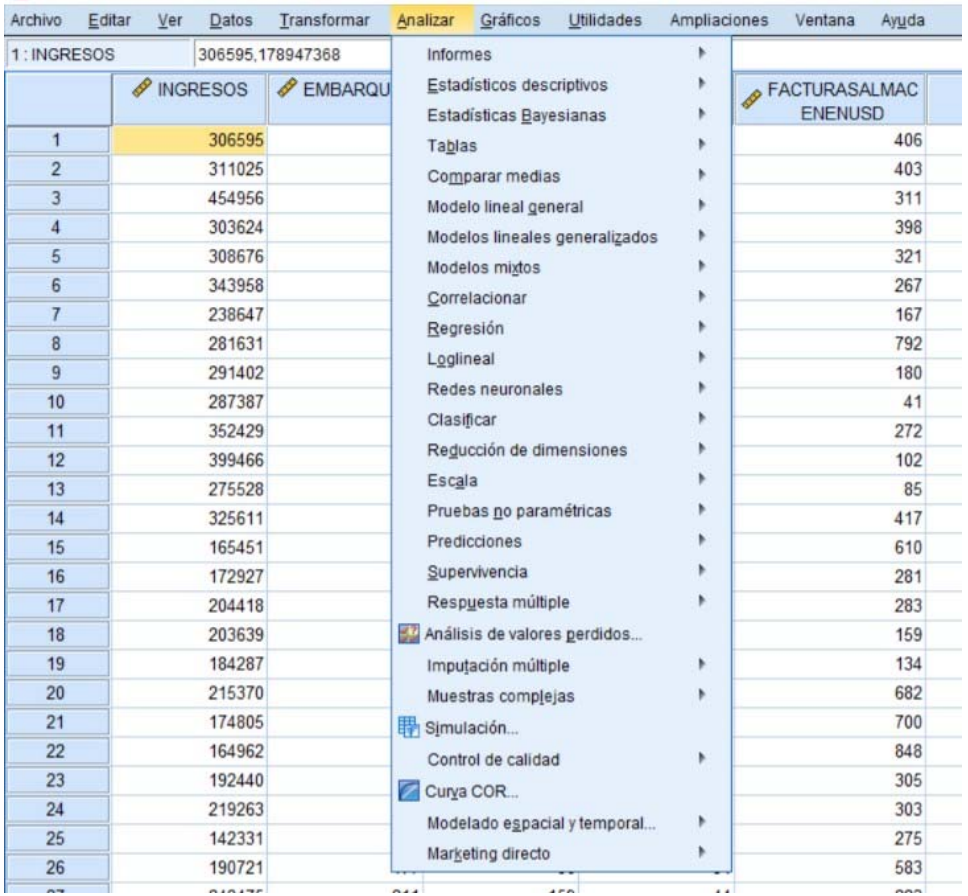

Para dar inicio a la herramienta estadística Regresión Lineal Múltiple se debe seleccionar la opción "Analizar", luego se elige la opción "Regresión” y finalmente se da clic en la opción "Lineales". 
A continuación, seleccionamos la variable dependiente para el análisis, así como las variables independientes. Una vez distribuida las variables, se procede a seleccionar la opción "Estadísticos" en donde se elige las opciones "Durbin Watson" y "Correlaciones Parciales y Semiparciales" y se presiona continuar. Después, se elegirá la opción "Gráficos" para poder seleccionar las opciones "Histograma" y "Grafico de probabilidad normal" y presionar continuar. Una vez contemos con todas estas opciones seleccionadas, se continuará con el análisis dando clic en "Aceptar".

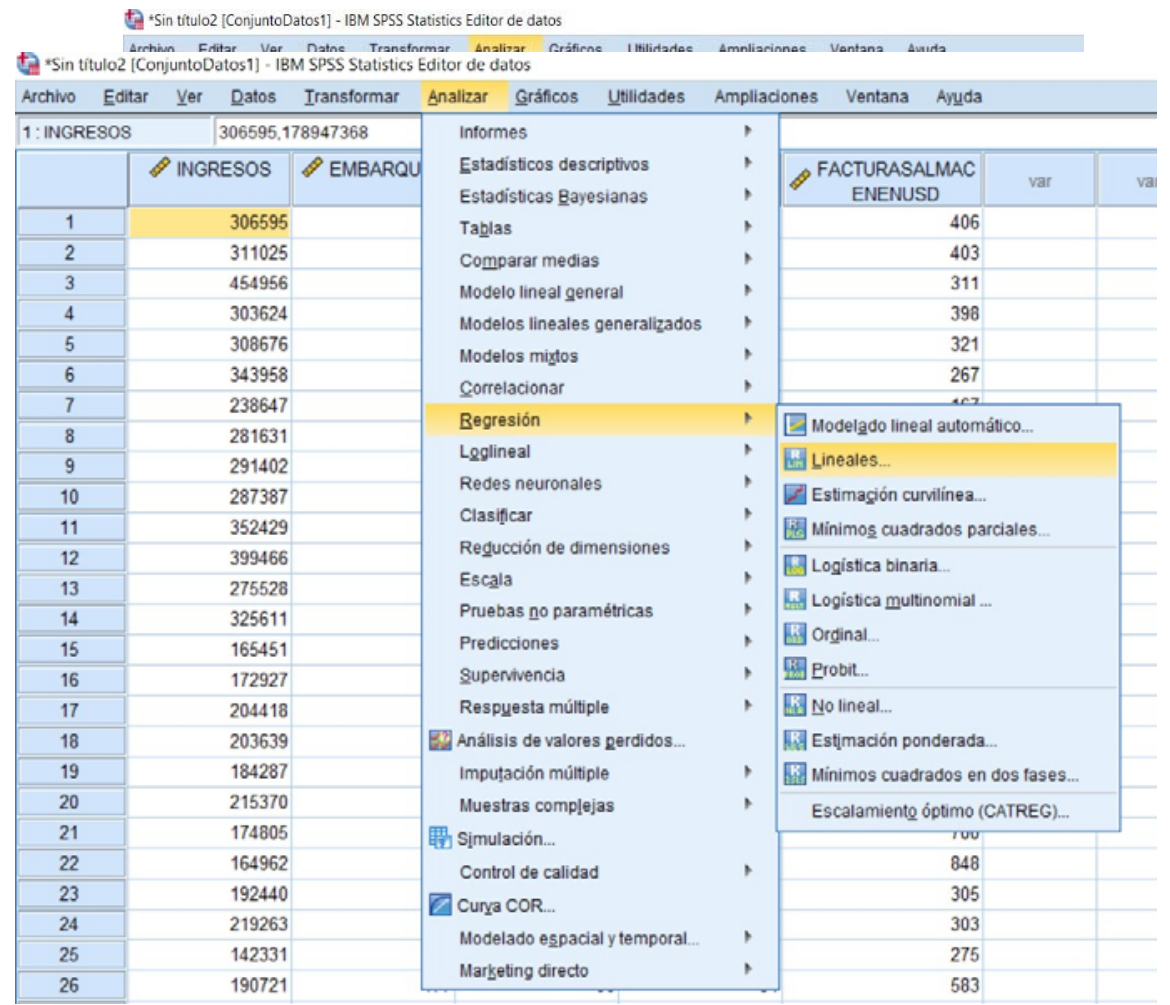




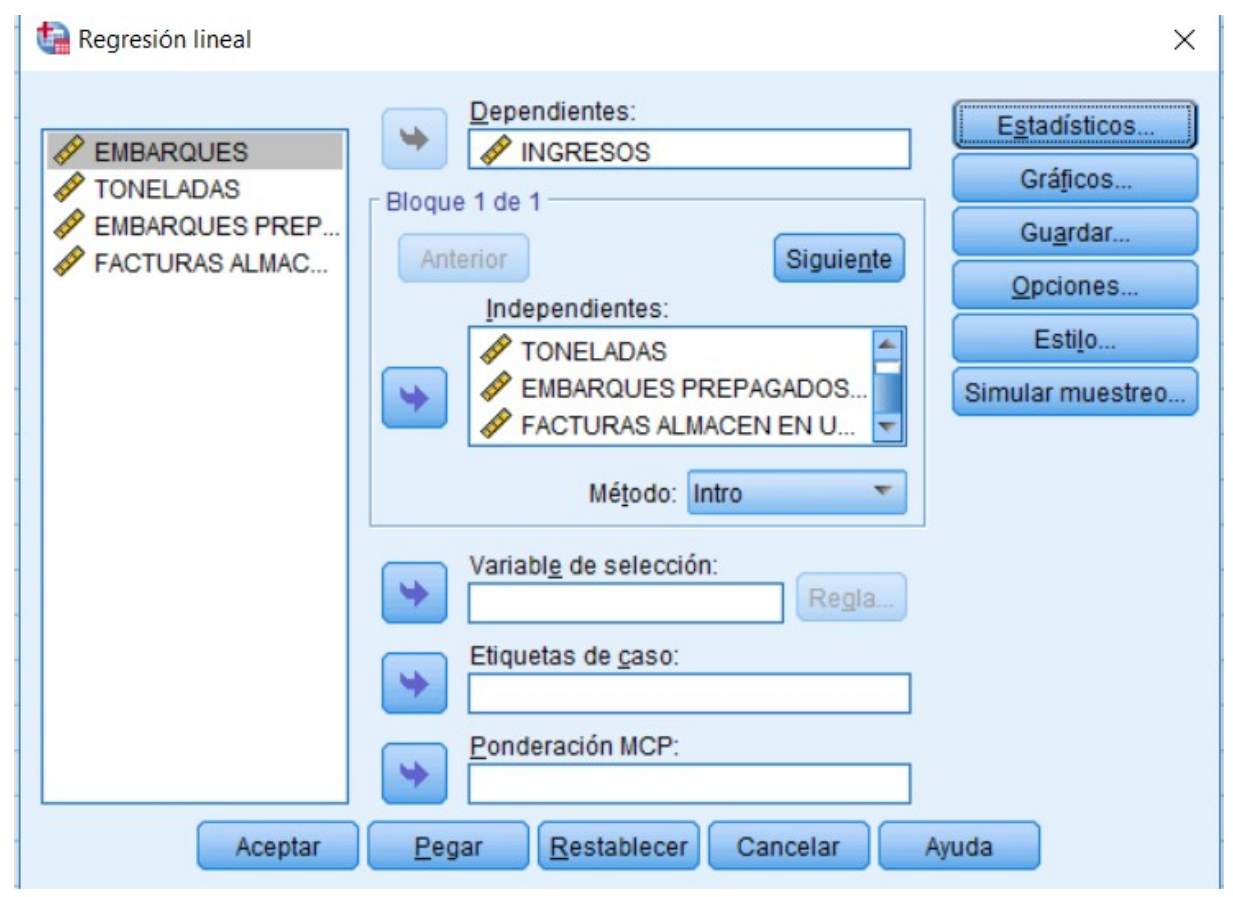

Regresión linea

x

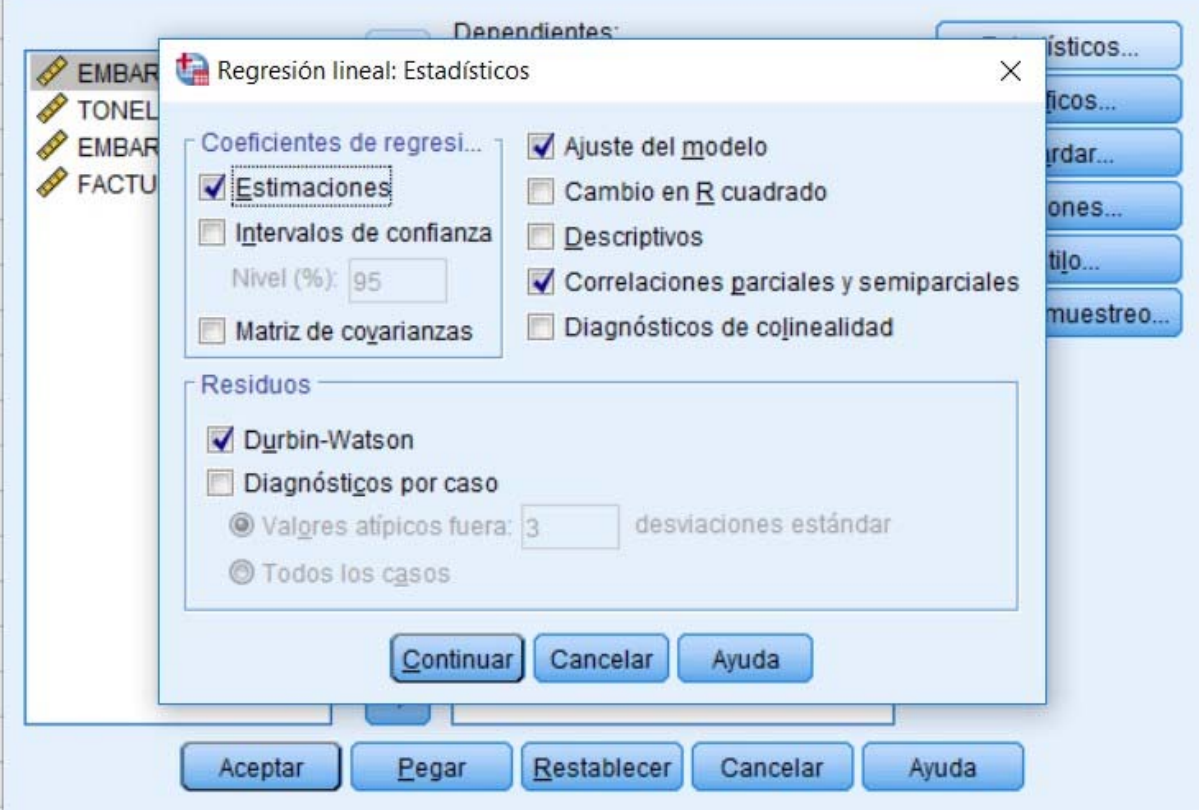




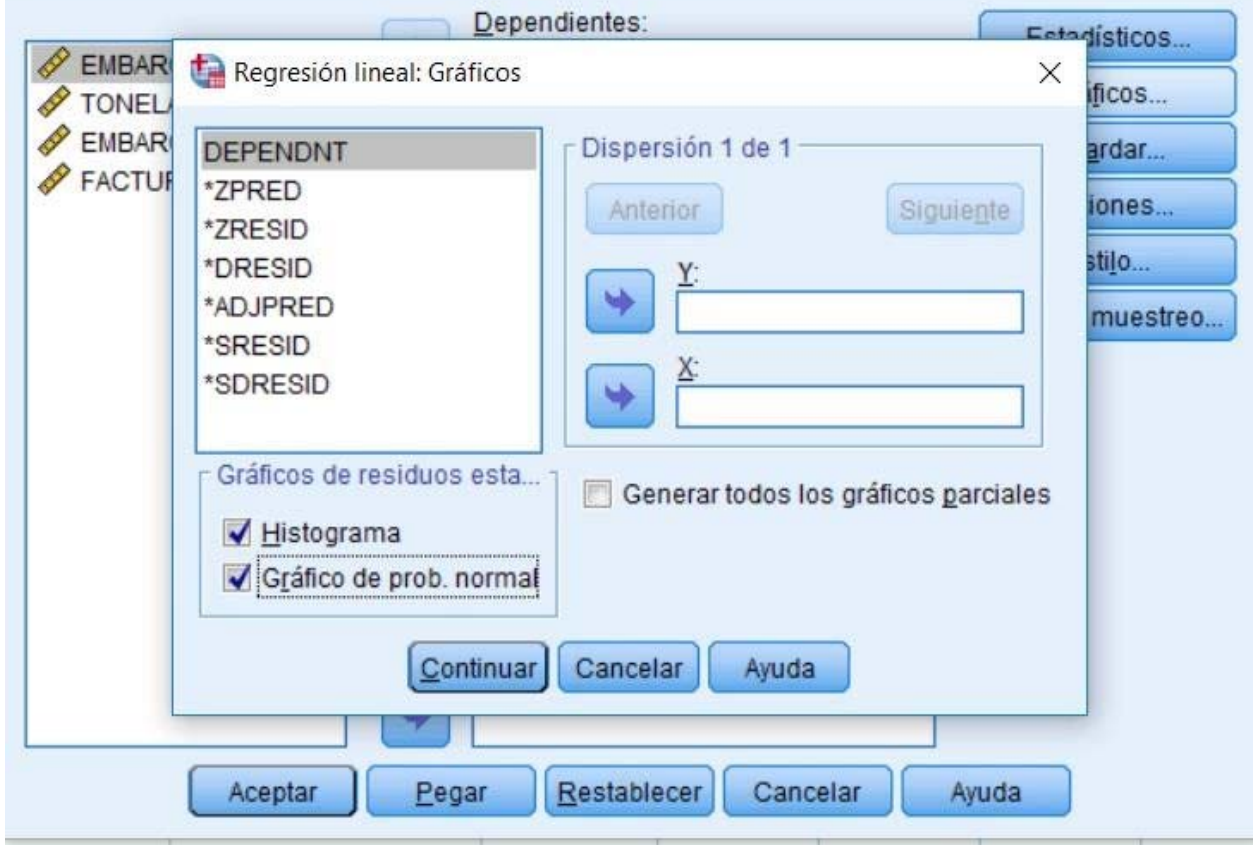




\section{ANEXO C ESTADÍSTICO DE DURBIN WATSON (nivel de significancia de 5\%)}

Estadistico de Durbin-Watson - Puntos criticos de $d_{L}$ y $d_{\mathrm{u}}$ al nivel de signiffcación del $5 \%$ $k^{*}$ corresponde al número de regresores del modelo excluido el término independiente (es decir, $k^{*}=k-1$ )

\begin{tabular}{|c|c|c|c|c|c|c|c|c|c|c|c|c|}
\hline & \multicolumn{2}{|c|}{$k^{*}=1$} & \multicolumn{2}{|c|}{$k^{*}=2$} & \multicolumn{2}{|c|}{$k^{*}=3$} & \multicolumn{2}{|c|}{$k^{*}=4$} & \multicolumn{2}{|c|}{$k^{*}=5$} & \multicolumn{2}{|c|}{$k^{*}=6$} \\
\hline $\mathrm{n}$ & $d_{L}$ & $d_{u}$ & $d_{L}$ & $d_{u}$ & $d_{L}$ & $d_{u}$ & $d_{L}$ & $d_{u}$ & $d_{L}$ & $d_{u}$ & $d_{L}$ & $d_{u}$ \\
\hline 6 & 0.610 & 1.400 & & & & & & & & & & \\
\hline 7 & 0.700 & 1.356 & 0.467 & 1.896 & & & & & & & & \\
\hline 8 & 0.763 & 1.332 & 0.559 & 1.777 & 0.368 & 2.287 & & & & & & \\
\hline 9 & 0.824 & 1.320 & 0.629 & 1.699 & 0.455 & 2.128 & 0.296 & 2.588 & & & & \\
\hline 10 & 0.879 & 1.320 & 0.697 & 1.641 & 0.525 & 2.016 & 0.376 & 2.414 & 0.243 & 2.822 & & \\
\hline 11 & 0.927 & 1.324 & 0.658 & 1.604 & 0.595 & 1.928 & 0.444 & 2.283 & 0.316 & 2.645 & 0.203 & $3.00 \mathrm{E}$ \\
\hline 12 & 0.971 & 1.331 & 0.812 & 1.579 & 0.658 & 1.864 & 0.512 & 2.177 & 0.379 & 2.506 & 0.268 & 2.832 \\
\hline 13 & 1.010 & 1.340 & 0.861 & 1.562 & 0.715 & 1.816 & 0.574 & 2.094 & 0.445 & 2.390 & 0.328 & 2.692 \\
\hline 14 & 1.045 & 1.350 & 0.905 & 1.551 & 0.767 & 1.779 & 0.632 & 2.030 & 0.505 & 2.296 & 0.389 & 2.572 \\
\hline 15 & 1.077 & 1.361 & 0.946 & 1.543 & 0.814 & 1.750 & 0.685 & 1.977 & 0.562 & 2.220 & 0.447 & 2.472 \\
\hline 16 & 1.106 & 1.371 & 0.982 & 1.539 & 0.857 & 1.728 & 0.734 & 1.935 & 0.615 & 2.157 & 0.502 & 2.388 \\
\hline 17 & 1.133 & 1.381 & 1.015 & 1.536 & 0.897 & 1.710 & 0.779 & 1.900 & 0.664 & 2.104 & 0.554 & 2.318 \\
\hline 18 & 1.158 & 1.391 & 1.046 & 1.535 & 0.933 & 1.696 & 0.820 & 1.872 & 0.710 & 2.060 & 0.603 & 2.257 \\
\hline 19 & 1.180 & 1.401 & 1.074 & 1.536 & 0.967 & 1.685 & 0.859 & 1.848 & 0.752 & 2.023 & 0.649 & 2.206 \\
\hline 20 & 1.201 & 1.411 & 1.100 & 1.537 & 0.998 & 1.676 & 0.894 & 1.828 & 0.792 & 1.991 & 0.692 & 2.162 \\
\hline 21 & 1.221 & 1.420 & 1.125 & 1.538 & 1.026 & 1.669 & 0.927 & 1.812 & 0.829 & 1.964 & 0.732 & 2.124 \\
\hline 22 & 1.239 & 1.429 & 1.147 & 1.541 & 1.053 & 1.664 & 0.958 & 1.797 & 0.863 & 1.940 & 0.769 & 2.090 \\
\hline 23 & 1.257 & 1.437 & 1.168 & 1.543 & 1.078 & 1.660 & 0.986 & 1.785 & 0.895 & 1.920 & 0.804 & 2.061 \\
\hline 24 & 1.273 & 1.446 & 1.188 & 1.546 & 1.101 & $1 . t$ & 1.013 & 1.775 & 0.925 & 1.902 & 0.837 & 2.035 \\
\hline 25 & 1.288 & 1.454 & 1.206 & 1.5 & 1.123 & 1.8 & 1.038 & 1. & 0.953 & 1.886 & 0.868 & 2.012 \\
\hline 26 & 1 & 1.461 & 1. & 1.5 & 1.143 & 1.652 & 1.062 & 1. & 0.979 & 1.873 & 0.897 & 1.992 \\
\hline 27 & 1. & 1.469 & 1.240 & 1.5 & 1.162 & 1.651 & 1.084 & 1. & 1.004 & 1.861 & 0.925 & 1.974 \\
\hline 28 & 1.328 & 1.476 & 1.255 & 1.560 & 1.181 & 1.650 & 1.104 & 1.747 & 1.028 & 1.850 & 0.951 & 1.958 \\
\hline 29 & 1.341 & 1.483 & 1.270 & 1.563 & 1.198 & 1.650 & 1.124 & 1.7 & 1.050 & 1.841 & 0.975 & 1.944 \\
\hline 30 & 1.352 & 1.489 & 1.284 & 1.567 & 1.214 & 1.650 & 1.143 & 1.739 & 1.071 & 1.833 & 0.998 & 1.931 \\
\hline 31 & 1.363 & 1.496 & 1.297 & 1.570 & 1.229 & 1.650 & 1.160 & 1.735 & 1.090 & 1.825 & 1.020 & 1.920 \\
\hline 32 & 1.373 & 1.502 & 1.309 & 1.574 & 1.244 & 1.650 & 1.177 & 1.732 & 1.109 & 1.819 & 1.041 & 1.909 \\
\hline 33 & 1.383 & 1.508 & 1.321 & 1.577 & 1.258 & 1.651 & 1.193 & 1.730 & 1.127 & 1.813 & 1.061 & 1.900 \\
\hline 34 & 1.393 & 1.514 & 1.333 & 1.580 & 1.271 & 1.652 & 1.208 & 1.728 & 1.144 & 1.808 & 1.080 & 1.891 \\
\hline 35 & 1.402 & 1.519 & 1.343 & 1.584 & 1.283 & 1.6 & 1.222 & 1. & 1.160 & 1.803 & 1.097 & 1.884 \\
\hline 36 & 1 & 1.525 & 1.354 & 1.5 & 1.295 & $1 . t$ & 1.236 & & 75 & 1.799 & & 1.877 \\
\hline 37 & 1.419 & 1.530 & 1.364 & 1.590 & 1.307 & 1.655 & 1.249 & 1. & 1.190 & 1.795 & 1.131 & 1.870 \\
\hline 38 & 1.427 & 1.535 & 1.373 & 1.594 & 1.318 & $1 . t$ & 1.261 & 1. & 1.204 & 1.792 & 1.146 & 1.864 \\
\hline 39 & 1.435 & 1.540 & 1.382 & 1.597 & 1.328 & 1.658 & 1.273 & 1.722 & 1.218 & 1.789 & 1.161 & 1.859 \\
\hline 40 & 1.442 & 1.544 & 1.391 & 1.600 & 1.338 & 1.659 & 1.285 & 1.721 & 1.230 & 1.786 & 1.175 & 1.854 \\
\hline 45 & 1.475 & 1.566 & $1.430)$ & 1.615 & 1.383 & 1.666 & 1.336 & 1.720 & 1.287 & 1.776 & 1.238 & 1.835 \\
\hline 50 & 1.503 & 1.585 & 1.462 & 1.628 & 1.421 & $1 . t$ & 1.378 & 1. & 1.335 & 1.771 & 1.291 & 1.822 \\
\hline 55 & 1.528 & 1.601 & 1.490 & 1.641 & 1.452 & 1.681 & 1.414 & 1.724 & 1.374 & 1.768 & 1.334 & 1.814 \\
\hline 60 & 1.549 & 1.616 & 1.514 & 1.652 & 1.480 & 1.689 & 1.444 & 1.727 & 1.408 & 1.767 & 1.372 & 1.808 \\
\hline 65 & 1.567 & 1.629 & 1.536 & 1.662 & 1.5003 & 1.696 & 1.471 & 1.731 & 1.438 & 1.767 & 1.404 & 1.805 \\
\hline 70 & 1.583 & 1.641 & 1.554 & 1.672 & 1.525 & 1.703 & 1.494 & 1.735 & 1.464 & 1.768 & 1.433 & 1.802 \\
\hline 75 & 1.598 & 1.652 & 1.571 & 1.680 & 1.543 & 1.709 & 1.515 & 1.739 & 1.487 & 1.770 & 1.458 & 1.801 \\
\hline 80 & 1.611 & 1.662 & 1.586 & 1.688 & 1.5600 & 1.715 & 1.534 & 1.743 & 1.507 & 1.772 & 1.480 & 1.801 \\
\hline 85 & 1.624 & 1.671 & 1.600 & 1.696 & 1.575 & 1.721 & 1.550 & 1.747 & 1.525 & 1.774 & 1.500 & 1.801 \\
\hline 90 & 1.635 & 1.679 & 1.612 & 1.703 & 1.589 & 1.7 & 1.566 & 1.7 & 1.542 & 1.776 & 1.518 & 1.801 \\
\hline 95 & 1.645 & 1.687 & 1.623 & 1.709 & 1.602 & 1.732 & 1.579 & 1.755 & 1.557 & 1.778 & 1.535 & 1.8002 \\
\hline 100 & 1.654 & 1.694 & 1.634 & 1.715 & 1.613 & 1.736 & 1.592 & 1.758 & 1.571 & 1.780 & 1.550 & 1.803 \\
\hline $15 x$ & 1.720 & 1.746 & 1.706 & 1.760 & 1.693 & 1.774 & 1.679 & 1.788 & 1.665 & 1.802 & 1.651 & 1.817 \\
\hline 200 & 1.758 & 1.778 & 1.748 & 1.789 & 1.738 & 1.799 & 1.728 & 1.810 & 1.718 & 1.820 & 1.707 & 1.831 \\
\hline
\end{tabular}

